\title{
GENDER, BODIES AND CYBERSTALKING: EMBODYING THEORY, DEVELOPING METHODOLOGY
}

\author{
BY
}

RACHEL WILLIAMS

\author{
A THESIS \\ SUBMITTED TO VICTORIA UNIVERSITY OF WELLINGTON \\ IN FULFILMENT OF THE REQUIREMENTS FOR THE DEGREE OF \\ MASTER OF ARTS IN CRIMINOLOGY \\ SCHOOL OF SOCIAL AND CULTURAL STUDIES \\ VICTORIA UNIVERSITY OF WELLINGTON
}




\begin{abstract}
The exponential growth of advanced communication technologies has corresponded with diverse opportunities for criminal offending within this arena. New forms of deviance are supported by the unique characteristics of the Internet environment, whilst pre-existing crimes are also paralleled online. Research indicates that content related offences, including cyberstalking and online sexual harassment, mirror offline gender disparities, although research addressing this disparity is minimal. The disparate victimisation of women, and the characteristics of cyberstalking, facilitates the recognition of this offence as a gendered form of harassment and the development of a theoretical framework responsive to this disparity. However, current theories addressing the Internet often display concepts concurrent with what is commonly referred to as the online disembodiment thesis. These concepts, namely the promotion of an absolute demarcation between the online and offline environment and the notion that bodies can be transcended online, are problematic when addressing the online victimisation of women as feminist theorists have located much of women's power in the centrality of the body. To inform the development of a gendered framework appropriate for an assessment of cyberstalking this thesis rejected the online disembodiment thesis, alternatively employing the theories of the body to develop a theoretical framework appropriate for an examination of cyberstalking. Criminologists are currently in an exploratory research era in regards to cybercrime, the growth of which has thus far not been matched by criminological scholarship. Consequently, there currently exists little methodological precedent for the researcher intending to qualitatively examine the online victimisation of women. The lack of methodological precedent prioritised the development of a methodological framework suitable for researching the online victimisation of women. The development of an alternative theoretical framework that recognised the immutability of bodies online subsequently informed the development of two key methodological considerations. The methodological considerations developed in this thesis lay the foundations for additional research on cyberstalking and prioritise a gendered assessment of this crime.
\end{abstract}




\section{ACKNOWLEDGEMENTS}

First and foremost I offer my sincerest gratitude to my supervisors Dr Jan Jordan and Dr Fiona Hutton for the input, guidance, assistance and encouragement they have provided me during the course of this thesis.

I would also like to extend my gratitude to the lecturers and students who gave their time to assist in the distribution and completion of the Participant Recruitment Questionnaire. I would also like to thank the staff of the School of Social and Cultural Studies and the Institute of Criminology for their assistance and feedback.

I would like to thank the board and staff of the YWCA of Wellington and Hutt Valley for their support and encouragement during the course of writing this thesis.

I would like to sincerely thank the many women who shared their stories and experiences with me. For every story shared the importance of this research was made apparent and for that I am truly grateful.

I would like to thank my parents, Lorraine, Leo, Ross and Anne for your love and support.

Finally, I truly believe that without the love and support of four extraordinary women this thesis would not have been possible and I dedicate this thesis to them. To my wonderful and inspiring grandmother. To my sisters, Hannah and Claire, for your compassion, humour and encouragement. And, finally, to my mother for sharing your strength and wisdom. For your unerring support. For instilling in me the importance of education and the need to constantly question. And for setting your expectations high and expecting nothing less.

Thank you. 
Even if a world of "only minds" were possible, it would be highly undesirable. For without our embodiment - including the plethora of physical differences and limitations following it - we lose one of our greatest resources. The body is a deep well of both strength and wisdom. We know in, with and through our bodies. To assert otherwise is to vastly misconstrue, even distort, the nature of human experience, in ways that are highly damaging not only to women, but to every person on this planet indeed, to the planet itself.

(Underwood, 2000:283)

Forgetting the body is an old Cartesian trick, one that has unpleasant consequences for those bodies whose speech is silenced by the act of our forgetting; that is to say, those upon whose labour the act of forgetting the body is founded.

(Stone, 2000:525) 


\section{CONTENTS}

INTRODUCTION

CHAPTER ONE: CYBERCRIME AND CRIMINOLOGICAL THEORY ............................................................11

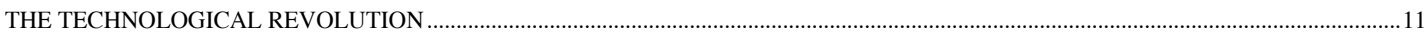

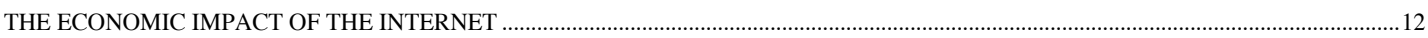

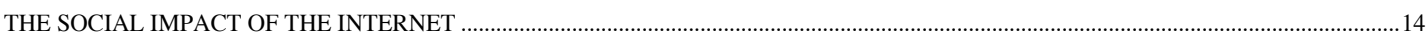

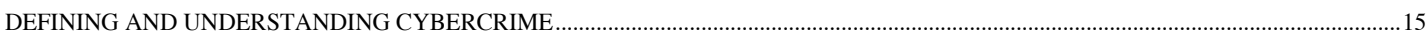

Academic Definitions of Cybercrime ...................................................................................................................................................15

The Production of Cybercrime Knowledge and Popular Discourse .................................................................................................................18

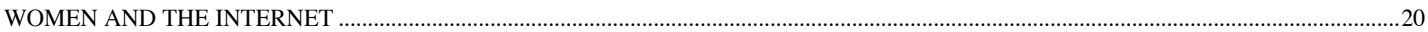

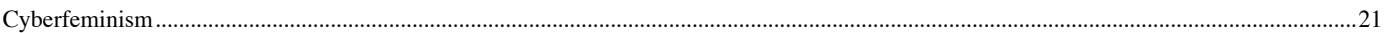

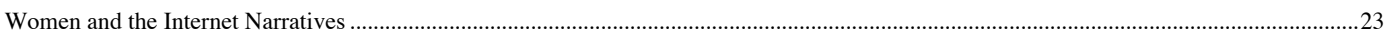

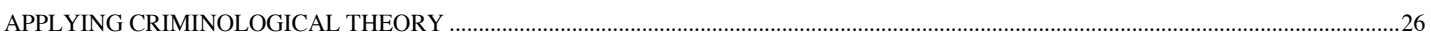

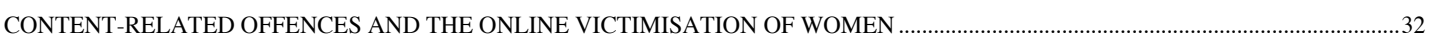

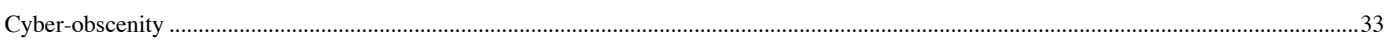

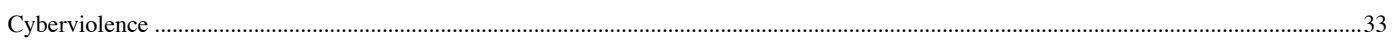

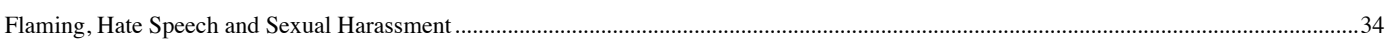

CHAPTER TWO: A REVIEW OF CYBERSTALKING LITERATURE................................................................37

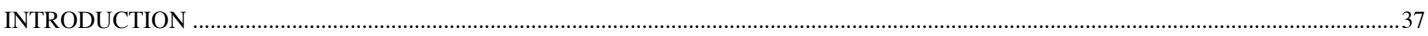

IS CYBERSTALKING AN EXTENSION OF OFFLINE STALKING? ......................................................................................................

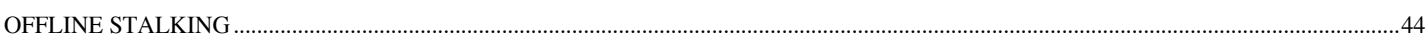

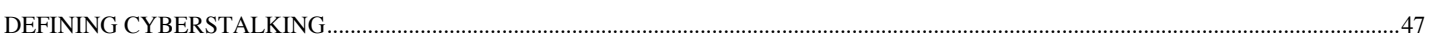

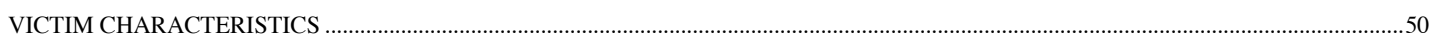

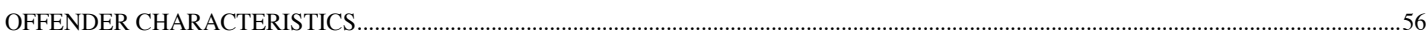

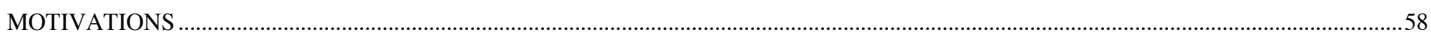

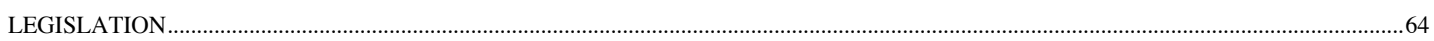

CAMPUS STUDIES

CHAPTER THREE: APPLYING THE THEORIES OF THE BODY TO ESTABLISH A THEORETICAL

FRAMEWORK FOR A GENDERED ASSESSMENT OF CYBERSTALKING ....................................................74

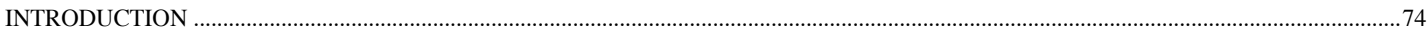

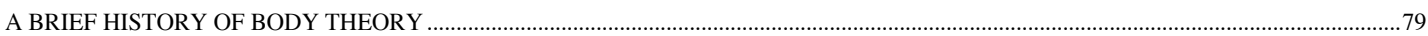

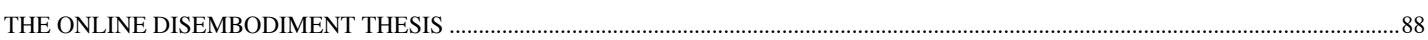

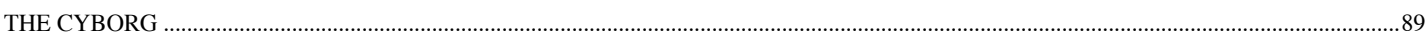

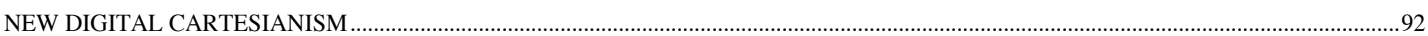

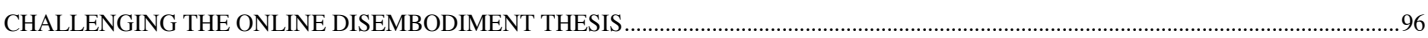

ALTERNATIVE EXPLANATIONS FOR VICTIMISATION IN RELATION TO THE THEORIES OF THE BODY ........................................107

Discursively (De)constructed Bodies ..............................................................................................................................................................107

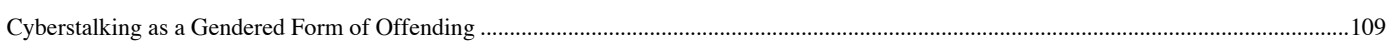

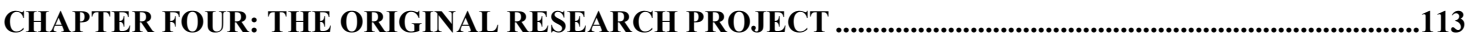

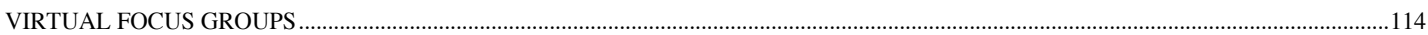

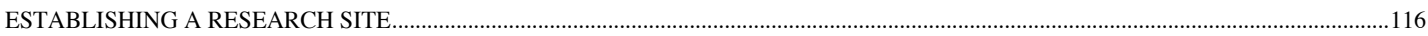

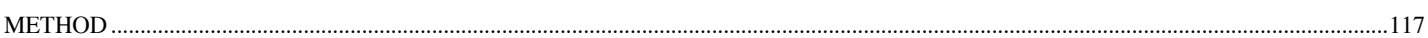

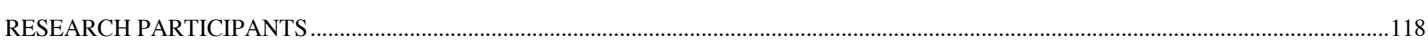

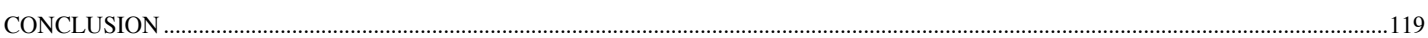




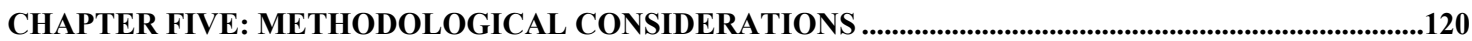

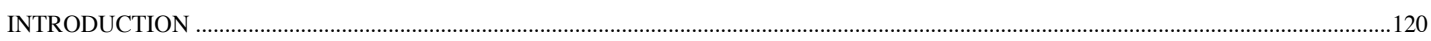

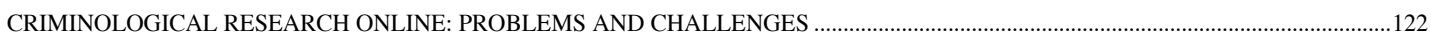

METHODOLOGICAL CONSIDERATION ONE: REJECTING THE ONLINE/OFFLINE DEMARCATION ....................................................125

METHODOLOGICAL CONSIDERATION TWO: THE IMPORTANCE OF EMBODIED PRESENCE IN THE APPLICATION OF VIRTUAL

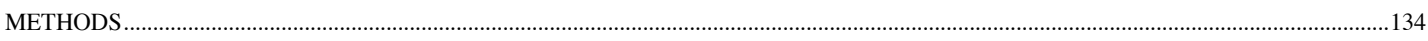

CRITICAL REFLECTIONS ON THE ORIGINAL RESEARCH PROJECT ...................................................................................................

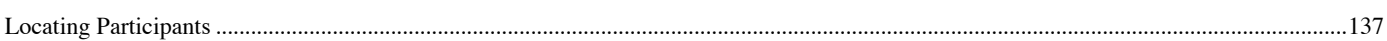

Are Virtual Focus Groups a Useful Method for Researching Online Victimisation? ..........................................................................139

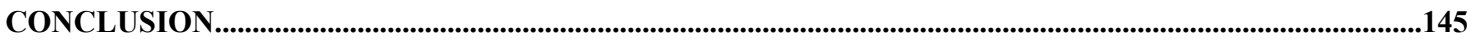

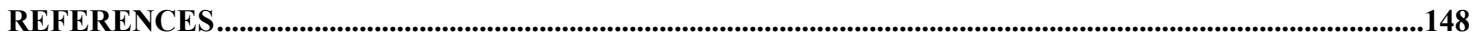

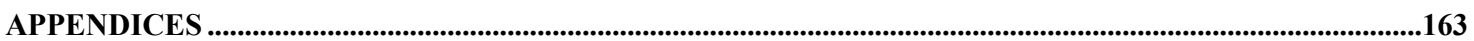

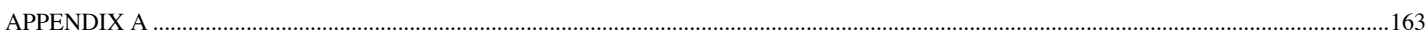

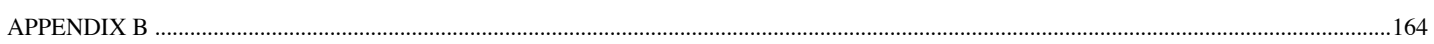

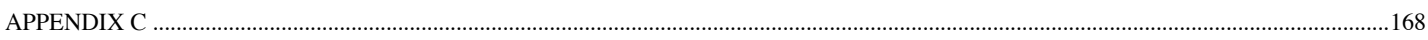

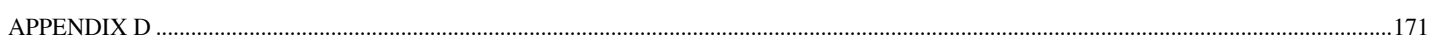




\section{INTRODUCTION}

To introduce this thesis I would like to give an indication of its development. The progression of this thesis has, by no means, been formulaic and for every question that has been resolved several more have arisen. The problems I encountered run parallel to the challenges criminologists are currently facing in what Smith (2007:7) calls an "exploratory research era". Few would challenge the assertion that the exponential growth of the Internet, and subsequently cybercrime, has not been matched, thus far, by criminological research. The original aim of this thesis was to develop an online, or 'virtual', focus group to examine how the concept of disembodiment contributes to the evident gender disparity in cyberstalking victimisation. It was also initiated by Adam's (2005) assertion that, beyond her own work and that of Ellison (2001), there has, thus far, not been a comprehensive gendered assessment of cyberstalking despite an evident gender disparity in cyberstalking statistics.

There currently exists no methodological precedent for the researcher intending to employ virtual methods to examine the online victimisation of women. Whilst the absence of methodological precedent, and participant recruitment problems, influenced the implementation of the original method, the methodological problems I encountered also subtly exposed a number of theoretical and methodological issues. The development of a theoretical and methodological framework for the examination of the online victimisation of women subsequently became the central concern of this thesis. 
This process challenged my initial hypothesis regarding the contribution disembodiment makes to the online victimisation of women and subsequently initiated an alternative theoretical and methodological position.

To inform the development of a comprehensive understanding of cybercrime, as it relates to criminological theory, this thesis begins with a discussion of the history of the development of the Internet, the rapid and exponential growth of which has implications for the development of applicable criminological theory. Additionally, the prioritisation of a gendered assessment of cyberstalking is supported by a discussion of cyberfeminism and Scott et al's (2001) women and the Internet narratives. A discussion of these perspectives provides the reader with an understanding of the interaction between feminist theories and the Internet, subsequently informing a discussion of a number of content related offences of which women are primarily the victims. This chapter concludes with an assessment of the application of criminological theory to cybercrime and the current criminological response.

Chapter Two provides a review of current literature addressing the online crime of cyberstalking. Whilst cyberstalking is currently regarded as under-researched, and lacking a comprehensive critical and theoretical assessment, one area in which critical scholarship has been applied to the crime of cyberstalking relates to the discontinuities and continuities between the online crime of cyberstalking and the offline crime of stalking. A discussion of this debate is therefore supported by a brief discussion of offline stalking. Following a discussion of a number of definitions of cyberstalking, 
current cyberstalking literature has been reviewed within four broad overlapping themes: victim characteristics, offender characteristics, motivations and legislation. This chapter concludes with a review of a number of campus-based studies and additionally studies that address the victimisation of children and young people. To facilitate a clearer critique and comparison between the individual findings these studies have been addressed aside from the thematic analysis which constitutes the former part of the literature review.

Following a review of cyberstalking literature the development of a theoretical framework applicable to a discussion of cyberstalking, yet also appropriate to inform the development of suitable methodology, was required. The overall purpose of this thesis was supported by the application of the theories of the body to develop a methodological framework suitable for an assessment of cyberstalking. This chapter begins by justifying the application of the theories of the body in contrast to the prevailing notion that bodies are absent online. The application of the theories of the body is initially supported by a brief discussion of the history of body theory and subsequently the rejection of the online disembodiment thesis and related theories, including cyborg theory and new digital Cartesianism. To conclude this chapter the theories of the body were then used to inform the development of a theoretical framework applicable to a gendered assessment of cyberstalking and the subsequent development of a suitable methodology. 
Prior to a discussion of the key methodological considerations developed in this thesis Chapter Four provides a brief discussion of the original research project. As previously stated, the original aim of this thesis was to employ virtual methods to qualitatively examine the online victimisation of women. Online, or 'virtual', focus groups were originally identified as an innovative and applicable method suitable for an assessment of the chosen subject matter and Chapter Four provides an assessment of this original method and the initial steps taken to implement this method.

The final chapter addresses a number of methodological considerations in response to the unique theoretical framework developed in this thesis and the problems that arose from the original research method discussed in Chapter Four. A discussion of the problems and challenges criminologists are currently facing when researching cybercrime is followed by the development of two key methodological considerations. These methodological considerations resulted from the synthesis of a review of cyberstalking literature, the application of the theories of the body and an assessment of the current problems and challenges criminologists are facing in relation to cybercrime. To conclude this thesis the original research method is assessed in response to the methodological considerations developed in this thesis. 


\section{CHAPTER ONE:}

\section{CYBERCRIME AND CRIMINOLOGICAL THEORY}

\section{THE TECHNOLOGICAL REVOLUTION}

As Manuel Castells (2000:1) argues, we are witnessing a "technological revolution, centred around information technologies [which are reshaping], at accelerated pace, the material basis of society". The development of the Internet can be firmly located within the military industrial complex (Scott et al, 2001) as attempts, in the 1960's, by the United States Defence Department to prevent Soviet destruction of communications technologies led to the creation of ARPANET $^{1}$ (Castells, 2000; Yar, 2006; Williams, 2006; Slevin, 2000). ARPANET consisted of thousands of autonomous computer networks, linked to each other, but without a central server, to prevent destruction (Castells, 2000). During the 1980's ARPANET was adapted from the military, private and university sector to the domestic arena (Williams, 2006). The first commercial Internet Browser, Netscape, was launched in 1994 and allowed browsing from personal computers (Yar, 2006). Also, at this time, numerous Internet Service Providers (I.S.P's) began offering connection to the Internet via telephone lines (Yar, 2006). Since the mid-1990's the Internet has grown exponentially, signalling the advent of what Castells (2000) has called the Information Technology Revolution.

\footnotetext{
${ }^{1}$ ARPANET is an acronym for the Advanced Research Projects Agency Network (Boni and Kovasich, 2000)
} 
The Statistics New Zealand Household Use of Information and Communication Technology Survey: 2006 provides an indication of the widespread use of the Internet in New Zealand. The survey indicates that:

- $\quad 1.011$ million households had access to the Internet at home in the December 2006 quarter.

- $\quad 33.2$ percent of New Zealand households had broadband access to the Internet, while 30.9 percent had dial-up access.

- $\quad 69.0$ percent of individuals used the Internet in the previous 12 months; 28.6 percent made an online purchase.

(Statistics New Zealand, 2007:1)

The exponential growth and widespread adoption of the Internet has initiated complex economic, social and criminological implications. This growth has, as yet, not been met by academic, and especially criminological, scholarship.

\section{THE ECONOMIC IMPACT OF THE INTERNET}

An examination of the social and economic impact of the Internet is required due to the subsequent interaction with new and altered opportunities for criminal offending within this environment. Castells (2000) argues that the Internet has created a new economy that is informational, global and networked. The new, Internet-based, economy is 
informational as "the productivity and competitiveness of units or agents ... fundamentally depend[s] upon their capacity to generate, process and apply efficiently knowledge-based information" (Castells, 2000:77). The establishment of the Internet as a conduit for economic activity has created a "new order" (Wall, 2004:78) whereby intellectual property becomes as important, if not more so, than physical property. Wall (2007:32) notes that "cyberspace is a virtual environment in which economic value is attached to the ideas and their virtual expression rather than physical property". The value of these ideas, and subsequent 'netspionage' (Boni and Kovacich, 2000) to obtain it, has become a defining feature of 21 st century economics.

The new economy is also organised on a global scale as traditional geographies of distance are collapsed (Castells, 2000) and, a distinctive networked economy is created to the point where, as Wall (2007:37) states, "no island is an island". As Williams (2006) notes, the intersection of economics and the Internet has also led to the creation of 'information industries' which constitute a large part of the new economy and are intrinsically linked to, and rely on, information technology. Williams (2006) also highlights the increasing number of individuals employed as 'information workers' within the new economy as opposed to traditional industrial workers. The use of information as a raw material within the new economy, the pervasiveness of the technology, the flexibility and the lack of spatial restriction (Williams, 2006), whilst contributing to the new economy, also allows for new opportunities for criminal offending within this environment. 


\section{THE SOCIAL IMPACT OF THE INTERNET}

An examination of the social impact of the Internet is an important precedent to an examination of cyber crime. Changes in social interaction, facilitated by the Internet, have promoted a "social deskilling of the individual, specializing and compartmentalising modes of interaction" (Wall, 2004:78) and although the Internet ensures the avoidance of what Sennett (1992) calls a "destructive Gemeinshaft", the lack of interpersonal connection may also impact adversely on social relationships. As Wall (2007:33) argues, virtual relationships "contain neither the full panoply of social relationships nor the cohesive or organic expectations of Gemeinshaft".

Despite the rapid adoption of information technologies (Castells, 2000) there has emerged a global 'digital divide"2 (Castells, 2000; Wall, 2005; Williams, 2006; Guillén \& Suárez, 2005). Adoption of the Internet is not egalitarian and those unable to access the Internet, and information technologies, find themselves predisposed to an "information exclusion" (Wall, 2004:78). Knowledge has been redefined as that which is gained through the use of technology, consequently excluding some people from participating in the knowledge society (Wall, 2004). Whilst socioeconomic status, cost and accessibility are regarded as key contributors to the creation of a global digital divide, Guillén and Suárez (2005) also argue democratic political regimes are more supportive of equal access to the Internet. China, for example, currently has the largest

\footnotetext{
${ }^{2}$ Any research conducted on the Internet and advanced communication technologies needs to be conducted with an awareness of the digital divide and the ways in which unequal access, along ethnic, gender and socio-economic lines, influences research. An examination of the digital divide in relation to gender will be addressed later in this thesis.
} 
number of imprisoned 'cyber-dissidents', and technology which blocks and filters Internet content containing phrases including 'democracy', 'freedom' and 'human rights' has been developed and implemented (Amnesty International, 2006). The Internet also allows users to communicate without temporal and spatial restrictions and Internet information is "transitory ... difficult to stop, retract or erase because it is likely to be stored in countless computers" (Havick cited in Guillén \& Suárez, 2005:687).

This is more acceptable within countries characterised by democratic government (Guillén \& Suárez, 2005).

\section{DEFINING AND UNDERSTANDING CYBERCRIME}

By itself, cybercrime is fairly meaningless as it tends to be used metaphorically and emotionally rather than scientifically or legally, usually to signify the occurrence of harmful behaviour that is somehow related to the misuse of a networked computer system (Wall, 2007:10).

Wall (2007) identifies four key discourses within which definitions of cybercrime can be located; legislative/administrative discourse, academic discourse, expert discourse and popular discourse. As legislative and expert discourses are based on areas of specialisation, law and technology respectively, it is the academic and popular discourses that will be examined at this point due to their overall relevance.

\section{Academic Definitions of Cybercrime}


Schell and Martin (2004:2) define cyber crime broadly as "a crime related to technology, computers, and the Internet" and place cyber crimes within several distinct categories; cracking, piracy, phreaking, cyber-stalking, cyber-pornography and cyberterrorism ${ }^{3}$. Thomas and Loader (2000:3) define cyber crime as "computer-mediated activities which are either illegal or considered illicit by certain parties and which can be conducted through global electronic networks". Their distinction between that which is 'deviant' and that which is 'criminal' highlights the often absent legal parallels (see also, Wall, 2004; Yar, 2006). Spinello (2002) places cyber crime within three categories; software piracy, electronic break-ins and computer sabotage. Cyber stalking and child pornography are not included within this category and are classified as computer facilitated crimes ${ }^{4}$ rather than cyber crimes (Spinello, 2002). Whilst I disagree with Spinello's (2002) exclusion of cyberstalking and child pornography from the mainstream classification of cybercrime, the problems associated with the definition of cybercrime mitigate the problem of this exclusion. The inclusion and exclusion of specific offences aligns with gender in addition to the technicalities of the way in which the technology was used.

Wall (2005) also places cybercrime within three distinct categories defined by the behaviours exhibited rather than actual offences (see Appendix A). A behavioural typology is appropriate as it delineates a number of offences possessing very different

\footnotetext{
${ }^{3}$ The terms used by Schell and Martin (2004:2-3) are further explained here. Cracking involves "gaining unauthorized access to computer systems to commit a crime". Piracy involves "copying protected software without authorization". Phreaking involves "obtaining free telephone calls or having calls charged to a different account by using a computer". Cyberterrorism involves "unlawful attacks and threats of attack by terrorist against computer, networks and the information stored therein". Cyberstalking and cyberpornography are addressed at a later point in this thesis.

${ }^{4}$ Computer facilitated deviance may be a more appropriate term for categorising these crimes due to the lack of parallel legal support.
} 
motivations. Cybercrime is a broad term encompassing crimes that span from economic crime to interpersonal violence. The first are computer integrity-related offences. These range in seriousness from computer hacking to cyberterrorism ${ }^{5}$. The second category involves computer related offences, crimes facilitated by the use of a computer. These include fraud, identity theft and piracy. The third category involves content related offences. This category bifurcates into two forms of content offences: cyber-obscenity and cyber violence (Wall, 2002). Cyber-obscenity involves the trade of sexually expressive materials online (Wall, 2002). Cyberviolence or harm involves the violent impact of actions within cyberspace including cyberstalking, hate speech and virtual rape (see Dibbell, 1994). As Wall notes, "although such activities do not require a direct physical expression, the victim nevertheless will feel the violence of the act and may bear long-term psychological scars as a consequence" (Wall, 2002:84). There is also recognition, however, that often "the virtual leaches through the porous boundaries of cyberspace" (Wykes, 2007a:168) and cybercrime often has serious offline parallels. This conceptualisation of a number of cybercrimes as a form of violent crime correlates with the increasing propensity, within criminology, to classify crimes as violent when no physical contact occurs between the victim and the offender, including corporate crime. Wall (2007) further expands on these three categories in the recently published Cybercrime, which reflects the rapidly changing nature of cybercrime. Wall $(2007: 49)$ also observes that it is "becoming harder to disaggregate the three [categories] in practice within the new generation of automated cybercrime". This recent revision

\footnotetext{
${ }^{5}$ Cyberterrorism includes "unlawful attacks and threats of attack by terrorists against computers, networks, and the information stored therein to intimidate or coerce a government or its people to further the perpetrator's political or social objectives" (Schell and Martin, 2004:3).
} 
indicates not only the rapid evolution of cybercrime but also the degree of responsiveness required by criminologists. Revision of cybercrime theory is constantly required due to the constant changes occurring in this area.

\section{The Production of Cybercrime Knowledge and Popular Discourse}

Due to the complex nature of the Internet, a lack of legal consensus or parallel legislative support and conflicting discourses on cybercrime a single definition is elusive. Definitional problems are exacerbated by the media, and cybercrime often has "no specific reference point in law" (Wall, 2004:79). However, cyber crime has become cemented in the public lexicon and posited as a cause for public concern, an anxiety heightened by the exponential growth of Internet users (Schell and Martin, 2004). As Wall (2007:10-11) has observed "not only has the term 'cybercrime' acquired considerable linguistic agency, but over the past decade 'cybercrimes' have become firmly embedded in public crime agendas as something that must be governed". A key concern for criminologists, therefore, is to understand how knowledge about cybercrime is produced and the associated problems. These include the role of the media, the reliability of statistics and underreporting. These issues, interestingly, are salient across all area of criminological scholarship.

The role the media plays in crime construction, and amplification, is an established area within criminology (see Jewkes, 2004) and a growing awareness of cybercrime has also led to intense media attention (Wall, 2007). This level of attention has been regarded as 
contributing to a moral panic surrounding cybercrime (Levi, 2001; Yar, 2006; Jewkes, 2007). For example, a survey of two major newspapers by Dowland et al (1999) over a two and a half year period found an average of two cybercrime related stories per week, often employing sensationalised language and over-emphasising risk. Whereas the intersection of crime and the media is an established area within criminology the environment in which cybercrime operates is also the environment that poses the greatest threat to the influence the media has on public perceptions of crime. The Internet has allowed for the development of independent media sites ${ }^{6}$ and provides individuals with the opportunity to access unlimited information. As Sambrook (cited in Wall, 2007:14) argues, the Internet has led to a "major restructuring of the relationship between public and media ... public discourse is becoming unmediated". Fictional representations of cybercrime, primarily focused on computer hackers, provide the opportunity for the public to develop an often distorted understanding of complex concepts. As Wall (2007:16) argues, "contemporary movie and media imagery subconsciously orders the line between fact and fiction and has crystallized 'the hacker' offender stereotype as the archetypal 'cybercriminal'”.

There exists very little 'official' data on cybercrime. Whereas the majority of crime statistics are filtered through a single source, such as the Police, cybercrimes lack a single regulatory body and the collation of statistics are problematic. Wall (2007) advocates the increased use of victim surveys as an alternative measure of victimisation. The British Crime Survey (2008) and New Zealand Crime and Safety

\footnotetext{
${ }^{6}$ See, for example, www.indymedia.org.nz and www.scoop.co.nz
} 
(2006) have both incorporated questions on e-crime victimisation. Unofficial measures of cybercrime are hampered, however, by under-reporting and a lack of knowledge about victims and offenders (Wall, 2007). Commonly accepted explanations for underreporting are equally applicable to cybercrime. Additionally, Wall (2007) for example, highlights the degree to which many victims of cybercrime, including fraud, are not aware that they have been victimised. There is also insufficient information about offenders although studies have indicated that although cyber criminals share similarities with their offline counterparts, in that the majority are young and male, they also have opposing personal characteristics, including introversion (Wall, 2007). The environment in which they offend is also significant as they are able to commit crimes at a distance that, without the Internet, would be beyond their means. Combined with their isolation from others, detection is difficult. At this point, due to its relation to the overall purpose of this thesis and its relevance at this point the complex relationship between gender, the Internet and crime requires further examination.

\section{WOMEN AND THE INTERNET}

An examination of the online victimisation of women, and the problems associated with researching victimisation online, must be preceded by a closer examination of the complex relationship between gender, the Internet and crime. This relationship will be examined by drawing on the principles and perspectives of cyberfeminism, a field characterised by a lack of cohesive, unified theory which paradoxically celebrates and critiques the role of Internet technology in women's lives. Scott et al's (2001) 
discussion of the three predominant, and conflicting, 'women and the internet' narratives will also be discussed. Whilst Scott et al's (2001) narratives and the perspectives which characterise cyberfeminism paradoxically celebrate and critique the impact of the Internet on women's lives, it is important to examine the manifestation of gender inequality and discrimination on the Internet, a concept that will be addressed throughout this thesis. The various ways in which the Internet has impacted adversely on women's safety, freedom and equality online will be examined in relation to the applicable theory.

\section{Cyberfeminism}

It should initially be recognised that cyberfeminism addresses, critiques, and is the product of, a highly contradictory environment offering both promises and problems for women. As Elm and Sunden (2007:3) have observed:

Cyberfeminism has grown out of an emergent use of digital media and new communication technologies. These technologies have been ascribed with both promises and threats, with the potential of simultaneous empowerment and suppression. They offer the means to open up communicative spaces and communities, to engage in play politics and to access information and create networks. But they also have the ability to monitor and keep track of their users, exclude non-users and divide the world into the 'information rich' and the 'information poor', as well as multiply and sometimes reinforce different forms of oppression-sexism, racism and homophobia.

This contradictory environment has, therefore, contributed to the problems associated with the identification of a singular, cohesive definition of cyberfeminism. Practically, cyberfeminism, as theory, can be directly aligned with the third wave of feminism and 
"operates primarily on a sophisticated theoretical level of third wave feminism and techno-science studies" (Elm and Sunden, 2007:4). Definition is hampered by the multidisciplinary nature of cyberfeminism that spans the disciplines of art, politics, communication, technology and culture. It is also hampered by the celebration or critique of the Internet adopted by various strands of cyberfeminism. For this reason there is no doubt that these inherent contradictions have contributed, in part, to the propensity by those who practice (cyber)feminist politics on the Internet to reject definition. Critical definitions of cyberfeminism have attempted to negotiate these inherent contradictions by focussing on the goals of cyberfeminism. Millar (cited in Hawthorne and Klein, 1999:3) defines cyberfeminism as "a women-centred perspective that advocates women's use of new information and communication technologies for empowerment". In addition, Paterson (cited in Hawthorne and Klein, 1999:4) defines cyberfeminism as a:

Philosophy [with] the potential to create a poetic, passionate, political identity and unity without relying on a logic and language of exclusion. It offers a route for reconstructing feminist politics through theory and practice with a focus on the implications of new technology rather than on factors that are divisive.

While for some the newness of the medium offers the chance for a 'fresh start' in terms of gender relations, others observe the replication of discrimination online as disproving this assertion. 


\section{Women and the Internet Narratives}

The 'women and the Internet' narrative falls into three categories as developed by Scott et al (2001). Whilst Scott et al's (2001) three-fold assessment of the impact of the Internet on the lives of women provides a useful framework for the assessment of the online victimisation of women, the myriad problems associated with defining 'women' as a homogenous group also need to be acknowledged. Scott et al's (2001) examination of inequality neglects to acknowledge the inequalities of access, participation and victimisation which occur between groups of women as well as between genders. For example, in terms of ethnicity, Bocij (2004) identified that American Indian/Alaskan Natives experienced more cyberstalking victimisation than other ethnic minorities in the United States. The 2006 New Zealand Crime and Safety Survey (Mayhew and Reilly, 2007:8) found that "Maori tended to report many of the e-crimes more often [and] the picture for Pacific peoples was often similar". Therefore, whilst Scott et al's (2001) assessment of the impact of the Internet on women's lives will be employed, it is also important to have an awareness of the operation of the digital divide as operating not only between genders and but also within genders in relation to class and ethnicity.

Scott et al (2001:3) identify women's use of the Internet as an 'origin story ${ }^{7}$ consisting of a "fixed beginning, a contested centre and an open ending". The story of women and the Internet begins within the military and academic realm. Added to this is the

\footnotetext{
${ }^{7}$ Scott et al (2001) borrow the concept of the origin story from Haraway (1986).
} 
additional engineering and industrial origins of the Internet and what is clearly identifiable is its origination in male dominated industries (Scott et al, 2001). Empirical evidence indicates that women are still excluded from Internet participation (Scott et al, 2001) and as Spender (1995) notes, if Internet technology is the 'new literacy' then by virtue of this exclusion from participation women have been rendered illiterate. Contemporarily the 'women and the Internet' narrative, according to Scott et al (2001), splits into three competing versions, which each have different implications for an examination of gender and Internet crime, and will be individually discussed. They name these three competing stories: the 'webbed utopia', 'flamed out' and 'locked into locality'.

The 'webbed utopia' thesis argues that "electronic networks offer women new possibilities for networking and for participative democracy" (Scott et al, 2001) and parallels can be found here with areas of cyberfeminism (see Halbert, 2004; Haraway, 1990; Plant, 1997). Whilst evidence does suggest that the Internet can be used to promote feminist principles, and there is a strong feminist presence on the Internet, the primary concern of Scott et al (2001) is that in doing so, utopian feminists are failing to challenge the use of the Internet for furthering more dangerous and discriminatory agendas, including crime committed against women and the proliferation of pornography.

The 'flamed out' thesis takes a paradoxically dystopic view of the Internet as a realm for pornography, violence, stalking and 'virtual rape' (see MacKinnon, 1997 for a 
discussion of virtual rape). Whilst evidence suggests that these incidents are pervasive on the Internet, Scott et al (2001:12) argue that this narrative "can be counterproductive for feminists; if cyberspace is so dangerous, women might well come to believe that their daughters would be safer spending their time somewhere else" thus further problematising exclusion from participation on the Internet and hampering attempts to secure equal participation. A University of Maryland study found Internet users with female pseudonyms were $25 \%$ more likely to be harassed online (Greer, 2007:15). As Greer (2007:15) notes, "misogyny is quick to surface when there are no rules of social decorum to temper it" and her discussion of the online abuse directed at the online feminist community is indicative of the 'flamed out' thesis.

The final version, 'locked into locality', is characterised by the idea that "while the social, economic and political action is taking place in a distant public space, most women are still shut away at home" (Scott et al, 2001:12) and while the Internet comes to be defined as the new public sphere it remains inaccessible to women. Linked to the fin de siecle struggle by Victorian feminists for access to literature and print, millennium women too must struggle for equal access to technologies that would allow them full and equal participation in the information technology revolution. It is essentially a story characterised by access and the barriers - temporal, spatial, financial, educational and vocational - preventing equal access for women. It is this final narrative that the authors favour, stating that "in its steady focus on the material factors both the dangers and the opportunities posed by the Internet are placed in perspective" (Scott et al, 2001:14). A discussion of the 'dangers' posed by the Internet is a central 
concern of this thesis. Additionally, the identification and application of relevant theory is crucial. At this point a discussion of cybercrime is facilitated by the identification of a number of criminological theories.

\section{APPLYING CRIMINOLOGICAL THEORY}

Rapid technological adoption and its attendant problems has also proven challenging for criminologists addressing crime within this environment. As Yar (2005) notes, the Internet has its own epistemological and ontological structures therefore requiring a reconceptualisation of research when conducted online. This has proven challenging for criminologists and the place pre-existing criminological theories have in the assessment of 'cyber crimes' has been queried (Wall, 2005). Wall (2005:77) questions whether criminologists are "looking at an entirely new phenomenon through the wrong lens", and cites the unique and complex characteristics of the Internet environment as a contributory factor on criminality. It is the Internet's disorder of time and space that has resulted in social interaction being "lifted out of local contexts of interaction and restructured across indefinite spans of time-space" (Giddens, 1990:14), challenging traditional theories of social interaction and rendering pre-existing criminological theories incompatible or redundant. Yar (2005:410) also argues that the characteristics of the Internet, including the easy manipulation of identit(ies), "renders us vulnerable to an array of potentially predatory others who have us within instantaneous reach, unconstrained by the normal barriers of physical distance". The implications for 
criminology are immense and numerous challenges emerge as criminologists attempt to address, what Capeller (2001:234) calls "an abstract and systemic criminal field".

As Wall (1999:110) notes, “cybercrimes possess qualities which turn many existing conceptions of traditional crime on their head" and classifying cyber crimes in relation to offline crimes are impeded by the distinctive characteristics of online offending. Cyber crimes are distinctive in several ways. Firstly, they have no definable boundaries and are unrestrained by concepts of time, space and location. As Yar (2006:11) argues, “cyberspace variously 'transcends', 'explodes', 'compresses', or 'collapses' the constraints of space and time that limit interactions in the "real world"'. This also means they are inter-jurisdictional, which has consequences for prosecution. They also lack a "core set of values" (Wall, 1999:109) and there does not exist a consensus, legal or otherwise, as to what constitutes a cyber crime. The technical knowledge required to commit a cyber crime also creates certain restrictions on who is capable of offending. Whereas traditional crimes tend to be primarily offender based, cyber crimes are largely offence based. As Yar (2006:16) notes:

Cybercrime ... is an inherently de-territorialized phenomenon. Crimes in cyberspace bring together offenders, victims and targets that may well be physically situated in different countries and continents, and so the offence spans national territories and boundaries.

This has created challenges for policing and criminal justice. As previously discussed the rapid emergence of cyber crime has proven challenging for criminologists as the Internet "exhibits structural and social features that diverge considerably from 
conventional 'terrestrial' settings" (Yar, 2006:17). The removal of a clearly recognisable offender and location in this new 'anti-spatial' and anonymous environment has rendered pre-existing criminological theories, such as Cohen and Felson's (1979) routine activity theory, redundant. However, whilst Wall (1999) considers cyber crime to in fact be a new crime theorists, such as Grabosky (2001:243) are more inclined to view cyber crime as simply "old wine in new bottles". It is also worth noting at this point that Yar's $(2005,2006)$ theories could be classified as falling between those of Wall (1999) and Grabosky (2001). Yar, whilst arguing that new tools are needed to address cybercrime criminologically, also recognises that cybercrime can often be explained using established theories of crime causation. Grabosky (2001), however, argues that it is the medium that has changed whilst the underlying characteristics and motivations have remained the same. However, as Wall (1999:133) concludes, "we shall be left with a series of new types of criminal behaviour which in some cases will cause us to rethink and augment our existing understandings of crime and deviant behaviour". ${ }^{8}$

Yar (2006) outlines the two key problems for criminologists addressing cybercrime; the 'where' and the 'who'. The problem of 'where' is compounded by cybercrime as preexisting criminological theories are based on ecological assumptions, grounded in a place, which has specific social and cultural characteristics. Space and time are important features of criminological theory, including routine activity theory, and

\footnotetext{
${ }^{8}$ A similar debate on the new, or simply modified, nature of offending is evident in an examination of the link between online and offline stalking which will be discussed in the subsequent literature review and precede a comprehensive examination of cyber stalking.
} 
therefore the non-spatial Internet environment creates problems. It is interesting to note, however, a growing number of researchers involved in mapping the Internet (see Dodge and Kitchin, 2000) and the implications this could have for environmentallybased explanations of crime causation. The issue of 'who' also becomes problematic due to the accessibility of the Internet and the anonymity afforded by this environment. As Yar (2006:18) argues, despite debate within criminology centred around the idea that offenders exhibit a "preponderance of ... certain shared characteristics", the addition of the Internet renders problematic theories of crime causation concerned with attributing offending to certain sections of society including the socially excluded. Yar (2000:19) concludes by stating that "rather than simply being able to transpose an existing 'stock' of empirical assumptions and explanatory concepts onto cyberspace, the appearance of Internet crimes might require considerable theoretical innovation". Despite this claim, Yar (2005) and Williams (2006) have taken the pre-existing criminological theories of routine activity theory and control theory, respectively, and applied these to an assessment of cybercrime.

Yar (2005) argues that the successful application of routine activity theory to an online environment would support Grabosky's (2001) claim that cybercrime is simply 'old wine in new bottles' and support the concept of continuity between the online and offline environment. Whilst parallels can be found between 'motivated offenders', both online and offline and certain characteristics of 'suitable targets' exhibit similarities, problems exist in the location of 'capable guardians'. As Yar (2005:423) notes, "in terms of formal social guardianship, maintaining such a co-presence is well nigh 
impossible, given the ease of offender mobility and the temporal irregularity of cyber spatial activities". Yar (2005) argues that, despite the problems of 'formal' guardianship online, it is simply an exacerbation of offline problems with policing and the Internet has allowed for the creation of alternative private and informal guardians including automated technological guardians. Yar's (2005:424) main concern in the application of routine activity theory to cybercrime centres around the spatial and temporal disorganisation of cyberspace, concluding that cybercrime may not be old wine in new bottles but alternatively, "old wine in no bottles".

Alternatively, Williams (2006) takes the established criminological theory of 'control' and applies it to cybercrime. Developed by Hirschi (1969), control theory explains offending as resulting from the lack of attachment, commitment, involvement and belief. Williams (2006) highlights how the lack of social bonds, disinhibition and a lack of self-control results in deviant offending online and that online communities can foster the creation of social bonds in a similar way to offline communities. Individuals lacking social bonds online may be predisposed to offending online. Williams (2006) also notes how techniques of neutralisation (Matza and Sykes, 1957) are supported by "anonymity, a sense of physical detachment, time and space distanciation and transience" (Williams, 2006:43) on the Internet. Despite the inherent problems with applying 'terrestrially-based' explanations of crime causation to online crimes, Williams' (2006) application of control theory and Yar's (2005) application of routine activity theory indicate that pre-existing criminological theory has, thus far, not been rendered redundant. 
Capeller (2001:230), however, argues "a revision of criminological patterns is necessary, as the criminological universe is incapable of explaining the new forms of criminality and deviance which make up cybercrime". Capeller's (2001:230) assessment of cybercrime is framed within the study of late modern society "in which traditional human relations are replaced by disembodied relations". Whilst Capeller's (2001) article applies the dichotomous theoretical concepts of trust/risk and accountability/anonymity to a discussion of cybercrime, it is the distinction between the Internet as an 'environment' and a 'support' that will be drawn on to precede the subsequent literature review.

Capeller (2001:234) argues that to effectively examine and respond to cybercrime, criminologists need to be aware that "cyberspace is not only a means or a support for criminal action, it is a true autonomous environment in which systemic and abstract criminal actions are spreading". The interaction of the abstract concepts of trust, risk, accountability and anonymity form the basis of an abstract community and "real material frameworks" (Capeller, 2001:234) that accommodate "disembodied interactive activities" (Capeller, 2001:234) and foster unlawful relationships.

In the last decade there has been a "shift from the occasionally provocative deviance, committed within the electronic computer system, towards a more and more sophisticated virtual criminality" (Capeller, 2001:235). A gender disparity in online 
victimisation is also evident and for the overall purpose of this thesis, and prior to a discussion of cyberstalking, a number of these offences require further examination.

\section{CONTENT-RELATED OFFENCES AND THE ONLINE VICTIMISATION OF WOMEN}

At this point it is important that several additional offences that share similar characteristics with cyberstalking are examined. These offences can be situated on the continuum of online victimisation of women and their brief examination is important for the overall purpose of this thesis. As Spender (cited in Hawthorne and Klein, 1999:8) observes, "for every feminist issue in the real world the same issues apply in the cyberworld"; including the victimisation of women. Wall (2005) places cybercrime within three distinct categories defined by the behaviours exhibited rather than the actual offences (see also Appendix A). For the purpose of this thesis it is important, at this point, to further explore Wall's (2005) concept of content-related offences as they relate to the online victimisation of women. The category of content related offences devised by Wall (2005) bifurcates into two sub-categories; cyber-obscenity and cyberviolence ${ }^{9}$. Each will be discussed by drawing on applicable theory to further explore the ways in which women are victimised online.

\footnotetext{
${ }^{9}$ Herring (2002), alternatively, includes a discussion of what she terms, 'degrading representations', within a discussion of cyberviolence.
} 


\section{Cyber-obscenity}

Historians of pornography have long shown that technological developments and pornography are deeply connected [and] it cannot be noted without irony that cyberspace owes a considerable part of its development to the pornography industry (Chatterjee, 2001:75).

Few would deny that the Internet has become, perhaps in realisation of Scott et al's (2001) 'flamed out' thesis, a tool for the production, storage and dissemination of sexually violent and explicit images of women and children. As noted above, Wall (2005) defines cyber-obscenity as the trading of sexually expressive materials on the Internet ${ }^{10}$. Although online pornography is not the primary focus of this thesis it is important to briefly recognise the ways in which cyberfeminist critiques of online pornography draw on the theoretical arguments surrounding the body. As Adam (2002:133) observes, "we may begin to think in terms of bodily invasions of privacy, where bodies are watched, looked at or subject to surveillance or indeed where bodies are actually violated and the violations watched on-line". Halbert (2004), in reference to online pornography, also notes the opportunities provided by the Internet for the 'efficient' trade in the virtual and real bodies of women.

\section{Cyberviolence}

Herring (2002:187) defines cyberviolence as "online behavior that constitutes or leads to assault against the well-being (physical, psychological, emotional) of an individual

\footnotetext{
${ }^{10}$ It should be noted that not all online pornography is illegal and there are "considerable moral and legal differences regarding the criteria that enable law enforcement to establish obscenity and depravation (Wall, 2004:84)".
} 
or group". It is the indirect nature of cyberviolence that constitutes its uniqueness and, as Wall (2004:84) notes, "such activities do not require direct physical expression, the victim nevertheless will feel the violence of the act (authors italics)". Flaming, hate speech and sexual harassment will now be addressed in relation to the applicable theory.

\section{Flaming, Hate Speech and Sexual Harassment}

Language can act in certain ways that parallel the infliction of physical pain and injury (Butler cited in Williams, 2006:100)

Williams' (2006) examination of what he terms 'derisory textual performances' provides an excellent theoretical perspective from which to examine the ways in which women are victimised online through speech and text. Williams (2006), who has neglected to provide a gendered examination of harmful online speech, does explore a number of forms of victimisation which are predominantly directed towards women online, including sexual harassment and virtual rape. Combining the work of Williams' (2006) with Spender's (1995) assessment of male behaviour online in relation to power provides a useful framework for the examination of how gender discrimination manifests itself online via text. Williams' (2006) argument is particularly important for the overall purpose of this thesis as it addresses how language and embodiment are inextricably tied. As he notes, "the social existence of the body is made possible partly by being interpellated within the terms of language" (Williams, 2006:100). Williams (2006:100) cites Judith Butler, to further indicate that "if language can sustain the body 
it can also threaten its existence". For this reason if the body is constituted through language then language can, paradoxically, disestablish an individual's identity (Williams, 2006). If 'being' can be constituted through language then online abuse and harassment via language contributes to an individual's ontological precariousness. The ways in which speech can harm in a face-to-face situation are equally plausible in an online environment to the extent where the environment itself may contribute to the increased severity of a verbal attack that is not tempered by the restrictions of embodiment or physical presence.

Williams' (2006) central thesis is based on the idea that those who invest themselves in an online environment, who create alternative and multiple identities and who are, essentially, more ontologically secure in an online environment are therefore more vulnerable to harmful speech. Spender (1995:183) addresses a specific form of harassment via text, known as flaming ${ }^{11}$, and argues:

What some of these men do online - what they put on their screens and on those of the women students - has to be seen to be believed. To my mind it is nothing short of sexual terrorism, designed to drive women away from the centre of power.

Spender (1995) identifies the cause of flaming, a specifically Internet-based phenomenon, as resulting from two key factors. Firstly, the anonymity afforded by the Internet environment is identified as a key factor enabling a harasser to engage in

\footnotetext{
${ }^{11}$ Flaming is defined as "the act of posting or sending offensive messages over the Internet. These messages, called "flames," may be posted within online discussion forums or newsgroups, or sent via e-mail or instant messaging programs. The most common area where flaming takes place is online discussion forums, which are also called bulletin boards" http://www.techterms.com/definition/flaming Date accessed 28th, January 2009
} 
coercive and abusive communication online. Secondly, flaming is less likely to occur offline, in face-to-face conversation, as it is tempered by a person's physical presence. Spender (1995:193) uses 'power' as a primary explanation for "male menace on the superhighway". She highlights how, offline, men dominate conversation noting that "men perform up to 99 per cent of the interruptions in mixed-sex conversations" (Spender, 1995:193). Research indicates that these patterns are replicated online (Spender, 1995) and flaming inevitably results when women attempt to challenge the status quo. In addition to flaming, sexual harassment is equally destructive and pervasive online. Referred to as "the systematic means of keeping women out of male territory" (Spender, 1995:203), sexual harassment functions equally well online. Scott et al's (2001) 'flamed out' thesis is indicative of the manifestation of this discrimination. Cyberstalking, an additional form of cyberviolence, is the primary focus of this thesis and will now be addressed. 


\section{CHAPTER TWO:}

\section{A REVIEW OF CYBERSTALKING LITERATURE}

\section{INTRODUCTION}

The exponential growth of the Internet has corresponded with the diffusion of criminal behaviour within this environment. New forms of deviance are supported by the unique characteristics of the Internet environment, whilst pre-existing crimes are also paralleled on the Internet. Williams (2006:18) highlights the extensive opportunity for offending on the Internet, stating that:

At one end of the spectrum we see organised criminals taking advantage of new technologies and networks to facilitate their illegalities, while at the other extreme the 'empowered small agent' is able to commit crimes that were previously beyond their means.

The spatial and temporal restrictions placed on conventional offline crimes are superseded in an online environment. The spatially ambiguous online environment has allowed the perpetration of crime to occur at a distance with no contact occurring between offender(s) and victim(s). Whilst temporally "a fraudulent transaction can take place over thousands of miles in milliseconds while a harasser can subject their victim to derisory discourse at great distance in real time" (Williams, 2006:19). The identification of the commission of virtual, or cyber-, violence has emerged as one of the most challenging manifestations of crime online, due, in part, to the perceptions of 
the lessened degree of harm potentially experienced if time and space are distanciated. The previous chapter briefly discussed a number of offences which constitute cyberviolence, which includes "online activities which have the potential to harm others via text and other 'digital performances"' (Williams, 2006:25). An examination of an additional form of cyberviolence, cyberstalking, will now follow.

Identifying literature and research on cyberstalking is not a difficult task due, primarily, to the evident lack of research on this subject. The subject has been active, in a research sense, for a comparatively short period of time. Unlike other areas within criminology, which have an extensive historical precedent and a more visible impact, cyberstalking has emerged very recently in an environment characterised by spatial ambiguity and anonymity. The majority of cyberstalking scholarship is, therefore, not supported by empirical research. For this reason the Internet's unique characteristics provide the opportunity for methodological innovation.

In this literature review, the literature on cyberstalking will be assessed within four broad overlapping themes: victim characteristics, offender characteristics, motivations, and legislation. These themes have been chosen as they align with the dominant strands of cyberstalking research and allow a comprehensive overview of literature within this field. The selected literature is both qualitative and quantitative, spans various mediums and its synthesis provides an indication of the current academic position on cyberstalking. There is also a lack of critical theoretical scholarship on the subject with the research focus tending to be more practical than theoretical. Whilst the majority of 
cyberstalking research has few contentions, the key argument centres on the idea that cyberstalking is, or is not, an extension of offline stalking, an argument which evokes several key arguments surrounding cyber criminality more broadly (see Wall, 1999 and Grabosky, 2001). It is also an area, which despite an evident gender disparity, has not been addressed from a gendered perspective $\mathrm{e}^{12}$.

Whilst several arguments exist on the online/offline distinction, few exist which explicitly draw on distinct gender disparities to define this argument. Doing so requires, initially, a brief examination of the much older crime of stalking and the gendered nature of this crime. To conclude this literature review it is important to examine, separately from other literature, the range of contradictory quantitative studies that have examined cyberstalking in a college setting and amongst juveniles. This will include the New Zealand report 'Girls on the Net' produced by the Internet Safety Group (2001). Whilst arguments can be levelled at college samples as merely 'samples of convenience', evidence suggests that 'stalking within the ivory tower' (see Lee, 1998) may be more prevalent due to several unique factors present on campuses and, therefore, this environment provides a useful context in which to examine cyberstalking. An increase in reported incidents of cyber bullying and bullying via text message $(\mathrm{Li}, 2007)$ indicates a propensity, within the younger age demographic, to employ advanced communication technologies for the purposes of harassment ${ }^{13}$ and

\footnotetext{
${ }^{12}$ The work of Alison Adam $(2001 ; 2002)$ on cyberstalking from a theoretical perspective will be examined further in this thesis and remains one of the few examinations of cyberstalking from a feminist perspective.

${ }^{13}$ Although this is not a central concern of this thesis it will be addressed briefly.
} 
studies which include a younger age demographic will also be examined due to the future influence these findings may indicate.

\section{IS CYBERSTALKING AN EXTENSION OF OFFLINE STALKING?}

One can perceive a change in behavioural patterns as deviant and criminal behaviour appear in virtual space. Discontinuities emerge in the criminal field which does not mean, however, that there is a drop in the traditional forms of criminal activities. The latter continue to exist, thus also assuring continuities. Continuities appear as soon as a traditional form of criminality enters the virtual world, such as organized crime. The possibility of transnational organized crime filtering into virtual contexts is unquestionable, reinforcing the possibility of new sites where interactive crime can develop (Capeller, 2001:230, author's italics).

One of the main contentions within the body of literature which addresses cyberstalking is the proposition that cyberstalking is simply an extension of offline stalking and that new computer technology has simply been co-opted as an additional tool for the offline stalker. Whilst the majority of theorists argue cyberstalking is an extension of offline stalking (see Ogilvie, 2000; Spitzberg \& Hoobler, 2002; Jewkes, 2002), others hold the view that cyberstalking is a new form of criminal behaviour unrelated to offline stalking (see Bocij and McFarlane, 2003; Bocij, 2004; Ashcroft, 2001). Bocij (2004) argues that cyberstalking is an entirely new form of criminal behaviour, which can occur with no offline counterpart. Bocij (2004) highlights the lack of cyberstalking incidents during the 1980's and early 1990's as an indication of

the difference between the two types of stalking. Bocij (2004) has, however, failed to address the lack of cyberstalking research at this point in time which may have 
contributed to what appears as a small number of incidents ${ }^{14}$. Bocij (2004) cites the low number of cyberstalking incidents during this time as indicative not of a reluctance by offline stalkers to use the technology but a gradual creation of a new form of behaviour $^{15}$ - cyberstalking. Bocij (2004) argues that if cyberstalking was an extension of offline stalking then these technologies would have been adopted almost instantaneously as an additional tool for those engaging in offline stalking behaviour. Few theorists can be found whose ideas reflect those of Bocij, although Ashcroft's (2001:2) report to Congress on cyberstalking, whilst arguing that cyberstalking is an "existing problem aggravated by new technology", also identifies three important differences between online and offline stalking in support of the ideas proposed by Bocij. These concepts will be discussed further in this thesis and include:

1. The lack of spatial and temporal restrictions when stalking is committed within an online environment.

2. The ease at which perpetrators can incite others to engage in third party cyberstalking or stalking by proxy.

3. The removal of barriers to harassment which do not necessitate the need for an offender to physically confront their victim to cause harm.

\footnotetext{
${ }^{14}$ The only justification for this would be retrospective quantitative research, no evidence of which exists or is alluded to by Bocij. This is once again indicative of the methodological problems associated with cyberstalking.

${ }^{15}$ See Mullen et al (2000) for a discussion of the protracted historical precedent for offline stalking behaviours.
} 
It is evident from Ashcroft's (2001) distinctions that these have been selected due to the practical ramifications of these differences and the opportunities for legislation and prevention that an awareness of these issues provides.

The overwhelming majority of cyberstalking literature links online stalking to its terrestrially based counterpart and draws similarities in both victim and offender characteristics and offender motivations. Joseph (2002) draws attention to the link between online and offline stalking arguing that they share several important characteristics including the desire by the offender to assert control over the victim. She also draws attention to the common existence of a prior offline relationship between the offender and the victim and the significant gender disparity evident in both forms. Spitzberg and Hoobler (2002:74) also advocate the idea that cyberstalking is an extension or variant of offline stalking, locating their argument parallel to an assessment of offline stalking and arguing that "given the opportunity to pursue their prey in the convenient, highly adaptable, and relatively anonymous realm of cyberspace, pursuers indulge themselves in the new technological opportunities for intrusion". Ogilvie (2000:3) recognises the ways in which cyberstalking often "spill[s] over into "physical space" and that the majority of cyberstalking incidents are accompanied by offline traditional stalking behaviours (see also Spitzberg and Hoobler, 2002; Lee, 1998). There is also recognition that whilst cyberstalking can escalate into offline stalking, the Internet can also be used as a tool for stalking following a relationship breakdown. Stalking following the breakdown of a relationship has been well documented (see Tjaden and Thoennes, 1998). Bocij and MacFarlane (2003), 
however, found that ex intimates are not as likely to extend their stalking online and the majority of cyberstalking incidents involved those who had only recently met. Williams (2006:99) explores the danger of denying the links between online and offline offending arguing that "such a strict dichotomy between the 'real' and the 'virtual' must be rejected if the consequences of abusive acts online are to be fully acknowledged".

Alternatively, Yar (2006) takes a balanced view, as does Wykes (2007a:127), and argues that "cyberstalking ought to be understood as a new variant of an existing pattern of criminal conduct. One that exhibits both continuities and discontinuities from its terrestrial counterpart". Wykes (2007a:167) argues that cyberstalking is not necessarily a new crime, but "acted out in a new place, where the boundaries between the virtual and actual blur, as do those between actors and audiences, watchers and watched, producers and consumers; criminals and detectives". These 'continuities', a key example of which is the evident gender disparity, and 'discontinuities' need to be examined in more detail as few theorists attempt to fully examine the relationship between online and offline stalking.

Differentiation between online and offline stalking neglects two vital 'continuities' between offline and online stalking - the predominance of women as victims, and the predominance of males as offenders (WHOA, 2007; Bocij, 2004; Joseph, 2002). Although this will be examined at a later point in this thesis, it is important to recognise this inconsistency at this point prior to an examination of offline stalking. One 
explanation put forward for the gender disparity in online harassment victimisation is the gender differences in computer mediated communication (Ellison, 2001). The Internet is, first and foremost, a discursive environment (Gajalla, 2000). As Ellison (2001:144) states, "men tend to be more adversarial in their online interactions and use intimidation tactics to dominate and control online discussion" (see also Spender, 1995). A brief examination of offline stalking ${ }^{16}$ in relation to cyberstalking is vital as it establishes a link between two types of offending which can be placed on a larger continuum of violence and intimidation against women. The interrelatedness of these offences must not be ignored.

\section{OFFLINE STALKING}

Greater recognition of stalking, in the past twenty years, has led to a proliferation of definitions for this historical phenomenon (Mullen et al, 2000, Westrup \& Fremouw, 1998). Pathé and Mullen (1997) define stalking as "a constellation of behaviours in which one individual inflicts on another repeated unwanted intrusions and communications" (Pathé and Mullen cited in Mullen et. al, 2000:7). Goode (Goode cited in Ogilvie, 2000:1) defines stalking as "one person caus[ing] another a degree of fear or trepidation by behaviour which is on the surface innocent, but which, when taken in context, assumes a more threatening significance". Behaviours that fall under the rubric of stalking include: unwanted phone calls, unwanted physical contact,

\footnotetext{
${ }^{16}$ Space does not permit a comprehensive examination of offline stalking, especially due, in part to the protracted historical precedent. The primary focus of this thesis will be cyberstalking.
} 
spreading rumours, maintaining surveillance, following and loitering, and can be placed on a continuum of severity (Bocij, 2004). The potential for stalking to escalate into more serious violent offences is also widely acknowledged, especially in the context of prior relationships (Ashcroft, 2001).

Bocij (2004) notes that the prevalence of stalking varies according to age and gender and women are disproportionately the victims of stalking. Bocij (2004) also notes, however, the reluctance of men to report stalking victimisation. The United Statesbased 'National Violence Against Women Survey' found that "one out of every 12 women (8.2 million) and one out of every 45 men ( 2 million) have been stalked at some time in their lives" (Department of Justice cited in Bocij, 2004:37). Spitzberg (2002), in a meta-analysis of 103 studies on stalking, found an average of 23.5 percent of women affected by stalking compared to 10.5 percent of men. Subsequently, Walby and Allen's (2004) Home Office Report found that in the United Kingdom 18.9 percent of women and 11.6 percent of men reported experiencing stalking. The British Crime Survey (1998) also found that women and young people were more likely to be stalked. The Australian Bureau of Statistics found that 15 percent of women reported being the victim of stalking at some point in their lives (Bocij, 2004). A recent Australian survey of 3,700 adults found that 23.4 percent of those surveyed had been the victim of stalking at some point in their lives (Mullen et al cited in Bocij, 2004:39). There is currently no New Zealand based research on the prevalence of stalking although Hughes et al's (2007) study of the stalking experience of mental health professionals, a group with an increased risk of stalking victimisation, provides preliminary data. From 
a sample of $280,70.4 \%$ had experienced one or more kinds of stalking behaviour including unwanted gifts or letters, loitering outside the person's home or threatening the clinician. Women were more likely $(72.6 \%)$ to have experienced one or more of the stalking behaviours than men $(24.4 \%)$.

Mullen et al (2000) draw on the influential work of Lowney and Best (1995) to outline the construction of stalking as a social problem. The first period of social construction occurred during the 1980 's prior to the establishment of the term stalking. Terms including 'psychological rape' or 'obsessional following' were used to describe behaviours characteristic of what is now commonly known as stalking (Mullen et al, 2000). Public concern over the issue was not yet galvanised and victims were often held partially responsible for their victimisation. From 1989 to 1991 the public became increasingly interested in the stalking of celebrities and mental illness and violence were perceived as key characteristics of stalking (Mullen et al, 2000, see also Wykes, 2007a). Between 1992 and 1994 stalking became re-conceptualised as a by-product of a failed relationship (Mullen et al, 2000). Statistics indicate stalking is most likely to occur between intimates after a relationship breakdown (Ashcroft, 2001; Tjaden and Thoennes, 1998). Stalking also became associated with male violence and was consequently reframed as a women's issue. Mullen et al (2000) argue that the social construction of stalking "does not reflect a single influence but the concatenation of a number of trends and concerns, many of which had remained inchoate before the concept and the very word 'stalking' gave them a medium for expression" (Mullen et al, 2000:19). They credit this social construction as being the product of three distinct 
social factors. The first is the increasing public concern with privacy in the 1970's and 1980's. The second factor was the "change in how people experience themselves in relation to other people of their society" (Mullen et al, 2000:20). Human interaction was changing, 'communities' were disappearing and coupled with the increased need for privacy, "neighbours were increasingly becoming strangers" (Mullen et al, 2000:20). The third factor was the increased awareness of newly created strangers with the potential to cause harm. People suffering mental illness or addiction were regarded as a greater threat to society with a propensity for violence. This was in addition to intense media fascination with celebrity stalking (Wykes, 2007b). These factors culminated to influence the current concerns over stalking. Lee (1998:373-374) also makes an important observation noting that "stalking is not predominantly socially deviant behavior, but in fact, to a certain extent, socially sanctioned behavior, instituted and encouraged by Western courtship mores and ideas of romance”.

\section{DEFINING CYBERSTALKING}

One of the key theorists to address cyberstalking, Paul Bocij, defines cyberstalking as $^{17}$ :

A group of behaviors in which an individual, group of individuals, or organization uses information and communications technology to harass another individual, group of individuals, or organization. Such behaviors may include, but are not limited to, the transmission of threats and false accusations, identity theft, data theft, damage to data or equipment, computer monitoring, solicitation of minors for sexual purposes, and any form of aggression. Harassment is defined as a course of action that a reasonable person, in

\footnotetext{
${ }^{17}$ Bocij's (2004) definition is comprehensive and will become the point of reference when defining cyberstalking in this proposal.
} 
possession of the same information, would think causes another reasonable person to suffer emotional distress (Bocij, 2004:14).

Many definitions of cyberstalking tend to favour the use of the term 'harassment' over the term 'stalking' to remove comparisons with its established terrestrial counterpart. The term stalking also implies an often absent, physical presence whereas in cyberstalking offences there may be no physical contact between the victim and the offender and the 'following', as implied by the word stalking, may occur solely in an online environment. Although the terms harassment and stalking are used interchangeably in the majority of cyberstalking literature, Harvey (2003), from a legal perspective, makes a clear distinction. Harvey (2001:1) notes that, "the nature of the behaviour is an effects-based one upon the victim wherein the stalker is anonymous, although the harasser may not be". He also notes that stalking is characterised, as noted above, by pursuit and the intentional instillation of fear by an often anonymous perpetrator, whereas harassment is less serious and more of an annoyance (Harvey, 2003).

Another definition cited by several theorists is that provided by D'Ovidio and Doyle (2003:10) who define cyberstalking as, "the repeated use of the Internet, email or related digital electronic communication devices to annoy, alarm, or threaten a specific individual". A broad definition such as this allows for the inclusion of various behaviours. Internet safety group 'Wired Safety' lists a number of characteristics, the presence of one of more of which would constitute cyberstalking. They include: 
- Malice

- Premeditation

- Repetition

- Distress

- Obsession

- Vendetta

- No Legitimate Purpose

- Personally Directed

- Disregarded Warnings to Stop

- Harassment

- Threats

(http://www.wiredsafety.org/cyberstalking_harassment/definition.html)

Several categories of cyber bullying proposed by Li (2007) could also be included under a definition of stalking and these behaviours include flaming, denigration, masquerade (impersonating someone else online) and outing (publicly exposing private information about an individual online).

The increasing legal attention on cybercrime has also necessitated the creation of legal definitions of cyberstalking. California, the first United States state to pass specific cyberstalking legislation, states that cyberstalking is committed when:

[A] person who, with intent to annoy, telephones or makes contact by means of an electronic communication device with another and addresses to or about the other person any obscene language or addresses to the other person any threat to inflict injury to the person or property of the person addressed or any member of his or her family, is guilty of a misdemeanour (Sec. 5. Section 653m of the Penal Code, $C A L)$. 
Cyberstalking emerged in the 1990's with the advent of advanced communication technology, or 'technologies of interpersonal contact' (Spitzberg and Hoobler, 2002), including the World Wide Web or Internet. These technologies subsequently became a conduit for criminal activity (Wall, 2002). Following the emergence of cyberstalking several prevalence studies have been conducted. Bocij (2004) notes, however, that the prevalence of cyberstalking incidents is a controversial issue as studies are impeded by definitional issues and the anonymity of participants. Cyberstalking remains an under researched field with researchers also hindered by the rapid adoption of technology (Spitzberg and Hoobler, 2002). Like many cybercrimes, quantification of cyberstalking has been negated in favour of a more qualitative examination in light of the vast size and anonymity of the Internet environment.

\section{VICTIM CHARACTERISTICS}

Cyberstalking incidents are often predicated on the percentage of offline incidents (United States Department of Justice, 1999 cited in Bocij, 2004) and Bocij (2004) therefore warns of the problems associated with cyberstalking statistics as they are often based on supposition and estimation. The U.S. Department of Justice Report states that:

Assuming the proportion of cyberstalking victims is even a fraction of the proportion of persons who have been the victims of offline stalking within the preceding 12 months, there may be potentially tens or even hundreds of 
thousands of victims of recent cyberstalking incidents in the United States (Reno cited in Bocij, 2004:40).

Bocij (2004) conservatively places the United States prevalence of cyberstalking at 76,000 cases annually. There is currently no New Zealand based research on cyberstalking, including its prevalence; however individual case studies can be identified through the news media and indicate that cyberstalking is occurring in New Zealand in ways which mirror international examples.

\section{Case One:}

Newspaper reports from 2001 highlight the case of author Patricia Bartle harassed via email by an American, Peggy Phillips, for two years. When Bartle ended email conversations with Phillips, Phillips' emails escalated to email harassment and telephone calls. Phillips also travelled to New Zealand to attempt to see Bartle. The case highlighted the problems of addressing cyberstalking occurring between countries. At the time New Zealand had no laws to address cyberstalking and issued Phillips with a trespass notice. Bartle also laid a complaint with Californian police. New Zealand police would have, at the time, needed to go through Interpol to act on the harassment, which would have been a lengthy and expensive process (Humphries, 2001).

\section{Case Two:}


A second case highlighted how email harassment fell under the domain of criminal harassment resulting in a conviction. A Blenheim woman was subject to email harassment of a sexually explicit and threatening nature from an unknown person. As the emails became more disturbing and alluded to offline contact she contacted the police who were able to trace their origin. The victim said that she "felt almost mentally raped", stating that, "every time I got an email I held my breath. I had no idea who it was and I was always looking over my shoulder” (Skinner, 2003). This case also indicates the serious effects cyberstalking can have on a victim.

Whilst no New Zealand research exists which addresses the nature and incidence of cyberstalking the findings from the 2006 New Zealand Crime and Safety Survey (Mayhew and Reilly, 2007) provide an overall picture of e-crime victimisation in New Zealand. Questions examining offensive webpage material and harassing email messages will be explored in more depth. The study found that 15 percent of computer users reporting exposure to offensive webpage material. One in ten computer users reported receiving threatening or harassing emails with females (12 percent) reporting victimisation more than males (9 percent) (Mayhew and Reilly, 2007).

Research on cyberstalking, thus far, indicates that women are more at risk of being victims of cyberstalking than men. Online organisation Working to Halt Online Abuse (WHOA) found that cumulative figures from 2000 to 2007 indicated that women comprised an average of 72.5 percent of cyberstalking victims (WHOA, 2007). Males 
comprised an average of 22 percent of cyberstalking victims ${ }^{18}$ (WHOA, 2007). Recent WHOA figures exclusively from 2007 indicate women comprised 61 percent of victims, males comprised 21 percent with 18 percent of an unknown gender (WHOA, 2006). When examining these gender disparities it is important to note however, that several theorists have highlighted reluctance by men to report incidents of cyberstalking (Bocij, 2004). The majority of cyberstalking victims between 2000 and 2007 were between $18-30$ years old ( 44 percent), followed by the $31-40$ year age bracket (27.25 percent) (WHOA, 2007). Cumulative findings from $2000-2007$ indicate that 49 percent of victims knew their harasser prior to the cyberstalking incident and 50.75 percent of victims did not know their harasser prior to the cyberstalking incident (WHOA, 2007).

There is a discernable lack of quantitative and qualitative cyberstalking research with research tending to be more theoretical than empirical; however, several theorists have assessed the effect of cyberstalking on victims. The effects of offline stalking have been paralleled with the effects of online stalking; however the detached nature of cyberstalking produces interesting differences. The U.S. Department of Justice special report into stalking and domestic violence states that, "A number of victims described stalking as a nightmare that invaded all aspects of their lives. They spent a great deal of energy, time, and money just trying to stay alive" (Ashcroft, 2001:23). It is the serious psychological effects that dominate discourse on the effects of cyberstalking and stalking. The effects of cyberstalking are complex and pervasive, extending beyond the

\footnotetext{
${ }^{18}$ In $5.5 \%$ of cases reported, gender was unknown.
} 
psychological to affect various aspects of a person's physical and mental health and influencing the way in which they live their life (Bocij, 2004). The effects of cyberstalking can be mediated, however, by the degree of computer literacy possessed by the victim (Bocij, 2004). When asked to rate their distress on a scale of one to ten, participants who considered themselves expert computer users comprised only 28.6 percent of people classifying their experience as a ten (Bocij, 2004). However, fifty percent of novice users reported their distress as a ten (Bocij, 2004). The lower level of distress experienced by experienced computer users may be a result of their ability to more adequately protect themselves from cyberstalking by employing various measures, including the use of firewalls ${ }^{19}$, to prevent remote access (Bocij, 2004). For novice users cyberstalking may appear more of a threat due to the unfamiliar environment in which they are being victimised and the inability to address their victimisation pragmatically. Due to the lack of research into the effects, on the victim of cyberstalking, parallels with offline stalking are necessary. It is also worth noting that one third of cyberstalking incidents escalate into offline stalking (Bocij, 2004). The threat of this potentially occurring may also impact on the victim as indicated by the second New Zealand case study. Prior to a discussion of the numerous effects of stalking and cyberstalking it is worth noting the subjective nature of the impact of cyberstalking on the victim, as Finch (2002:424) notes, "Victims respond in a variety of ways ranging from amusement or indifference on the one hand to more extreme reactions causing significant psychological damages at the other end of the continuum". Common experiences of stalking victims include:

\footnotetext{
${ }^{19}$ Firewalls are "programs used to provide additional security on networks by blocking access from the public network to certain services in the private network" (Schell and Martin, 2004:225)
} 
- Powerlessness/loss of control

- Feelings of desperation and isolation

- Self-blame or shame

- Hypervigilance or over-reactivity

- Sleep disturbances such as nightmares and difficulty falling asleep or staying awake

- Avoidance of intimacy

- Weight loss or gain

- Substance abuse

- Intense fear of specific and general things such as being alone or in crowds

- Anxiety and depression

- Spiritual crises

(Ashcroft, 2001:24).

Spitzberg and Hoobler's (2002) study of obsessive relational intrusion ${ }^{20}$ and cyberstalking assessed the ways in which victims applied various 'coping' mechanisms. They discuss coping as falling within three distinct sets of behaviour. These include unilateral protection which includes various techniques such as changing one's actions, aggressive protection which includes seeking legal support and confronting a stalker, and interaction which includes communicating with the stalker to cease their behaviour (Spitzberg and Hoobler, 2002).

\footnotetext{
${ }^{20}$ They define obsessive relational intrusion, a subset of stalking which can also be applied to cyberstalking, as the "unwanted pursuit of intimacy through the repeated invasion of a person's sense of physical or symbolic privacy" (p. 73). Adam (2005:180) is critical of Spitzberg and Hoobler's (2002) examination of obsessive relational intrusion, an examination she calls "remarkably gender blind".
} 
In addition to the psychological/emotional affects experienced by victims, harm can extend beyond the aforementioned conditions to include secondary effects. Victims incurred financial costs associated with stalking. These costs arose from seeking professional help, paying legal fees and missing work (Ashcroft, 2001). Stalking also extended beyond the victim to include friends and family members of the victim (Bocij, 2004). Pathé and Mullen (1997) found $37 \%$ of cases resulted in a victim changing jobs, schools or careers. Finch (2002:425) highlights that each case is unique and "there are cases in which no vestige of the victim's life remains unaffected".

\section{OFFENDER CHARACTERISTICS}

Several typologies exist to classify offline stalking and these have been appropriated to classify online offenders with the majority able to be co-opted to explain online behaviour. Ogilvie (2000) places these typologies within three categories: offendervictim relationship, psychiatric classifications and behaviour. Brian Spitzberg's (2002) seven-fold typology falls under the third category and is the most easily applied to online stalking ${ }^{21}$. Spitzberg classifies behaviour in the following categories:

- Hyper intimacy, or behaviours displaying excessive interest in developing a relationship;

\footnotetext{
${ }^{21}$ See my italics for explanations of adaptation.
} 
- Proximity/surveillance, or following types of behaviour; (can include following someone into chat rooms and message boards and monitoring their movements on the Internet)

- Invasion, in which the stalker trespasses on the victim's property, space or privacy; (can include accessing another person's computer remotely and obtaining files and personal data)

- Proxy, in which the stalker involves associates of the victim or third parties to pursue victim; (see footnote ${ }^{22}$ for an example of cyberstalking-by-proxy)

- Intimidation and harassment, whereby the stalker threatens or otherwise attempts to psychologically manipulate the victim;

- Coercion and constraint, through which the stalker controls the victim through extortion, threat, or force;

- Aggression, which takes the form of violence, whether sexual or nonsexual.

(Spitzberg, 2002:262).

Similar behaviour profiles are replicated in other research (see Mullen et al, 2000; Emerson et al, 1998; Zona et al, 1993). Although Spitzberg's (2002) research can be applied to online stalkers, that is not its primary aim. Few studies exist which focus on the offender (Bocij, 2004). Studies that do address the characteristics of the offender tend to do so through information garnered by, and from, the victim. There is overwhelming evidence that the majority of offenders are male (D'Ovidio and Doyle,

\footnotetext{
${ }^{22}$ In example of stalking-by-proxy (Bocij, 2004) 50 year old security guard Gary Dellapenta, after being rejected by 28 year old victim Randi Barber, proceeded to post on Internet message boards imitating the victim. In these posts, Dellapenta claimed Barber was "into rape fantasy and gang-bang fantasy" (Griffiths cited in Bocij, 2004:100). Barber received numerous obscene phone calls and visits to her home by a number of men as a result of Dellapenta's online posts (Bocij, 2004).
} 
2003) For example, WHOA reported that between 2000 and 2007 the average percentage of male offenders was 49.5 percent, females comprised 28.5 percent $^{23}$ (WHOA, 2007). Recently released figures from 2007 indicate that 39 percent of harassers were male, 30 percent were female and 31 percent were unknown (WHOA, 2007). It is important to note that a large proportion of offenders remain anonymous and their gender remains unknown. Spitzberg and Hoobler (2002) note that the actions of the offender, and the seriousness of these actions, are greatly influenced by their computer literacy. It is the actions and online movements of the victims that have provided the majority of information about their stalkers (Bocij, 2004). Gathering information on offenders is also problematic due to the anonymity afforded to them in an Internet environment.

\section{MOTIVATIONS}

Bocij and McFarlane (2003) identify four major themes of the cyberstalking relationship and motivations from their small-scale Internet based study and classify offenders within four categories ${ }^{24}$. These typologies have an additional focus on the relationship between the victim and the offender. They are the vindictive stalker, the composed stalker, the intimate stalker and collective stalkers. Vindictive stalkers were found to have threatened their victims more than any other group and displayed the highest likelihood of transferring their behaviour offline. Composed stalkers concerned

\footnotetext{
${ }^{23}$ Multiple offenders comprised $1.5 \%$ and $21.5 \%$ unknown.

${ }^{24}$ Once again, due to the anonymity afforded to offenders, information on offenders is often that obtained by the victim during the commission of an offence.
} 
themselves with constantly annoying and irritating their victims and were likely to make threats. The intimate stalker was concerned with winning the affections of their victims. This category bifurcates into two sub groups determined by previous acquaintance. 'Ex-intimates' had a previous relationship with the victim, whereas 'infatuates' did not but attempted to instigate a relationship, and messages became increasingly threatening with increased rejection. Parallels can be drawn with Spitzberg and Hoobler's (2002) concept of obsessive relational intrusion. Collective stalkers were characterised by two or more offenders acting together and displaying an advanced knowledge of technology and utilising techniques such as identify theft, spamming and intimidating media. A sub group of collective stalkers are corporate cyberstalkers (see also Bocij, 2002 for a more detailed discussion of corporate cyberstalking). Corporate cyber stalkers involved a threatening reaction by corporations or clients towards each other for perceived wrongs. Cyberstalkers can also be categorised using Mullen et al's (1999) five overlapping categories: the rejected stalker, intimacy seekers, incompetent suitors, resentful stalker and predatory stalkers. The use of offline typologies for classifying online stalker indicates congruence between online and offline behaviour.

Bocij (2004) identifies two categories under which the motivations for cyberstalking can be classified: technological and social. Bocij (2004) begins by highlighting the Internet's propensity for promoting criminal offending (see also Barak, 2005). The Internet is, "as broad as the human psyche, it naturally encompasses all of the darkest manifestations of evil imaginable: every form of denigration of human dignity and antisocial behaviour, from racial hatred ... to virulent misogynism" operates on the 
Internet (Berg cited in Bocij, 2004:91). In addition to the support the Internet provides for pre-existing offline offending to be mirrored in this environment, Bocij (2004) also argues that the Internet produces a unique form of criminal offending unparalleled in an offline environment. People who would not engage in criminal offending offline may do so online due to the factors outlined below (see also Bocij and MacFarlane, 2003). As Bocij notes, "technology provides both the mechanism through which the individual can act and the protection needed against arrest or other punishment" (Bocij, 2004:92). The technological opportunities provided for criminal offending include:

- Access: Access to computers and the Internet have increased.

- Familiarity: Increased access to technology has led to greater familiarity with technology.

- Anonymity: The Internet affords an offender a greater level of anonymity.

- Disguise: People can easily disguise their criminal activities.

- Evidence Destruction: Evidence of offending can be easily destroyed.

(Bocij, 2004; Bocij and MacFarlane, 2003)

The Internet also creates social motivations for people to commit cyber crimes as it typifies what Lee (1998) regards as a decontextualised medium. As Meloy (cited in Williams, 2006:26) notes, "the Internet allows communication with another person unconstrained by social reality, thus creating a certain psychodynamic appeal for the perpetrator". The anonymity provided by the Internet creates disinhibition as users are 
not "constrained by the social rules that govern interpersonal communication ... users reside in relative anonymity and physical safety, distant from others in interaction, often unaware of their identities and personalities, as well as the negative consequences of their risky or potentially damaging behaviour" (Buba cited in Bocij, 2004:97). The anonymity provided by the Internet also allows for the dehumanisation of others. The Internet provides the opportunity for groups of people to be dehumanised through message boards, newsgroups and chat rooms. Also, the opportunity is created for the establishment of deviant groups, unrestrained by geography (Bocij, 2004). Bocij (2004) cites the number of homophobic and racist websites as an indication of the processes of dehumanisation present on the Internet.

Perceptions of control and power are also fostered on the Internet in two ways. These can also manifest themselves via discourse (Spender, 1995). Bocij and MacFarlane (2003) identify the operation of deindividuation on the Internet. Deindividuation, a "state where an individual's self awareness is reduced through membership of a group" (Willison cited in Bocij and MacFarlane, 2003:211) may also result in deviance on the Internet. Individualism may be subjugated by a group environment and group norms may be adopted. As Bocij and MacFarlane note, "the disembodied nature of the Internet makes it relatively easy to depersonalise others" (2003:212). They link the concept of deindividuation to the Stanford Prison Experiment (Zimbardo, 1972) and identify two ways in which the Internet supports dehumanisation of others. First, the absence of physical contact creates an emotional and physical distance between the offender and the victim, thereby facilitating harm due to the surrealism provided by a 
lack of contact (Bocij, 2004). Also, a lack of 'regulating feedback' on the Internet in the form of body language or facial expression "obscures the boundaries that would generally separate acceptable and unacceptable forms of behaviour" (Ellison, 2001). Secondly, the ability to inflict harm from a distance provides the offender with a sense of power (Bocij, 2004). The Internet also provides offenders with opportunities to create 'cyber-identities'. Talamo and Ligorio (2001) argue that "identity is not a static characteristic ... Rather, it is negotiated through discourse in interaction, based on the context features and the roles assumed by the participants within the context" (Talamo \& Ligorio, 2001). The creation of numerous cyberidentities indicates how an individual can engage in criminal offending online but not offline (Bocij, 2004). The lack of policing on the Internet and the absence of Felson's (2002) 'capable guardian' also allows people to engage in online criminal activity (see Yar 2005, for a discussion of routine activity theory and cybercrime).

Additionally offender actions need to be examined in relation to predation and sexual offending. Research on Internet harassment is also framed within the more established field of sexual harassment (Ellison, 2001; Adam, 2005). Stalking and harassing behaviour, including cyberstalking, is "deeply gendered, sexualised and oppressive" (Wykes, 2007b:129). In addressing sexual harassment Smart (1995:223) argues that the process "locates woman in her body ... makes her simply a body". The operation of sexual harassment on the Internet where the body is often not visible is indicative of the complex relationship between the body and harassment, which will be addressed later in this thesis. Philips and Morrissey (2004:67) examine the sexual elements of 
cyberstalking and argue that, "sex can be a very efficient weapon to make victims feel distressed, vulnerable and threatened". They discuss the concept of cyberpredation and highlight the often deliberate selection process of cyberstalkers. An adapted online paedophile profile explains the process of victim selection which includes:

- Entering an online environment as a silent observer, also known as lurking.

- Identifying a suitable target

- Joining a chat to isolate a target

- Garnering personal information about the victim

- Arranging contact with the victim

(Philips and Morrissey, 2004)

Cyberstalking offending is also characterised by a number of distinct behaviours. The definition put forward by Bocij (2004) provides examples of individual cyberstalking behaviours which precede victim selection as does the 24-fold typology proposed by Spitzberg and Hoobler (2002). It is important to avoid lapsing into the mindset, at this point, that cyberstalking is unavoidable and women, once identified as a suitable target, are unable to influence the course of events. Greater awareness and education on Internet safety is providing Internet users with the awareness and the tools for preventing victimisation ${ }^{25}$. Recent research by WHOA (2007) outlines the most common methods of contact between victims and offenders. The five most common methods of contact were email, instant messaging, message boards, websites and chat

\footnotetext{
${ }^{25}$ The following chapter also outlines resistance in the form of reappropriating the gaze (Adam, 2005).
} 
rooms. As Internet technology evolves, however, new technological devices and forms of social networking provide new opportunities for offending.

\section{LEGISLATION}

Despite the protracted history of stalking, laws addressing stalking did not begin to emerge in the United States until the 1990's following the murder of actress Rebecca Schaeffer (Bocij, 2004). Since this time legislative responses have been rapid. Enactment of cyberstalking in law has not been as easily achieved due, in part, to the reticence to accept the seriousness of the offence, the anonymity afforded to the perpetrator and the transjurisdictionality of the offence. Cyberstalking is often considered as a subsidiary of offline stalking and harassment in law (Bocij, 2004). In New Zealand the following acts can provide protection against the actions of cyberstalkers and parallels can be drawn with Australian legislative options as outlined by Philips and Morrissey (2004). Judge David Harvey (2003) outlines and analyses New Zealand legislative options to address cybercrime.

The New Zealand Harassment Act (1997) defines harassment as a person “engag[ing] in a pattern of behaviour that is directed against [another] person, being a pattern of behaviour that includes doing any specified act to the other person on at least 2 separate occasions within a period of 12 months". These 'specified acts' include traditional stalking behaviours which can also apply to stalking using the Internet. Individual 
aspects of each crime may also fall within the bounds of the Crimes Amendment Act (2003) and the Domestic Violence Act (1995). The amendment to the crimes act included the additional offences of:

- Accessing a computer system for dishonest purposes (Section 249)

- Damaging or interfering with a computer system (Section 250)

- Making, selling, distributing or possessing software for committing crime (Section 251)

- Accessing a computer and system without authorisation (Section 252)

The Domestic Violence Act (1995) includes harassment occurring in the context of a 'close' personal relationship. Whether a relationship conducted solely online qualifies as a domestic relationship, as it is a close personal relationship, has been contested (Harvey, 2003). To determine whether a close personal relationship has occurred three factors must be taken into account:

- The amount of time spent together

- The places where that time is spent

- The manner in which the time is spent

Sexual contact is not required to constitute a close relationship (Harvey, 2003). The case of a relationship which developed online and then moved offline indicates a willingness by the courts to consider the prospect of online relationships (Harvey, 2003). 
An act which directly refers to the use of communications technology, the Telecommunications Act (2001), states that an offence occurs when a person, "uses ... any telephone device for the purpose of disturbing, annoying, or irritating any person, whether by calling up without speech or by wantonly or maliciously transmitting communications or sounds, with the intention of offending the recipient". Specific behaviours may also fall under other sections of the Crimes Act (1961). For example if a threat was made to cause grievous bodily harm this would fall under the crimes act (Harvey, 2003). Harassment in a workplace setting would also be covered under the Employment Relations Act (2000) and the Human Rights Act (1993). Civil remedies may also exist for certain behaviours and as Harvey (2003) also notes, the New Zealand courts may consider establishing a new tort of harassment. Currently prosecution under cyberstalking legislation is uncommon and the anonymous global nature of the Internet, and subsequently cyberstalking, impedes prosecution (Maxwell, 2001). These factors have also created enforcement problems. Calls for increased regulation of the Internet need to be balanced with protection of free speech and human rights (Ellison, 2001; Harvey, 2003). Ellison (Ellison, 2001:147) concludes "the positive value of anonymous communication more than offsets the dangers [and] restrictions on anonymity on-line would be both premature and harmful to individual users and to the Internet community at large".

In addition to prosecution, steps can be taken ad-hoc and post-hoc to address cyberstalking. Cyberstalking prevention can be achieved by controlling and protecting 
personal information. Restricting and controlling access to personal information can be achieved through the implementation of tools such as firewalls but can also be achieved by avoiding providing personal information voluntarily that can consequently be used against a person's wishes. Just as the anonymity of the Internet provides an opportunity for unidentifiable criminal offending, victims can also ensure their safety by remaining as anonymous as possible. If harassment does occur several steps can be taken to ensure the harassment does not continue or is dealt with by law enforcement. The first step identified by Bocij (2004) is the identification by the victim that they are a victim of cyberstalking, that there is a credible threat and that more than one incident has occurred. The next step, according to Bocij (2004), and supported by several cyberstalking agencies, involves contacting the offender. Studies of offline stalking indicate a request by the victim to end the harassment often has favourable results (Bocij, 2004). However, this should only be attempted once as "any additional communication is not only counterproductive, but also extremely dangerous" (WiredPatrol cited in Bocij, 2004:195). If harassment continues evidence of abuse must be recorded and collated prior to contacting a law enforcement agency. Bocij (2004) notes that if the physical safety of the victim is endangered, or if violence is threatened, police involvement is necessary. However, due to the difficulty in locating cyber stalkers self-regulatory measures are required foremost to prevent cyberstalking from occurring. 
The numerous campus studies undertaken will now be addressed. An examination of these various studies will be conducted separately from the material already covered to allow a clearer critique and comparison between the individual findings.

\section{CAMPUS STUDIES}

As Lee (1998:406-407) notes, “campuses are fertile ground for online stalking behavior" and for this reason numerous studies have been conducted within this environment. An examination of these various studies has been conducted separately from the material already covered to allow a clearer critique and comparison between the individual findings.

A study by Finn (2004) found 10 - 15 percent of a sample of 339 college students had experienced threatening, harassing or insulting messages via email or instant messaging. More than half of the research sample had received unwanted pornography. Only 7 percent of victims reported the incident to the authorities. This contrasts with findings from WHOA (2007) which indicates that the majority of victims reported the incident. This may be explained through the role WHOA plays as a victim advocate. Finn (2004) also found that sexual minorities were more at risk of victimisation. One of the most interesting findings was that no differences existed between genders with each experiencing equal levels of victimisation. Brownstein (2000) also found that men comprised 42 percent of cyberstalking victims on campus although women were more likely to feel threatened and terrorised by their 
experiences. As previously outlined the effects of cyberstalking and perceptions of threat are individual and influenced by a number of factors including computer experience, and according to Brownstein (2000) the gender of the victim and the offender. Finn concludes that, "ubiquitous use of the Internet by college students will require colleges to address new social problems associated with online participation" (2004:477). Hitchcock's (2002) assessment of cyberstalking indicates how campuses have fallen behind in addressing cyberstalking. New Zealand universities have implemented statutes of conduct which cover the use of university computers. The Victoria University Statute of Student Conduct 2008, for example, prohibits misuse of university computer systems and includes the restriction on "publishing or distributing any material that is defamatory or offensive, or in any way constitutes harassment or excessive mail to other users" (Victoria University of Wellington, 2008:3).

Spitzberg and Hoobler (2002) found that 59 percent of university students, in a sample of 235, had experienced cyberstalking. A significantly higher number than Finn (2004). Burgess and Baker (cited in McFarlane and Bocij, 2003) found that 11 percent of a sample of 656 college students reported online harassment with females comprising 61 percent of those reporting harassment. A study by Alexy et al (2005) measuring perceptions of cyberstalking also identified levels of victimisation and identified 3.7 percent of their sample of 756 students had experienced cyberstalking, however 31.5 percent of those who had experienced offline stalking also experienced cyberstalking, therefore, indicating that cyberstalking often acts as an extension of offline stalking (see also Fisher et al, 2000 for similar results). Despite most of the aforementioned 
studies indicating that the majority of victims were female, even by a small margin, Alexy et al (2005) found that although females were more likely to be stalked offline than men, men were more likely to be the victims of cyberstalking. No other study of adults reflects these findings however, and no attempt is made by the authors to explain this finding. Additionally, the researchers have not recorded the gender of the offenders. This finding requires further examination in light of the overwhelming paradoxical evidence. One explanation may involve the physical competency of the offender and victim, whereby harassment of males using more terrestrially based methods may involve a greater risk to a female offender and therefore online methods pose less risk and are favoured.

Studies involving younger participants have also identified significant levels of victimisation. Li (2006) found that 25 percent of a sample of 264 had experienced cyberbullying $^{26}$. A subsequent study by Li (2007) found that $31.2 \%$ of males and $26.3 \%$ of females had been the victim of cyberbullying $(\mathrm{N}=461)$. Males were more likely to be victims and offenders. Li's (2006) earlier study found that females had experienced the majority of victimisation. These contradictory findings could possibly be explained by the small difference between the two figures. Alarmingly, the majority of Li's (2006) sample had not reported the abuse although females were more likely to report than males. The Cyberspace Research Unit, based in the United Kingdom, conducted a study of children aged between 9 and 16 and found that 20 percent of a

\footnotetext{
${ }^{26}$ Space does not permit a comprehensive examination of the emerging problem of cyberbullying and 'txt' bullying which has become increasingly prevalent amongst younger age groups. $\mathrm{Li}(2006 ; 2007)$ provides a comprehensive summary of this issue as does Kowalski et al (2008).
} 
sample of 1,369 children reported being harassed in a chat room (O'Connell et al, 2002). 14 percent also admitted to harassing other users. 53 percent of $8-11$ year olds also reported experiencing conversations of a sexual nature online Finkelhor et al (2000) found that 6 percent of youth in their sample reported online harassment and 2 percent reported feeling afraid and upset. There was no gender distinction in this age bracket and the majority of perpetrators were male (54 percent). Another interesting finding was the overwhelming majority of perpetrators were other juveniles. They conclude that, "youth have reported other threatening and offensive behavior directed to them on the Internet including threats to assault or harm the youth, their friends, family or property as well as efforts to embarrass or humiliate them" (Finkelhor et al, 2000:21). An Australian study involving 692 13-16 year olds found that young males were more likely than young females to be exposed to inappropriate behaviour and material online (Fleming et al, 2006). Increased Internet use by young males and the increased likelihood of young males frequenting violent and/or pornographic sites are the two primary explanations put forward by Fleming et al (2006) to explain the overrepresentation of young males in these findings.

In conclusion, although the majority of cyberstalking victims fall within an age bracket from approximately late teens to early thirties (WHOA, 2007; Bocij, 2004), it is also important to recognise the degree of victimisation occurring in this younger age bracket, the level to which this is not reported and the degree to which perpetrators are other juveniles. A New Zealand study of 357 female computer users aged between 11 - 19 indicated that 22.5 percent reported feeling threatened or unsafe while using the 
Internet (Internet Safety Group, 2001). The majority of threats were of a sexual nature. 27 respondents received implied sexual threats, 23 had strangers accessing their personal data, 14 experienced harassment and 12 experienced verbal abuse (Internet Safety Group, 2001:15-16).

Despite presenting a range of contradictory prevalence figures these studies do render several important findings. First and foremost, they indicate the cyberstalking research conducted within a college setting may be more than samples of convenience and there is strong evidence to suggest that cyberstalking is fostered in a campus environment. This may be due, in part, to the proliferation of advanced communication technologies and the concentration of computer use in this environment. Lee (1997:403) argues that stalking may proliferate in a campus environment as "it is an enclosed and selfsufficient community in which individuals remain for a significant length of time". It is also an environment characterised by a concentration of social and romantic interaction (Lee, 1997). The second important finding was the level of underreporting. Underreporting may be affected by a perceived lack of remedies for cyberstalking and overall perceptions of cyberstalking as a less serious crime. The third important finding was the prevalence of online harassment experienced by younger computer users. The prevalence of cyberstalking is this younger age demographic indicates the need for interventions to address victimisation. The number of offenders in this age bracket also requires further attention. 
The purpose of this literature review has been to provide an overview of literature that has examined the relatively recent crime of cyberstalking. An examination of the literature indicates that the majority of theorists tend to regard cyberstalking as an extension of offline stalking and similarities between victim impact and offender typologies are indicative of this continuity. Identification of continuity between stalking and cyberstalking also supports the examination of stalking from a perspective that is inherently feminist due to the apparent gender disparity in both of these crimes. The purpose of the preceding literature review is also to provide a support for the following section of this thesis that will critique the online disembodiment thesis in relation to victimisation. 


\section{CHAPTER THREE:}

\section{APPLYING THE THEORIES OF THE BODY TO ESTABLISH A THEORETICAL FRAMEWORK FOR A GENDERED \\ ASSESSMENT OF CYBERSTALKING}

\section{INTRODUCTION}

To inform the development of research methodologies for the examination of cyberstalking it is paramount that this research is supported by the development of an applicable theoretical perspective. For the purpose of this thesis the decision was made to focus on the theories of the body as a point from which to develop a theoretical foundation for an examination of cyberstalking. Initially, this decision may appear ill conceived, for where is the body perceived to be the least relevant than online. However, further examination of this area led to the identification of a unique relationship between the body, as a theoretical construct, and online victimisation. As this chapter will indicate, the body is not as absent online as cyber-enthusiasts desire. The online victimisation of women, and the serious ramifications of this victimisation, require a re-conceptualisation of the ways in which online victimisation is understood. To further clarify, it is not my intention to create a zero-sum relationship, whereby the offline victimisation of women is minimised by the identification of the online counterparts of these crimes. Perhaps it is the creation of this nominal similarity that has created a trade-off between the seriousness of offline victimisation and the 
trivialisation of their online counterparts. The lack of direct physical harm, which has characterised the online victimisation of women, has been invoked to not only minimise its seriousness but also confounds the problems of applying theories of the body to understand online victimisation. There is a need to further explore the relationship between online and offline crimes which share several defining characteristics without negating the seriousness of either. An examination of the individual effects of cyberstalking outlined by Ashcroft (2001:24) highlights the seriousness of the offence and as Wall (2002:84) argues, "although such activities do not require a direct physical expression, the victim nevertheless will feel the violence of the act and may bear long-term psychological scars as a consequence". These consequences alone justify the further examination of cyberstalking and the establishment of an applicable theoretical framework.

The online victimisation of women encompasses several offences and during the course of this thesis reference is made to not only the specific offence of cyberstalking but also more broadly a range of additional offences falling under the broader category of the online victimisation of women. A number of these additional offences have been discussed in the first chapter. More specifically, cyberstalking has been selected as it possesses a challenging and unique relationship to the theoretical concepts of the body. To return briefly to offline stalking, this crime also possesses what superficially may appear to be a tenuous link to theories of the body. Stalking is, after all, a detached crime and whilst its escalation often involves physical contact it is primarily carried out at a distance. Cyberstalking may be perceived as involving even less physicality as it 
takes place online. For this reason the application of theories of the body to an assessment of cyberstalking may appear unsuitable but I have done so for the following reasons.

Firstly, the nature of the online environment and the pervasive adoption of the online disembodiment thesis has facilitated the premature dismissal of the importance of the body in online social interaction and the (re)embodiment of theories addressing the Internet is required. Secondly, Adam (2005:108-109) notes that cyberstalking "has yet to receive systematic analysis against an appropriate theoretical framework which includes gender as central construct", the necessity of which is facilitated by the disparate victimisation of women online. The theories of the body are applicable in this instance. Thirdly, the perception that online and offline stalking are not related to physicality can be challenged by broadening the understanding of what a link with the body entails. It is imperative when understanding victimisation in relation to the body that this understanding goes beyond direct physical contact to include "bodily invasions of privacy, where bodies are watched, looked at or subject to surveillance or indeed where bodies are actually violated and the violations are watched online" (Adam, 2005:103). Therefore, direct physical contact is not a necessary prerequisite for the application of theories of the body. It is for these reasons that the theories of the body have been employed as a theoretical framework for the development of an understanding of cyberstalking. 
At this point a significant revision of the original theoretical basis of this thesis was required. The theoretical concept of disembodiment was adopted as a contributing factor in the online victimisation of women, and subsequently as a barrier to conducting online research. The adoption of a perspective that is, at its centre, criminological, initiated the hypothesis that the removal of the physical body, or physicality, from social interaction (see, for example, Bauman, 1989) may facilitate interpersonal online offending. For example, as Stone (2000:525) argues:

Forgetting the body is an old Cartesian trick, one that has unpleasant consequences for those bodies whose speech is silenced by the act of our forgetting; that is to say, those upon whose labour the act of forgetting the body is founded.

The problem lies, however, in the assumption that, from a theoretical perspective, 'disembodiment' and the 'removal of the physical body' are concurrent. An interrogation of what Campbell (2004) terms the 'online disembodiment thesis' indicates the myriad problems associated with the concept of disembodiment and its unsuitability as an explanation for online victimisation. Employing the term disembodiment is also problematic due, in part, to an identifiable lack of academic precedent. The vast majority of scholarship employing the term does so without establishing a definition of the concept and this lack of definitional precedent is compounded by the assumption that the term is self-explanatory, and its definition left to rest on any literal understanding of the term the reader may possess. This understanding is often informed by the prevailing "hyperbolic narrativisation of [the Internet's] possibilities" (Ajana, 2005: Para. 1) especially in relation to virtual bodies 
particularly prevalent during, what Kroker and Kroker (1996) call, the 'flesh-eating 90's'. As a theoretical concept 'disembodiment' still requires significant interrogation prior to its use as an explanation for cybercriminal offending or victimisation.

Original research problems were compounded by the uncritical adoption of disembodiment as a credible explanation for offending and the rather narrow interpretation of disembodiment as the "transcendence of body limitations through electronic prosthesis" (Ajana, 2005: Para. 2). Whilst I agree with Stone (2000:525) that "forgetting the body ... has unpleasant consequences for those bodies whose speech is silenced by the act of our forgetting", it is the nature of this forgetting, and the complexity of this process, which requires further examination. For this reason I have adopted Campbell's (2004) explanation of what he terms the online disembodiment thesis as a point from which to develop a critique of disembodiment in relation to online offending. The online disembodiment thesis:

Rests on the notion that there is an absolute demarcation between the real and virtual, and therefore a radical disjuncture between experiences in cyberspace and those in the physical world. Scholars subscribing to this proposition characterize cyberspace as a sovereign realm, distinct from and unaffected by the cultural, political and economic forces shaping the mundane world we inhabit. Thus some social scientists may see online experiences transforming offline perceptions, but seldom do these same researchers examine the ways in which offline circumstances inform online interactions (Campbell, 2004:11).

The adoption of this definition is supported by the correlation of Campbell's (2004) critique of the absolute demarcation of the 'real' and 'virtual' with the distinction between online and offline stalking addressed in the preceding literature review. 
Without further compounding this demarcation, a critical examination of the online disembodiment thesis as an explanation for online victimisation, will be preceded by a discussion of the earliest manifestations of the ideals that underpin the online disembodiment thesis, namely Cartesianism, binary logic and essentialism. Campbell's (2004) definition of the online disembodiment thesis subsequently facilitates a discussion of disembodiment beyond the narrow concept of bodily transcendence and a critique of disembodiment will be facilitated by a broad discussion of disembodiment and its corollaries including cyborg theory and new digital Cartesianism. I will conclude by critically examining the concept of disembodiment and offer alternative explanations for the online victimisation of women.

\section{A BRIEF HISTORY OF BODY THEORY}

In certain contexts a discussion of theories of the body that occurred prior to the advent of the Internet would be superfluous. However, in this instance, a discussion, and subsequent critique, of the online disembodiment thesis from a criminological and feminist perspective rests on a number of theoretical concepts originating from these fields that, whilst preceding the advent of the Internet, remain vital to its interrogation. The body of theory addressing, and critiquing, disembodiment is united by several common elements. The first, of relevance, is the prevailing concern with the postEnlightenment work of Descartes and bodily transcendence. The second is the immense contribution feminist scholarship has made to this area. 
A review of literature on the 'body' indicates only a short history of sociological and feminist scholarship. Unlike their sociological counterparts, criminologists have been even more reluctant to adopt the body as a theoretical concept and have not, to a large extent, participated in the post-1980's revival of body theory, a revival which saw a veritable explosion of sociological interest in what could broadly be regarded as body theory. Perhaps it is the post-Positivist rejection of the early anthropomorphic studies of Lombroso (2006) and Sheldon (1970) that has left criminology, not only on occasion gender-blind, but disembodied itself, unequipped to address the body, or lack thereof, as a key contributor to victimisation and offending. Whilst it may seem apparent that the body, as a theoretical concept, plays a key role in crime there is very little criminological scholarship that addresses the body as both the site of victimisation and as a tool for offending ${ }^{27}$ from a theoretical perspective.

While I cannot present a detailed discussion of the role of the body in the history of social and cultural studies, nor philosophy, it is important that a discussion of feminist theories on the body, and the development of these theories, is preceded by a brief sketch of the history of 'body theory'. The history of body theory will be examined firstly by examining several explanations for the absence of the body within social and cultural studies.

\footnotetext{
${ }^{27}$ This is not to say that excellent criminological scholarship on the body does not exist but rather a comprehensive body of work is still absent. Excellent individual work can be located including Messerschmidt's (1999) examination of the intersection of adolescent masculinity, the body and violence or Smart's (1995:223) examination of the "discursive construction of woman as body" in regards to rape trials.
} 
As Howson (2005:14) notes, "the body was implicitly central to the analysis of many areas of social experience [however] little reference was made to the body within sociology ... beyond acknowledging the body as a taken-for-granted background to social agency and action". For this reason the body has come to be regarded as an 'absent-presence' within sociology (Shilling, 2007). Howson's (2005:15) conclusion that the body "can be understood as integral to the issues with which sociology deals, yet marginal as a legitimate focus of inquiry" is equally applicable to criminology and Howson (2005) identifies several reasons for the absence of the body within these disciplines. The first is the influence upon Western thought systems of Cartesian dualism. Whilst the contemporaneous influence of Cartesianism will be addressed at a later point in this thesis as it relates to the concept of digital Cartesianism, it is important at this point that Descartes' thesis is outlined due to its overwhelming and influential contribution to the philosophies on the body.

Descartes advocated an ontological distinction between the mind and the body in which the former was privileged over the latter (Howson, 2005). Reflecting the historical precedent of Plato's distinction between body and soul and the dominant Christian conception of the body as a source of sin, Cartesianism propagated the concept that "the rational actor, was disembodied in the sense that rational thought was located in the mind, already conceptually disconnected from the body and disassociated from 'attributes of physical presence"” (Howson, 2005:15-16). As Grosz (1994) notes, the Cartesian distinction between mind and body can be aligned with a number of other 
oppositional pairs. The representational alignment in which the body is devalued results in concurrent devaluation of 'female' in relation to 'male'.

The second explanation for the absence of the body within social and cultural studies is the predominant focus on structure and agency and the tension between the two (Howson, 2005). As Howson (2005:16) notes, "the intellectual autonomy of sociology from anthropology, psychology and from the naturalistic understanding of human nature epitomised by biology, was dependent of its capacity to deny the body any determining status in considerations of agency". Biological, bodily, explanations for social phenomena were routinely rejected and Cartesianism remained paramount.

The third explanation for the absence of the body within social science was the association of the (female) body with experiences deemed unnecessary and irrelevant to the social sciences and the production of knowledge. In contrast, criminology was less susceptible to these views and the anthropomorphic work of Lombroso (2006) contributed significantly to the discipline.

Shilling (2007:6) traces the development of several factors that have contributed to the contemporary "rise of the body". The development of sociological, and by virtue of its close association criminological, theory has been guided by a number of influential theorists whose overall theories require little explication. An examination of the works of, for example, Durkheim, Weber, and Comte, whilst addressing the body, do so as a derivative of their central concern; namely the development, structures and processes of 
the industrial society (Shilling, 2007). As Shilling (2007:3) notes, "sociology's determination to carve out its foundations from the bedrock of society, rather than from the materials that furnished other sciences, steered the subject away from attributing too much explicitly attention to embodiment".

It was not until the early 1980's that the body became a popular, and contested, area of study. Shilling (2007) traces these developments by drawing on several influential factors. The first factor that influenced the emergence of the body as a focus of study has been the rise in consumer culture and the ways in which "conspicuous consumption replaced ascetic denial as the normative counterpart of hard work in the sphere of production" (Shilling, 2007:7). This change also represented the parallel shift occurring away from Christian conceptions of the body as the 'container' of sin towards a focus on the performative role of the body and of appearance. The artifice associated with this shift also facilitated the influence of the second factor, which involves the creation of meaningful bodily experience; primarily the internal and external improvement of the body. The third influential factor, which will be explored in more detail at a later point in this thesis, was the second wave feminist adoption of the body as an area of study. In addition to challenging the role the female body assumed as a justification for inequality, corporeal feminists also addressed issues of compulsory heterosexuality, transgenderism and the relationships that exist between the body and identity, including sexual identity. The fourth influential factor identified by Shilling (2007:8) was the changing modes of governmentality; or the "governmental disciplinary regimes" concerning the body. Drawing on the work of Foucault, Shilling (2007) identifies the 
shift that occurred from a governmental focus on the regulation of physical bodies towards a holistic approach concerned with governance of both mind and body. The fifth influential factor was the increased uncertainty resulting from the 'opportunities' created by technological innovation. Technological advances, including for example, stem cell research and the Human Genome Project, instigated the beginning of a period in which the body is theoretically open to alteration and modification (Shilling, 2007). The final factor that has contributed to increased focus on the body is the increased, and multidisciplinary, adoption of the body as an area of study and a valuable "conceptual resource" (Shilling, 2007:9).

Ajana (2005: Para.5) argues, that to:

Understand the ontology or epistemology of disembodiment within any given discourse, it is first essential to understand the conditions of embodiment or put crudely, the reality of what constitutes the materiality, spatiality and experience of the body itself, however, beyond its Cartesian configuration.

A number of epistemological and methodological tensions exist, however, when theorising the body. An initial tension identified by Howson (2005), which is reflective, in part, of the evolution of the field, is that between academic attempts to 'theorise the body' and, conversely, 'embody theory'. Whereas to 'theorise the body' is to apply abstract and theoretical concepts to explain the relationship between the body and society, the embodiment of theory requires a "reshaping of the conceptual tools of the discipline" (Howson, 2005:20). In relation to this tension, and to provide a useful precursor to a discussion of feminist theories on the body, is the way in which preexisting feminist theories on the body have been co-opted by academics outside of the 
field of feminism. Whilst feminism should be credited with putting the body on the academic map a tension exists between "[feminism's] own focus on the 'abstract body' and the early feminist focus on the "concrete body' ... via the concept of experience" (Howson, 2005:20). As Howson (2005:20-21) notes, "feminism has not, until recently, attempted to theorize the body" and that the "abstract body' has itself been absent from feminism". Gatens (1996) and Grosz (1994) express similar sentiments, acknowledging the immense contribution feminism has made to the awareness of bodily self-determination and politicisation of the personal whilst arguing, "feminists have offered little by way of a coherent theory of the body" (Gatens, 1996:59). This absence of coherent theory has necessitated the adoption and application of pre-existing philosophical assumptions incompatible with the aims of feminism (Grosz, 1994), including the adoption of binary logic.

Firstly, it is important to note that there is no single feminist perspective on technology (Halbert, 2004) and those employed within this thesis have been chosen for their overall correlation with the thesis hypotheses. Howson (2005) identifies the body as possessing an ambiguous place within second-wave feminist theory. Dominated by liberal feminist theories, second wave feminism was not immune to Descartes' legacy, and in addition to the subsequent influence of Simone DeBeauvoir, the "burdensome status" (Howson, 2005:44) of the body was firmly entrenched. Feminist theorists have addressed the body primarily in relation to the ways in which, by association with the body, women have been excluded from full political and social participation. For this reason feminist theory has rarely focussed on the body nor contributed to the wider 
social scientific project to theorise the body. A "corporeal turn" (Howson, 2005:44) occurred however, in line with the increasing focus on corporeality in the 1980's, and feminist debate has shifted its concern to address the inclusion of the body within theory.

Brook (cited in Howson, 2005:44) observes that "all feminist thinking might be described as an engagement of one sort or another with what it means to be, and to be perceived to be, a female body". Whilst space does not permit a comprehensive examination of the numerous ways in which feminist theory has addressed the body, the interrogation of the online disembodiment thesis is facilitated by an engagement with a number of these concepts. In the interest of space, two concepts will be addressed: essentialism and binarism.

The online disembodiment thesis is predicated on an essentialised understanding of the body (Campbell, 2004). Stanley and Wise (2002:208) define essentialism as a:

Belief in the existence of fixed and essential properties which often invokes 'biology' or more loosely 'human nature' as the supposed basis of these. The subject is seen here as located within, indeed defined by, a fixed set of attributes treated as innately physical, intellectual or emotional, and thus deriving from the essential properties of body, mind or emotions.

A number of feminist perspectives have rejected essentialism on the grounds that is equated with biological reductionism and, additionally, conflates the problem of binaries. The correlation between the online disembodiment thesis and essentialism lies 
in the fixed notion of biology and the body. Campbell (2004:12-13) in rejecting essentialism, and concurrently the online disembodiment thesis, argues:

The body is both of a physical presence and a discursive figuration or performance. We communicate with our bodies ... but our bodies also act as objects of communication ... which may signal racial, ethnic, gender, or even sexualities beyond our intent ... society generally frames what is spoken based on the body that does the speaking.

While a discussion of binary logic flows on from one of essentialism, I want to briefly revert back to the foundations of binary logic. As previously noted, Descartes advocated an ontological distinction between the mind and the body in which the former was privileged over the latter (Howson, 2005). The mind/body dichotomy is mirrored by the hierarchical alignment of a number of additional oppositional pairs, including male/female. Therefore, it is of little surprise that the vast majority of criticism levelled at Descartes theory comes from those relegated to second position in the binary hierarchy. A number of theorists (see, for example, Grosz, 1994) have pointed out, however, that feminism has not been immune to the insidious nature of binary logic. Grosz (1994:10) notes the danger of the adoption of Cartesianism by feminist theorists, arguing that, "Insofar as feminist theory uncritically takes over these common assumptions, it participates in the social devaluing of the body that goes hand in hand with the oppression of women". The re-invigoration of binary logic and Cartesianism as underlying principles of the online disembodiment thesis initiates an interrogation of the online disembodiment thesis at this point. 


\section{THE ONLINE DISEMBODIMENT THESIS}

Cyberspace is a celebration of spirit, as the disembodied consciousness leaps and dances with unparalleled freedom. It is a realm in which the mind is free from bodily limitations, a place for the return of the omnipotence of thoughts (Bukatman cited in Ajana, 2005: Para. 11).

For couch potatoes, video game addicts and surrogate travellers of cyberspace alike, an organic body just gets in the way (Morse cited in Lupton, 2000:479).

Space does not permit a comprehensive examination of the numerous manifestations of attempts to transcend the body via electronic prosthesis. Additionally, the selection of relevant examples requires a negotiation of the blurred lines between science fiction and fact. For this reason I will briefly address two concepts that are concurrent with the online disembodiment thesis and the overall hypothesis. These are cyborg theory and new digital Cartesianism. Prior to doing so the online disembodiment thesis requires explanation in relation to the absence of physical presence online. It is the purpose of this thesis to highlight the ways in which, despite the intentions of advocates of the online disembodiment thesis, the body is present online. However, whilst I intend to challenge the principles of the online disembodiment thesis, it is also my intention to indicate how a lack of physical presence online contributes to victimisation. Essentially, the degree to which the physical body is absent online will be challenged and the continuities and discontinuities between online victimisation and embodiment will be explored. At this point it is important to examine two features of the online disembodiment thesis. 


\section{THE CYBORG}

One of the problems with this utopia, where all women think of themselves as cyborgs and are able to cruise the Web in conscious and subversive ways, is that the whole range of other women's experiences with new communication technologies are excluded. What kind of cyborg identity, for example, can the woman who has been harassed online construct for herself? (Sundén cited in Halbert, 2004:130)

Initial engagement with the topic of disembodiment is confounded by the prevailing influence of science fiction and it is Campbell's (2004:10) concern that these, "grand claims based on fanciful imagery are uncritically incorporated into scholarly discourse" noting also that "scholarship becomes problematic when it confuses such conceptual possibilities with what is actually occurring online" (p. 12). Equally the rejection of technological determinism and millennialism has gained momentum (see Sterne, 1999). Without contradicting my previous statement, a discussion of virtual bodies is incomplete without a brief engagement with the early influences from science fiction, primarily that of the cyborg and the contribution of cyberfeminist Donna Haraway's (1991) A Manifesto for Cyborgs.

The ultimate goal of cyberculture is "to leave the 'meat' behind and to become distilled in a clean, pure, uncontaminated relationship with computer technology" (Lupton, 1995:100). The cyborg, a 'humanoid hybrid' (Lupton, 1995) realised through the melding of computer technology and human flesh, represents perhaps the most obvious manifestation of this desire. The discourse of the cyborg includes the fantastical imagery of the cyborg in science fiction which is juxtaposed with that imagined by Haraway (1991). The ontologically confusing body of the science fictional cyborg 
obfuscates Haraway's (1991) vision. From a cyberfeminist perspective, Balsamo (1995:11) defines the cyborg as:

Hybrid entities that are neither wholly technological nor completely organic, which means that the cyborg has the potential to disrupt the persistent dualisms that set the natural body in opposition to the technologically recrafted body, but also to refashion our thinking about the theoretical construction of the body as both a material entity and a discursive process.

As prominent cyberfeminist Donna Haraway (1991:150) argues, "The cyborg is our ontology; it gives us our politics". Haraway (1991) positions the cyborg as "not simply an imaginary inhabitant of speculative fiction but the pattern for life in contemporary, late-capitalist society" (Brook, 1999:142). The cyborg facilitates an understanding of what we are becoming in an increasingly technological society and as Campbell (2004:14) argues, "we may already be in the state of becoming this cyborg subject".

The cyborg is not without criticism however, and whilst Haraway (1991) may find that techno-scientific intervention in reproductive technology creates "ontologically confusing bodies" (p. 186) this label could equally be applied to the cyborg and whilst Haraway (1991) argues that the cyborg is our ontology a number of theorists are critical of this hegemonic assumption. Hawthorne (cited in Brook, 1999:142) argues "cyborgs provide a haven for all those dominant-culture theorists who have suddenly left behind their own reification of difference" posing the question, "How can you claim difference if you are a white (fe)male heterosexual American? Answer: you claim your cyborg identity". 
Those advocating a cyborg existence prescribe equally to the principles of Cartesianism, however there exists an inherent contradiction whereby the body, albeit a reconstituted body, remains omnipresent. The transcendence of the body dominates contemporary technological pursuits, however, "[cyborg] discourse simultaneously uses language and imagery associated with the body and bodily functions to represent its vision of human/technological perfection" (Holland, 1995:165). A similar manifestation occurs in the construction and choice of avatars ${ }^{28}$ whereby the majority tend to mirror the bodily ideals of society. Talamo and Ligorio (2001:111) also observe how the use of avatars tend to mirror an individual's gestures and movements noting that, "the body is our primordial communication medium, and since communication tools are extensions of our sensorial system ... avatars should provide a further communication channel to express the self, both in terms of body and identity". Balsamo (2000) observes that if we look at the ways in which bodily reconstruction occurs offline, in the form of, for instance, bodybuilding or cosmetic surgery, these bodies display traditional race and gender markers of strength, beauty and sexuality. Therefore, reconstructing the body does not necessarily guarantee a reconstructed social identity (Balsamo, 1995). Aspects of the online disembodiment thesis are also identifiable in the area of new digital Cartesianism.

\footnotetext{
${ }^{28}$ An avatar is a "graphic identity you either select from a group of choices or create on your own to represent yourself to the other party in a chat, instant messaging (IM) or multiplayer gaming session. An avatar is a caricature, not a realistic photo and can be a simple image or a bizarre fantasy figure". http://www.pcmag.com/encyclopedia_term/0,2542,t=avatar\&i=38293,00.asp\# Date accessed: 28th, January, 2009.
} 


\section{NEW DIGITAL CARTESIANISM ${ }^{29}$}

Boler (2002:333) prefaces an initial discussion of new digital Cartesianism with an important, but often neglected, point noting the need, as a researcher, to "recognize compassionately the desire for transcendence". Too often in critiquing a concept we fail to observe and understand the unique position of its proponents. As previously noted, as there is no single feminist perspective on technology, to critique the online disembodiment thesis requires the researcher to both invoke and revoke certain aspects of feminist theory. For example, if we examine the limits of the body and its impermanence and vulnerability, the lengthy history of attempting to transcend these limitations becomes less implausible. Wendell (cited in Brook, 1999:144), in a discussion of disability, from a feminist perspective, and in opposition to critics of bodily transcendence, argues that these theorists "ignore one central reason why some might want to detach mind from body; chronic and consistent pain" and critics of bodily transcendence often neglect the "subjective appeal of mind-body dualism" ( $\mathrm{p}$. 144). The second position requiring observance, and of particular importance to this thesis, is the concept that online environments are desirable as they can be fluid and "online interactions [are] freed of bias, prejudice, and stereotypes". It is the goal of proponents including Stone (1995) and Haraway (1991) that static concepts of gender and race can be broken down in cyberspace.

\footnotetext{
${ }^{29}$ It is important to first note that Cartesianism manifests itself throughout a number of concepts addressed in this chapter, as do the concepts of new digital Cartesianism.
} 
Boler's $(2002 ; 2007)$ critique of what she initially termed 'digital Cartesianism with a twist' and subsequently 'New Digital Cartesianism' is useful primarily as both articles demonstrate how, despite their best intentions, new digital Cartesianists are unable to completely deny the body. Boler (2007:140) states that:

[W]hile marketing hypes and cyber-enthusiast hopes actively mythologize the potentials of disembodied CMC [computer mediated communication] with promises on anonymity and fluid identities, the actualities of the way in which users interpret and derive meaning from text-based communication often involve reductive bodily markers that re-invoke stereotypical notions of racialized, sexualized and gendered bodies. Ironically, this new digital Cartesianism, initiated by a rhetorical cheerleading of the mind/body split as a desirable aim of CMC, ultimately results in the invocation of stereotyped bodies in order to confer authenticity and signification to textual utterances.

Boler (2007) aligns these marketing 'hypes' with three prevailing goals: (1) the transcendence of bodies (2) the transcendence of difference and (3) the transcendence of temporal and spatial restrictions far beyond any form of conceptual transcendence. These ideals are, essentially, exaggerated ideals thus far unachievable now, nor in the near future, with technology available at our disposal. It is here, perhaps, that the more extreme cyborg discourse can best be located. These marketing hypes are problematic for several reasons including the implications of attempting to transcend any form of difference as the transcendence of cultural markers of difference neglects, for instance, the importance of these cultural determinants and the importance of difference. This neo-liberal Cartesian discourse (Boler, 2007) is equally hegemonic whereby the 
elimination of difference is the elimination of that which does not conform to the white, male, heterosexual norm.

If the media-driven hype attributed to technology is rejected, an examination of the hopes of cyberenthusiasts indicates less of a concern regarding the transcendence of difference but rather reflects "a yearning to change how we think about, experience and envision social identities [and] a desire to challenge static notions of identity, engage fluidity and break down traditional binaries" (Boler, 2007:149). Boler (2007) is critical of this goal however, noting that, the goal of transcendence is, and will always be, permeated with the stereotypical notions of difference. Whilst the transcendence of bodies and difference dominates cyberenthusiast pursuits, two alternative avenues replace the abstract concept of the cyborg.

The first is the fluidity of online identit(ies). Online spaces, including both text-based and visual spaces, allows users to construct "virtual 'fictional' identities that allow them to move beyond the usual social markers of ethnicity, class, gender, age and ability" (Boler, 2007:150) ${ }^{30}$. One manifestation of fluidity is gender-switching whereby users can select avatars, personas or user names of the opposite sex or choose to be gender neutral. However, Robert and Parks (cited in Boler, 2002:151) found that gender-switching was relatively infrequent: “approximately $60 \%$ of social $\mathrm{MOO}^{31}$ and

\footnotetext{
${ }^{30}$ Cooper's (2007) Alter Ego: Avatars and their Creators is a pictorial representation of the avatars people create for themselves and a useful visual resource for those exploring the ways in which people choose to develop either abstract online alter egos or create avatars that mirror their offline characteristics. Cooper's (2007) photography can also be viewed at http://www.alteregobook.com/gal1.html. Date accessed 28th, January, 2009.

${ }^{31}$ A MOO is object orientated, rather than textually based like its counterpart, the MUD. A MUD is "a computer program, usually running over the Internet, that allows multiple users to participate in virtual-reality role-playing games".
} 
$40 \%$ of role-play MOO users had never engaged in this behavior". The second alternative avenue to replace the abstract concept of the cyborg is the transcendence of binaries and dualisms. As Poster (cited in Boler, 2007:152) argues, the ability of users to "adopt a fictional role that may be different from their actual gender ... drastically calls into question the gender system of the dominant culture as a fixed binary". This assertion has been criticised, however, as it initially presupposes that an online textual body is performative and the biological, and gendered, body ends at the boundary between body and technology. As will be addressed at a later point in this thesis, the eschewing of bodily markers of difference is not as simple as cyber-enthusiasts propose. Secondly, Senft (cited in Boler, 2007:152) raises the issue of choice stating that the discourse on the possibility of the transcendence of binaries "reinforc[es] an idea that you put on gender, like a change of clothing and that gender doesn't wear you. In short, online or off it, identity and gender are complicated performances, particularly immune to Utopias".

The final 'hope' of cyberenthusiasts outlined by Boler (2007) is the transcendence of time and space on a level far more sophisticated than that is currently possible. These hopes envisage a new "technologically-mediated world ... a post geographical world, profoundly anti-spatial' in its nature" (Mitchell cited in Boler, 2007:152). It is the actualities and realities outlined by Boler (2007) that provide a useful point of departure from the unrealistic goals of digital Cartesianism and a useful starting point for a critique of the online disembodiment thesis.

http://www.answers.com/topic/mud-1 Date accessed January 29th 2009. Whereas a MUD is comprised entirely of text, a MOO allows users to perform object oriented programming. 
Boler's $(2002 ; 2007)$ critique of new digital Cartesianism centres on the actualities of online communication. For example, O’Brien (cited in Boler, 2007:154) notes that, even when the body is anchored elsewhere and unavailable as the source of symbolic cueing, central distinctions that reference the body as connected to self will still be evoked as the basis of meaningful communication.

It is these actualities of online communication that inform the following discussion which challenges the online disembodiment thesis and highlights the immutability of the body in online social interaction.

\section{CHALLENGING THE ONLINE DISEMBODIMENT THESIS}

It can unequivocally be concluded that disembodiment, including the transcendence of temporal and spatial limitations, is one of the most prominent utopian discourses around the opportunities offered by advanced communication technologies. The body, or 'meat' as it is often referred to, is regarded as an obstacle on the path to the attainment of the principles of Cartesianism and bodily transcendence. Morse (cited in Lupton, 1995:100) highlights how the goal of bodily transcendence has transformed contemporary human pursuits and that "the desire for an evolutionary transformation of the human has shifted focus from the preparation for the journey into 'outer space' from a dying planet to the virtual 'inner space' of the computer". Eschewing the burdensome body represents, for some, the first step on this journey. 
As previously stated, the theoretical concept of disembodiment was originally adopted as a contributing factor in the online victimisation of women, and subsequently as a barrier to conducting online research. However, in the course of developing an understanding of the concept its unsuitability became apparent, despite the prevalent application of a number of similar concepts to explain online harassment and victimisation including anonymity and deindividuation ${ }^{32}$. The previous examination of the online disembodiment thesis indicates that this concept has an established history, and set of defining characteristics, that make it unsuitable as an explanation for online offending. For this reason this chapter in general, but more specifically the discussion from this point forward, has several purposes.

Firstly, to address how the application of the concept of disembodiment to explain problematic social interaction online is incorrect. Disembodiment is not an accepted social fact but rather a goal of cyber enthusiasts, the widespread rejection of which undermines its use as a causal factor in offending. The key characteristics of, on the one hand, the online disembodiment thesis and, on the other, a number of explanatory factors employed from a criminological perspective are not concurrent and therefore the term itself is laden and its use disadvantageous for criminologists attempting to explain online victimisation. It is therefore advocated that, despite the original intentions of this thesis, the term disembodiment is avoided as an explanation for online offending due to its establishment as a concept possessing a meaning in contrast to that required from a criminological perspective. The concept is also rejected as an

${ }^{32}$ For example, Bocij and MacFarlane (2003:212) note that the, "disembodied nature of the Internet makes it relatively easy to depersonalise others". 
explanation for offending as conceptually it is not concurrent with the absence of physical presence online, the operation of which is a contributory factor in victimisation. Also adopting disembodiment as an explanation for offending fails to recognise the ways in which the presence of the body in online social interaction may facilitate victimisation.

The second purpose of this thesis is to provide not only further critique of the online disembodiment thesis but also proffer two alternative explanations for online victimisation in relation to the body.

At first glance the preceding discussion of disembodiment may seem superfluous leading the reader to inquire as to its necessity if the concept of disembodiment is, at this stage, rendered redundant. However, it is the nature of disembodiment itself that has facilitated this discussion. Despite the proliferation of the term 'disembodiment' in literature addressing the Internet, few theorists, excluding Campbell (2004) for instance, have positioned disembodiment as a theoretical concept open to interrogation and critique. Rather than existing as a defined concept its use is rather that of a fact, scattered throughout discussions on the Internet with little discussion given to its meaning, significance or truth. This usage subsequently initiates its acceptance as a feature of online interaction and concurrently as a plausible explanation for problematic social interaction online. However, further examination of the concept indicates its definition by few and its critique by an increasing number of theorists. 
The preceding discussion has provided an indication of a number of characteristics of the online disembodiment thesis and whilst it can unequivocally be concluded that disembodiment is one of the most prominent utopian discourses around the opportunities offered by advanced communication technologies, from a social scientific perspective negotiating the concepts comprising the online disembodiment thesis is a difficult task. Any inaccurate conclusions regarding the role of disembodiment could be partially contributed to the unique and complex nature of the Internet environment that lacks any ontological point of reference. Compounding the ontological problems of the Internet is the melding of science fiction and fact into which social scientists have entered and Campbell (2004:10) expresses concern "when grand claims based on fanciful imagery are uncritically incorporated into scholarly discourse”. Needless to say, the exponential growth of the Internet has not been matched, thus far, by criminological scholarship.

Despite the previous examples of the online disembodiment thesis I have, as yet, not interrogated this concept and I wish to do so from three angles, highlighting its unsuitability as an explanation for online offending and victimisation. Firstly, and to an extent I have already done so, the nature of the term disembodiment itself requires further examination. Examples of its use will be addressed followed by a number of alternative explanations for problematic online social interaction, including a number of which apply to the body. A number of theorists (see, for example, Bird, 2003; Campbell, 2004) go so far as to reject disembodiment as a myth and these concepts will also be explored. Secondly, I want to address the nature of the body in online social 
interaction including its immutability and the important role it plays as a mediator in online social interaction. Thirdly, the theoretical concept of disembodiment will be addressed, and subsequently critiqued, from a feminist perspective.

Although the previous discussion provided an explanation of several aspects of the online disembodiment thesis, the use of the concept requires further explication. Campbell (2004) addresses the concept from a critical perspective not dispelling its existence but rather relegating its use to those employing the term from extreme utopic and dystopic positions. Campbell (2004) is one of a number of theorists who position disembodiment as a subjective, yet unattainable, goal rather than a fact. It is the recognition of the subjectivity of the transcendence of bodily limitations online that facilitates its critique as an explanation for offending. Essentially, the online disembodiment thesis and its correlates are primarily characterised by subjective experience rather than objective fact. For every subscription to the online disembodiment thesis by a cyberenthusiast attempting to transcend bodily limitations there exists a computer user for whom embodied online experiences remain paramount. The ways in which the body manifests itself online will be explored at a later point in this discussion.

To return to Campbell (2004), it is his understanding of what he terms the online disembodiment thesis ${ }^{33}$ that is of particular importance for the overall purpose of this

\footnotetext{
${ }^{33}$ Campbell's (2004:11) online disembodiment thesis "rests on the notion that there is an absolute demarcation between the real and virtual, and therefore a radical disjuncture between experiences in cyberspace and those in the physical world. Scholars subscribing to this proposition characterize cyberspace as a sovereign realm, distinct from and unaffected by the cultural, political
} 
thesis and a discussion of cyberstalking. The creation of a demarcation between online and offline and the characterisation of cyberspace as "a sovereign realm ... unaffected by cultural, political and economic forces" (p. 11) whilst favourable in certain circumstances, including a number of cyberfeminist perspectives, does not favour an examination of the online victimisation of women. The creation of this demarcation fails to recognise how the discrimination and victimisation perpetrated against women offline manifests itself online in similar ways. The previous debate regarding the continuities and discontinuities between online and offline stalking indicates that the endorsement of a demarcation between the real and the virtual, especially in relation to the online victimisation of women, is problematic and as Gorski (cited in Halbert, 2004:126) notes, "most of the sex and gender inequities which occur in society are replicated online".

The demarcation between online and offline also invokes a binary logic rejected by a number of feminist theorists. Campbell (2004: 11) notes that proponents of the online disembodiment thesis believe that:

If the physical world is real, then cyberspace must be virtual and therefore something other than real; if the body is present in the physical world, then the body must be absent in the virtual world; if oppressive social constructs such as race, gender and sexuality are based on the body, then when the body is absent these constructs must also be absent.

and economic forces shaping the mundane world we inhabit. Thus some social scientists may see online experiences transforming offline perceptions, but seldom do these same researchers examine the ways in which offline circumstances inform online interactions". 
This thinking again, propagates the view that there is no link between the real and the virtual, further problematising the links between the online and offline victimisation of women.

Moving on from Campbell (2004), Ajana (2005) is also highly critical of what she facetiously terms the rhetoric of disembodiment, which she addresses primarily from a phenomenological perspective by drawing on the work of Merleau-Ponty (2002). The phenomenological perspective of Merleau-Ponty (2002:235) stresses the immutability of the body arguing that, "our own body is in the world as the heart is in the organism: it keeps the visible spectacle alive, it breathes life into it and sustains it inwardly, and with it forms a system". The body is not as easily forgotten as proponents of disembodiment posit and additionally the body is necessary for the formation of identity. As Ajana (2005: Para. 8) notes, "identity ... is a cognitive accumulation of phenomenological bodily experiences" and that "even at the very epic moment of transcendence and the highest level of phenomenological reduction, the body is still the reference, the anchor and the trajectory of any transcendently experiential instance, for denying the body is in itself recursively ratifying its inevitability". It is the phenomenological perspective on the immutability of the body and the translation of this theory to as assessment of online experience (Ajana, 2005) that further supports a critique of the online disembodiment thesis.

The realities of embodiment for computer users are often invoked to challenge the goal of disembodiment. As Lupton (2000:480) argues: 
While an individual may successfully pretend to be a different gender or age on the Internet, she or he will always have to return to the embodied reality of an empty stomach, stiff neck, aching hands, sore back and gritty eyes caused by too many hours in front of the computer terminal.

Additionally, despite the pervasive goal of transcendence and the rejection of the body, several theorists have observed the extent to which the computer has become anthropomorphised. Take for example the viral metaphor, the idea that computers like humans contract viruses through interaction with each other. This anthropomorphism extends to the symbiotic relationships humans create with computers. As Lupton (1995:97) states:

I am face-to-face with my computer for far longer than I look into any human face. I don't have a name for my personal computer, nor do I ascribe it a gender ... [h] [owever I do have an emotional relationship with the computer, which usually makes itself overtly known when something goes wrong.

Additionally, Stanley (2001:86) observes the ways in which the body "pushes through into cyberspace”. Stanley's (2001) examination of transcripts of online communication identified how the body is constantly appropriated in online communication. The use of smiley faces or emoticons are constantly employed in online communication. Additionally, Boler's (2007:154) discussion of new digital Cartesianism observes that, despite the pervasive goals of anonymity and transcendence, the "frequency with which users inquire about others' 'age/sex/location' ('asl') in order to interpret communication and/or to confirm one's projection of the other's identity". This tension between "disembodied exchange and [the] reinvocation of stereotyped bodies" (Boler, $2007: 155)$ is also indicative of the immutability of the body in online communication. An examination of the evolution of chat room communication, for example, indicates a 
move from solely text-based chat to the addition of voice chat options and more recently video chat. Recent years have also seen the increasing adoption of virtual reality communities including SecondLife ${ }^{\circledR}$ and Habbo ${ }^{\circledR}$. Online interaction takes place through three-dimensional avatars, the majority of which physically resemble the body of the person whom they represent. These shifts away from, not towards the principles of the online disembodiment thesis, will perhaps only be impeded by the desire to remain anonymous.

Bodies are absent in cyberspace and this absence is problematic. This absence is less the goal of disembodiment but rather the inevitable lack of physicality created by the medium. The problems associated with this lack of physicality do, however, indicate the problems associated with forgetting the body and perhaps discourage the desire to do so. Bird (2003:121) explores the problems associated with this lack of physicality from a psychopathological perspective and assessed the changes in human relationships online. There is, according to Klein (cited in Bird, 2003:123), "a kind of detached hostility that pervades the whole [online] relationship" which has serious ramifications in terms of online victimisation. Theorists of late modernity have observed the contribution advanced communication technologies have made to the changes in social interaction and that these interactions are increasingly transitory, shallow and instrumental. A lack of physicality, of embodied presence, has serious ramifications. For example, smiles, frowns, nods and the other myriad physical cues that proliferate offline communication and discourage a certain degree of conflict are absent online. As previously mentioned, Spender (1995) identifies the lack of physical cues as a key 
contributor to flaming. A lack of physical presence is also concurrent with anonymity and as Spender (1995:195) notes, "there is ample evidence which suggests that users can behave in a much more abusive and crudely coercive way when they are anonymous, than they would in a face-to-face situation". The body essentially acts as a mediator whereby embodied presence offline minimises the occurrence of a number of problems that do occur online. However, for every contribution disembodied interaction makes to online victimisation it may also be concluded that embodiment may also equally cause problematic social interaction online.

As previously noted, there is no single feminist perspective in relation to advanced communication technologies. There is, however, a branch of cyberfeminism explicitly concerned with "hybrid bodies, becoming disembodied through the construction of identity on the Internet, and the exploitation of women's bodies both real and virtual" (Halbert, 2004:123). While a number of feminist theorists advocate transcendence and the notion of the cyborg, others are understandably critical. Braidotti (cited in Brook, 1999:137) for example, argues "the last thing we need at this point in Western history is a renewal of the old myth of transcendence as flight from the body". Campbell (2004) argues that the online disembodiment thesis is predicated on the notion of an essentialised understanding of the body and the application of binary logic. As previously outlined, feminist theorists are critical of these concepts. Transcendence is equally problematic for, as Halbert (2004:130) notes, "feminist theorists have located much of women's power in the centrality of the female body" and "forgetting the body 
is an old Cartesian trick, one that has unpleasant consequences for those bodies whose speech is silenced by the act of our forgetting" (Stone, 2000:525).

The preceding literature review indicated that women are primarily the victims of cyberstalking and a number of other discursively manifested forms of victimisation online including harassment and flaming. However, this disparity does not correlate with the adoption of disembodiment, nor anonymity, as explanations for offending. For example if, as the online disembodiment thesis posits, the bodily markers of difference are erased online and anonymity is paramount, why are women disproportionately the victims of these offences? Sarkio (2009) addresses embodiment as not only the antithesis of the online disembodiment thesis but also as gendered. Sarkio (2009) argues that gender and, therefore, embodiment remain paramount in online social interaction. Following an assessment of gendered behaviour on an online message board targeted at teenage girls Sarkio (2009:32) concludes that "even though Turkle's idea of the disembodied woman might seem emancipatory, unfortunately, it is not reflective of the reality of the internet. Rather, internet users ... are embodied". Sarkio's (2009) findings are indicative of the presence of gender online rather than the erasure of difference favoured by those subscribing to the online disembodiment thesis. The correlation of embodiment and gender and the presence of both in online social interaction, when viewed in relation to the gender disparity in cyberstalking statistics, facilitate a gendered assessment of this crime. To conclude this chapter I would like to offer two alternative explanations for the disparate victimisation of women online in relation to the theories of the body. 


\section{ALTERNATIVE EXPLANATIONS FOR VICTIMISATION IN RELATION TO THE THEORIES OF THE BODY}

\section{Discursively (De)constructed Bodies}

Smart (1995) observes the discursive construction of women as, and reduction to, mere bodies. This assertion is supported by the following example:

Imagine a room full of men in a workplace or educational establishment. The door opens and a woman walks in. Her entrance marks the arrival of both sex and the body. A woman entering into such a room can hardly fail to recognize that she is disrupting an order which, prior to her entrance, was unperturbed by an awareness of difference or things corporeal (Smart, 1995:221).

Sexual harassment and sexual violence replicate this distinction and there is a:

Symbolic framework of meanings in which women are only their sexualized bodies, and being such they are open to use and abuse. [The act of sexual harassment or rape] locates women in her body; she had forgotten she has one, but the act makes her simply a body" (Smart, 1995: 223).

It is my assertion, in rejecting the notion of disembodiment online, that cyberstalking and online harassment function in the same manner. Bodies online are discursively constructed and despite the assertions of advocates of bodily transcendence, the disproportionate victimisation of women online indicates that Smart's (1995) discussion of sexual harassment translates onto the Internet. Women, as victims, are not disembodied online; rather, acts of victimisation repeatedly locate women in their bodies therefore reproducing, not rejecting, the concepts Smart (1995) is challenging. This process occurs online primarily though the use of discourse. Smart (1995) argues 
that within legal discourse women are discursively constructed as mere bodies. Smart (1995) is highly critical of the way in which victimisation reduces women to bodies and the way in which the female body is rendered problematic in legal discourse. Victimisation, according to Smart (1995:224), is "premised upon the idea of acts performed on the female body. The man's body is his instrument, the woman is her body" (author's italics). The concepts Smart (1995) is challenging, whilst still relevant in relation to offline victimisation, could be regarded as equally applicable to explaining online victimisation.

Additionally, as previously noted, Williams (2006:100) indicates that "if language can sustain the body it can also threaten its existence". For this reason, if the body is discursively constructed then language can, paradoxically, disestablish an individual's sense of self (Williams, 2006). It is in this sense that cyberstalking, and other forms of online victimisation against women, is problematic as it is perpetrated, primarily, though speech and text. These 'derisory textual performances' (Williams, 2006) locate woman in her discursively created body. Additionally, if an individual has a "strong psychological investment in, and identification with, their virtual personae" (Brook, 1999:150) then the act of cyberstalking, online harassment or flaming perpetrated against this discursively constructed personae will resonate psychologically. Williams' (2006) argument is that those who are more ontologically secure in an online environment are therefore more vulnerable to harmful speech. 
These assertions are supported by the disparate victimisation of women online. They are also supported by the location of cyberstalking on a continuum of victimisation against women and a close examination of the myriad ways in which cyberstalking shares characteristics within other forms of sexual violence. While further research is required to examine these similarities, an examination of individual case studies and individual cyberstalking characteristics (see, Spitzberg and Hoobler, 2002) indicate the sexually violent nature of the crime. As cyberstalking is conducted primarily through discourse, discourse analysis identifying the extent to which the body is invoked in these communications may also support these conclusions.

\section{Cyberstalking as a Gendered Form of Offending}

Despite the disparate victimisation of women online and the nature of this offending, few theorists (see Adam, 2005 and Ellison, 2001) have addressed cyberstalking as a gendered form of offending nor applied appropriate theory. Therefore, advocating the recognition of cyberstalking as a gendered form of offending and the links to the body this entails is the second alternative explanation this thesis will address. This recommendation is reinforced throughout this thesis. It is also supported by Sarkio's (2009) theory whereby embodiment and gender are viewed as concurrent concepts.

Adam (2005) argues that an analysis of cyberstalking should begin with an examination of online sexual harassment ${ }^{34}$ (see also, Ellison, 2001) and classifies cyberstalking as

\footnotetext{
${ }^{34}$ Adam (2005:109) employs MacKinnon's definition of harassment that involves "the unwanted imposition of sexual requirements in the context of a relationship of unequal power".
} 
an extreme form of online sexual harassment in line with the establishment of a gendered assessment of cyberstalking. The systematic analysis of cyberstalking against a theoretical framework which adopts gender as the central construct is prioritised by Adam (2005) who argues that such a framework should include an understanding of the psychology of the crime, a broader understanding of cybercrime and also a feminist analysis of cyberstalking in relation to privacy. In response to these requirements Adam (2005) is particularly concerned with an assessment of stalking-by-proxy ${ }^{35}$ and the manifestation of gendered issues this crime presents.

In developing a gendered theoretical perspective from which to address stalking-byproxy, Adam (2005) does so from a perspective that includes issues of privacy and the gaze. The differential views women and men hold in relation to online privacy has, thus far, not been fully considered (Adam, 2005). Adam (2005) argues that the online world most likely mirrors the offline world whereby women, who have traditionally had few rights to privacy, are less likely to recognise when their rights to privacy have been violated online. The gaze constitutes a direct form of privacy transgression whereby the power of the offender is reinforced through this process; however it has remained unexplored in relation to the Internet (with the exception of Adam, 2005). On the Internet the subject and object of the gaze are not present as in the more literal interpretations of the gaze (Adam, 2005). However, observation exists in a distinctive and unique way online. Examining the online environment in relation to the gaze initiates a unique reconceptualisation of physicality and physical presence online. Two

${ }^{35}$ Adam (2005) favours the term 'third party stalking' although the term 'stalking by proxy' has previously been used in this thesis and in the interest of consistency I will continue to do so. 
ways in which the gaze can be identified as operating online is in relation to stalkingby-proxy and also in the scopophilic nature of Internet.

Salecel and Zizek (cited in Adam, 2005) note the fetishistic and voyeuristic nature of the empowered male gaze and additionally the way in which the gaze operates as a method of control. Adam (2005) applies the issue of control, in this context, to stalking-by-proxy, whereby the stalker directs others to the victim. Adam also notes the scopophilic nature of the Internet, a concept that can be related to a discussion of online pornography addressed in this thesis. In relation to this concept, Denzin (cited in Adam, 2005:121) defines the gaze as:

[N]ot simply voyeuristic. It is regulated, has a trajectory, and evokes emotions and conduct which are differentially reciprocated and erotic. A gaze may be active, or passive, direct, or indirect and indifferent. It will always be engendered, reflecting a masculine or feminine perspective. A gaze may be the gaze of power of domination.

The adoption of a feminist perspective that incorporates issues of privacy and the gaze also initiates a method of resistance in the form of reappropriating the gaze. The gaze is a two way process whereby returning the gaze reverses the power imbalance and removes the anonymity of the offender. Additionally, the reappropriation of the gaze directly contradicts the principles of the online disembodiment thesis. The goal of disembodiment is challenged when embodiment, and the removal of anonymity, is positioned as a powerful form of resistance. In certain instances, the return gaze operates as a powerful form of resistance (Adam, 2005). 
The preceding discussion of the work of Smart (1995) and Adam (2005) are indicative of the importance of incorporating corporeal concepts into a discussion of the online victimisation of women despite the prevailing notion of the absence of bodies online. The theoretical concepts raised in this chapter have subsequently informed the development of a number of methodological considerations. Essentially the immutability of the body online can be paralleled with the identification of methodological positions that reject the primary concepts of the online disembodiment thesis. Prior to a discussion of these methodological considerations a discussion of the original research method is required.

Despite the conclusions drawn in this chapter, the original research method took the concept of disembodiment as a probable explanation for online victimisation. However, subsequent examination of the concept indicated its inherent problems and its unsuitability as a theoretical explanation for online victimisation. The uncritical adoption of the online disembodiment thesis subsequently informed the development of a suitable method. A discussion of this method is required prior to an assessment of its applicability in the final chapter. 


\section{CHAPTER FOUR:}

\section{THE ORIGINAL RESEARCH PROJECT}

It has previously been noted that the original research method could not be implemented. This obstacle offered two alternative solutions. While the first, and most obvious, decision was to simply alter the method it was the second alternative that proved the most salient due to the lack of methodological and criminological precedence in this field. The unsuitability of the original method subtly initiated the development of a theoretical and methodological framework suitable for an assessment of online victimisation.

While it could be concluded that the overall progression of this thesis, and the conclusions that will be drawn, render the original research project redundant and its inclusion here unnecessary, I have chosen to include it at this point. Its inclusion not only provides an indication of the progression of this thesis but also acts as foundation for the development of the methodological considerations developed in the final chapter. The method itself also has significant merit in terms of Internet research despite its unsuitability in this instance.

Whilst the final chapter critically examines the applicability of the original research method in response to the development of a number of methodological considerations, this chapter outlines the key features of the original research project. 


\section{VIRTUAL FOCUS GROUPS}

As Campbell and Wasco (2000:784) argue, “the task of understanding women's lives may be best achieved in group settings". Research conducted in group settings:

[Brings] women together to discuss their lives [and] brings attention to the myriad of ways gender oppression affects the day-to-day experiences of being female (Campbell and Wasco, 2000:785).

The original research method involved using the medium that facilitates victimisation to subsequently facilitate research by placing focus group research within an Internet environment. An online forum was established to act as a virtual focus group. With the introduction of computer technology to social science, research methodologies have increasingly employed this medium as a research tool (Anderson and Kanuka, 2002; Barbour, 2008) although this method has, as yet, not been applied to researching victimisation.

Online, or virtual, focus groups mirror their offline counterpart and involve discussion which "consists of one interviewer/moderator and a small group of interviewees. Participants are brought together for an in-depth, open discussion of a given topic under the guidance of a professional moderator" (Tse, 1999:407). The influence of virtual focus groups has been mixed with Bloor et al (2001:75) concluding that "virtual focus groups are not the future of focus group research ... However, virtual focus groups do offer a useful stablemate in the focus group tradition, and a worthwhile new tool for the social researcher". A review of literature on virtual focus groups has proffered a 
number of benefits. Firstly, the spatial and temporal restrictions placed on traditional focus groups are overcome, as are the costs incurred (Kenny, 2004; Tse, 1999; Turney and Pocknee, 2004; Moloney et al, 2003; Bloor et al, 2001). Secondly, homogenous responses are overcome as respondents feel more comfortable in challenging the opinions of others due to the lack of face to face contact and a certain degree of anonymity (Turney and Pocknee, 2004). Thirdly, the ability for participants to be involved in research from the comfort of their own home, at a time suitable for them, is an attractive option (Turney and Pocknee, 2004; Moloney et al, 2003; Kenny, 2004). Therefore, participants are easier to recruit due to the convenience and optional anonymity provided by online focus groups (Tse, 1999). Fourthly, the effects of nonparticipation (social loafing) or dominance (social posturing) are mitigated by this environment (Kenny, 2004). Tse (1999) found that an anonymous environment avoided bias and participants had less influence over the responses of others. Fifthly, participants have identified the online focus group as being a safe environment (Kenny, 2004; Moloney et al, 2003). Also, Tse (1999) found that dysfunction and conflict were mitigated in an online environment. Sixthly, the processing of data is much easier as it is already recorded (Kenny, 2004; Tse, 1999; Turney and Pocknee, 2004; Moloney et al, 2003). Tse (1999:407) notes that, "analysis of the information obtained in an electronic focus group discussion can be done faster because there is no need to go through the time consuming and labourious transcription process".

Also, two, of the four, characteristics of Campbell and Wasco's (2000) features of feminist methodologies are implicitly achieved by using an online focus group. The 
first is that participants are connected for group level data analysis. The use of online focus groups in social science research for and on women's issues is common (see Kenny, 2004; Moloney et al, 2003). The second feature is the creation of nonhierarchical research relationships. A non-hierarchical research relationship is characterised by "both parties invest[ing] their personal experiences by sharing experiences and information" (Campbell and Wasco, 2000:786). This mode of communication places the researcher in the primary role of facilitator whilst allowing participants freedom to influence the research direction and contribute to the research purpose. The traditional view of the researcher as the 'all knowing' expert neglects the knowledge that participants can bring to the research (Campbell and Wasco, 2000). By creating a non-hierarchical research relationship participants can positively influence the research direction. This was important, in terms of the original research project, as the complex concepts of disembodiment and identity needed to be understood as they related, or did not relate, to the online experiences of participants. A two-way, nonhierarchical research relationship aids in the understanding of complex theoretical topics by placing them into real-life situations. Reflexivity, on the part of the researcher, can also be beneficial. The participants not only interact with the researcher but the opportunity is also provided for participants to interact with each other in a safe research environment. The creation of an (online) non-hierarchical research community reflects the principles of feminist research.

\section{ESTABLISHING A RESEARCH SITE}


Focus groups can be established online in numerous ways. They can consist of a standalone forum or message board and these forums can be password protected to allow only certain people to enter. For the purpose of the original research project $\mathrm{phpBB}^{\mathrm{TM}}$, an open source Internet forum package, was applied to a privately hosted and secure website. This was an attractive option as a phpBB ${ }^{\mathrm{TM}}$ forum includes additional security features providing the researcher with the ability to restrict entry to the forum to research participants, remove participants and provide each participant with their own password.

\section{METHOD}

The focus group employed different forms of questioning, including scenarios, to form discussions around cyberstalking and disembodiment. Many researchers have devised definitions and typologies to further delineate the crime of cyberstalking and the 24 characteristics of cyberstalking as outlined by Spitzberg and Hoobler (2002:83-84) (see Appendix B) were used as the basis of scenarios for this research. These twenty-four characteristics also indicate that cyberstalking is a very broad term encompassing a number of unsolicited forms of online harassment. The opportunity for participants to contribute to the research direction through their unique and individual contributions was also allowed for. Due to the nature of virtual focus groups, questions are not restrained by a rigid chronological progression and participants can move backwards and forwards between questions. Kitvis (2005) provides practical guidelines for interviewing online whilst maintaining an interpersonal research relationship. These 
practical suggestions echo the principles of feminist research and include the importance of creating a safe environment for participants and fostering a positive research relationship characterised by trust. An interpretivist stance was originally adopted which involves participants interpreting situations and concepts from an individual perspective in relation to the theory. Kvale (cited in Babbie, 1999:259), describes interpretivism as representing:

A move away from obtaining knowledge primarily through external observation ... toward an understanding by means of conversations ... the subjects not only answer questions prepared by an expert, but themselves formulate in a dialogue their own conceptions of their lived world.

The online focus group reflects this aspect of an interpretivist position concerned with the ways individuals make sense of their world. The forum posts can then form part of a tangible record of the research.

\section{RESEARCH PARTICIPANTS}

The number of participants required for an online focus group varies. Traditional focus groups involve around six participants when dealing with complex topics (Krueger cited in Kenny, 2004). Online focus groups allow for a larger number, however, due to manageability. Kenny's (2004) research involved 38 participants; Tse's (1999) involved 71 participants and Moloney et al's (2003) involved 22 participants. A balance between the traditional focus group size and the larger online focus groups size is optimal and a cohort of between $10-15$ people would be sufficient for engaging in highly theoretical concepts within an online focus group. 


\section{CONCLUSION}

Whilst participant recruitment proved a major barrier to the implementation of the original method the development of a theoretical framework for the assessment of cyberstalking based on the theories of the body further highlighted the problems of applying this method to an examination of victimisation. The following chapter addresses these methodological issues and concludes with an assessment of the suitability of this original method in light of the theoretical framework established in this thesis. 


\section{CHAPTER FIVE:}

\section{METHODOLOGICAL CONSIDERATIONS}

\section{INTRODUCTION}

There has been an inclination, within social science research, towards the adoption and application of traditional and established methodologies when researching the Internet. The exponential growth of the Internet has surpassed methodological innovation leaving a researcher new to the field with a set of outmoded research tools. Researchers who have examined cyberstalking, primarily the quantitative survey-based research of Bocij (2004), have employed traditional, and primarily quantitative, research methods to examine the online victimisation of both genders. However, as Hine (2005:1) argues, "there is considerable anxiety about just how far existing tried and tested research methods are appropriate for technologically mediated interactions". Add to this the special considerations which need to be employed when researching victimisation and it becomes apparent that a researcher intending to examine this subject does not have at their disposal a set of 'tried and tested' research methods. As Hine (2005:1) notes, "methodological solutions gain much of their authority through precedent, and it is not clear as yet just how far the heritage of research methodology applies to new media and what gaps in our understanding are still to be exposed". Consequently, little methodological legacy exists for the researcher intending to 
undertake qualitative research online; especially one planning to research sensitive topics such as victimisation.

The original aim of this thesis was to develop an online, or 'virtual', focus group to examine how the concept of disembodiment contributes to the evident gender disparity in cyberstalking victimisation. This decision was supported initially by a slowly increasing number of empirical and theoretical studies that have paralleled, and responded to growing public concerns over Internet safety and cybercrimes. It was also prompted by the lack of research, especially qualitative research, on the subject. However, locating research that addresses the disparate victimisation of women online and the impact of this victimisation proved difficult. Although, initially, this lack of research could be attributed to the relatively short history of the Internet, and subsequently Internet research, a number of other explanations have become apparent and will be addressed in this chapter.

The evident lack of research in this field has facilitated an alternative research aim for this thesis; an alternation supported by my own problems in researching this subject. Therefore, the revised purpose of this thesis is two-fold. The first is to explain online victimisation, primarily cyberstalking, in relation to the theories of the body in contrast to the prevailing notion that the body is primarily absent in online interaction. Secondly, it is my intention in this chapter to apply the understanding of the links between online victimisation and the theories of the body developed in the previous chapter to the development of two key methodological considerations for researching 
the online victimisation of women. Firstly, the acceptance of the demarcation between the online and offline environment by those researching online phenomena will be critiqued. Secondly, the importance of researcher (re)embodiment and embodied presence in the application of virtual methods will be addressed. These methodological considerations will then inform a critical assessment of the suitability of the original research method: online or 'virtual' focus groups as discussed in the preceding chapter.

It is hoped that through combining an understanding of cyberstalking in relation to the body and subsequently applying this understanding to the development of these two key considerations that this thesis will usefully contribute to the development of academic precedence in the development of online criminological research methodologies. I will begin by briefly providing further discussion of virtual methods and online research and the particular challenge for criminologists conducting research that addresses cybercrime.

\section{CRIMINOLOGICAL RESEARCH ONLINE: PROBLEMS AND CHALLENGES}

The epistemic and ontological shift initiated by the advent of advanced communication technologies has had radical implications for the development of criminological research methodologies in response to cybercrimes. Whilst the challenges the Internet poses to criminologists have been addressed in the latter part of this thesis, the 
influence of technology on criminological research requires further examination at this point.

For the most part, criminological research has not relied on a technical understanding of the crime taking place; for example, Smith (2004:105) argues that, "it is not necessary to understand how an automobile is powered to research auto theft" whereas the development of an understanding of a number of cybercrimes are reliant on this technical understanding. Chapter One addressed the problems associated with the application of criminological theory to the online environment; however, less attention has been paid to the development of an understanding of the unique methodological implications of the Internet which is, as Capeller (2001:234) states, "an abstract and systemic criminal field". It is perhaps the combination of this abstract research environment and the highly technical nature of the crimes that has seen criminologists slow to respond. Capeller's (2001) reference to the abstract nature of the Internet can be linked to the unique ontological and epistemological challenges the Internet poses.

As Nunes (1995) so aptly states, you don't 'go somewhere' when picking up the telephone. The spatially and temporally disordered nature of the Internet, and the absence of the offline 'anchors' of identity within this environment, instigate a unique and complex ontology and epistemology. To call it an environment or (cyber)space implies a unique sense of imperceptible spatiality and in an attempt to achieve order we have not only created a set of spatial and kinetic metaphors but have also, to a degree, anthropomorphised the computer itself. Chesher (1997) is highly critical of attempts to 
understand the Internet through the invocation of spatial and kinetic metaphors and seeks to reinstate the notion of the Internet as discursive, a perspective that can perhaps be aligned with the preceding discussion of the discursive construction of bodies online (Williams, 2006). Chesher (1997:83) argues that "networks do not reproduce space they eliminate it" and categorises computers as invocational media. Understanding computers as invocational media rejects kinetic metaphors and inversely relates the computer to speech whereby data is invoked via a command. Rationally, we know cyberspace is aspatial; it exists not at an address but, as Chesher (1997:83) notes, "with an address". By entering the address that which has been invoked appears on the screen. Rather than 'going somewhere' online an Internet users invokes the media thereby bringing the content to them by entering an address. The aspatiality of the Internet is supported by the erosion of distance whereby, for example, sending an email to someone in the other room or in another country occurs at the same speed and time. As Chesher (1997:85) notes, "space in the physical world becomes time in the ontology of the digital domain [and] [d]istance is manifested in invocational delays of nano- or micro-seconds". Whilst it could be concluded that these complex ontological questions require resolution prior to the development of applicable methodologies to do so may further delay the process due to the complexity of the concepts. Perhaps the process of developing applicable methodologies and the resolution of ontological and epistemological problems would be best achieved through a parallel process.

The challenges the Internet has posed in relation to the development of criminological theory, addressed in Chapter One, are equally applicable to the impact on the 
development of criminological research methodologies. The exponential growth of the Internet has not only surpassed the development of a theoretical understanding of cybercrime but also surpassed methodological innovation. The scope and interjurisdictionality of cybercrimes are also problematic for the development of research methods that are required to respond to spatially dispersed populations. Understanding the unique aspects of the Internet is a vital prerequisite in the development of applicable research methods. In relation to the development of an understanding of the online victimisation of women as it relates to the theories of the body two key methodological considerations have been developed. It is intended that the development of the following methodological considerations not only inform further research but underpin the critical assessment of my own research problems in addressing the online victimisation of women.

\section{METHODOLOGICAL CONSIDERATION ONE: REJECTING THE ONLINE/OFFLINE DEMARCATION}

It is truly ironic that a technology of Internetworking gives us great difficulty when we seek to understand its social interconnectedness. If, however, we seek only to find interconnectedness within and between the technology and its antecedents, we will likely not make the connection we truly desire, the one between life on-line and its meaning in relationship to life off-line (Jones, 1999:22-23).

As previously noted, the rejection of the online disembodiment thesis is predicated on the rejection of the demarcation between online and offline. It also rejects extreme utopic and dystopic conceptions of the Internet. To once again cite Campbell 
(2004:11), due to the significance of his argument at this point, the online disembodiment thesis:

Rests on the notion that there is an absolute demarcation between the real and virtual, and therefore a radical disjuncture between experiences in cyberspace and those in the physical world ... Thus some social scientists may see online experiences transforming offline perceptions, but seldom do these same researchers examine the ways in which offline circumstances inform online interactions.

For this reason, those who proscribe to the view of the importance of embodiment in online social interaction are critical of the application of research conducted solely online. Orgad (2005) has observed the over reliance on virtual methods whereby Internet phenomena have predominantly been studied through the implementation of Internet-based methods with little regard given to offline context. The acceptance of the online disembodiment thesis and the application of solely Internet-based methods results in the failure to recognise a number of key methodological considerations. Firstly, there exists links between the online and offline experiences of research participants. As Kendall (1997:58) notes, “once on-line, participants draw on their offline resources, as well as understandings gained in off-line experiences, to negotiate and interpret their on-line interaction". Research relies, therefore, on an understanding of these important interconnections between the online and offline experiences of users. The creation of a demarcation between the online and offline experiences of users, which manifests in the application of solely Internet based methods, also neglects to recognise the significance and influence of a number of offline factors. Kendall (1997) also identifies a number of offline barriers to online participation whereby the problems 
of access and participation operating offline dictates the demographics of the online population. From a methodological perspective, access issues subsequently influence the representativeness of online samples. Interestingly, however, in terms of both online offending and online victimisation, issues of access ${ }^{36}$ dictate not only the demographics of the sample but may also dictate the likelihood of engaging in, or becoming the victim of, a number of these crimes. Therefore, any research into the demographics of online offenders or victims needs to be done with an awareness of the influence of access on demographics.

Kendall (1997:60) notes that, "individuals exist and participate in off-line social contexts both sequentially and simultaneously with their on-line participation”, an idea rejected by those subscribing to the principles of the online disembodiment thesis. The link between online and offline stalking established in this thesis is concurrent with the fluidity of movement between online and offline interaction and participation. The escalation of stalking from online to offline environments further supports the rejection of a demarcation. Kendall's (1997) research involving participates of an online forum further dispelled the prevailing views of cyber enthusiasts. Kendall's (1997:62) findings indicated that participants, “(a) perceive time and organize experience linearly, (b) privilege embodied experience over mediated experience, and (c) continually work to reincorporate their experiences of themselves and of others' selves into integrated, consistent wholes".

\footnotetext{
${ }^{36}$ See also, a discussion of the 'digital divide' addressed in Chapter One.
} 
The rejection of the online disembodiment thesis can be aligned with a number of principles from the field of cultural studies. Cultural studies offers a number of useful methodological considerations that align with the rejection of the online disembodiment thesis. In response to a body of writing that "seems to have nothing to do with the actual character of the Internet" (Sterne, 1997:265), cultural studies is concerned with developing alternatives to millennial conceptions of the Internet. As Sterne (1997:259) notes, "millennial claims about technology can take either technophilic or technophobic turns". The rejection of both is the mainstay of not only cultural studies but equally identifiable in the work of Campbell (2004) and the rejection of the online disembodiment thesis. Sterne (1997:265) does not doubt the contribution that these theoretical and speculative perspectives (see, for example, Plant, 1997 or Haraway, 1991) can make to the field but rather stresses the importance of recognising that "theorizations of the Net require the same level of specificity as other objects one might theorise, such as literature, music, politics, globalization, or the relationship between time and space". These speculative and highly theoretical texts whilst challenging, innovative and ground-breaking provide little assistance to a criminologist attempting to understand online victimisation. The degree of specificity advocated by Sterne (1997) is particularly necessary for criminologists addressing cybercrime. The importance of the concrete, everyday experiences of Internet users is also obscured in these texts. For this reason a cultural studies perspective and the practical rather than fanciful methodological suggestions it offers is a useful tool for the development of criminological research methodologies. In further support of the demarcation between the online and offline environment, cultural studies warns of the 
epistemological and political implications of studying the Internet as a singular phenomena, divorced from other cultural phenomena. The theory of the links between a user's online and offline experiences provided by cultural studies can be viewed in conjunction with the practical methodological considerations provided by Orgad (2005) and Sanders (2005) in their studies of interactive breast cancer websites and the online sex work community respectively.

Orgad's (2005) examination of interactive breast cancer websites involved the triangulation of online and offline qualitative interviewing. This decision was based on the recognition that Internet use takes place within an embedded offline social context and this particular topic of study was amenable to this triangulated method. This is not to say that all topics would benefit from the combination of online and offline methods. Orgad (2005:53) notes that, in some instances, the "researcher might place themselves in an asymmetric position, using more varied means of communication to understand informants than those used by the informants themselves". Nevertheless a number of research topics that lend themselves to a qualitative analysis are equally amenable to the combination of online and offline research methodologies. The decision to employ these methods is supported by a number of issues raised above including the rejection of the dichotomy between a users online and offline lives. The combination of online and offline interaction with research participants provides a means to contextualise their online behaviour and also add authenticity to the research findings garnered in an online research environment (Orgad, 2005). Orgad (2005) highlights several key 
features relating to the combination of online and offline interaction with participants that can effectively inform the development of research methodologies.

Orgad (2005), by addressing the intentions behind the combination of online and offline research, stresses that doing so should be informed by the desire to gain greater understanding through triangulation rather than using offline methods to temper the unauthenticity that results from conducting online research. Again, the combination of online and offline methods is not always necessary and the decision to do so should be driven by the opportunity for deeper understanding offered by understanding the embedded social context of online interaction. Orgad's (2005) method involved the development of online relationships prior to the move to face-to-face interviews. The requirements of the development of online research relationships will be examined at a later point in this thesis in relation to embodiment. For Orgad (2005), despite the development of a trusting online relationship, the move to offline interviewing proved difficult and she notes that instant rapport with participants online proves as difficult to establish as offline. The trust required for a participant to move from the flexible, semianonymous, textually based online environment to participate in face-to-face interviewing is significant and any researcher involved in implementing a combination of online and offline qualitative research would be required to negotiate the complexities of this process. The decision to combine online and offline research methods should primarily be in relation to the chosen research topics. Firstly, not all topics need to be understood in relation to an embedded (and embodied) offline social context. Secondly, due to the reticence of participants in Orgad's (2005) study to 
progress to face-to-face interviewing the willingness of participants also requires consideration. Perhaps the effects of this reticence could be mediated at an earlier stage, or in the initial stages, of the development of the research relationship through the introduction of a face-to-face meeting earlier on. This may however affect participant disclosure that would not occur if the participant had not already met the researcher face-to-face. These problems are indicative of a unique feature of Internet research. Evidence suggests that people disclose more about themselves online (Joinson, 2005). Additionally, Joinson (2005) notes that 'socially desirable responding', whereby people present themselves positively when participating in research, is less common in online research and people tend to disclose more about themselves in online research than they would in offline research. Therefore, the stage at which the researcher meets a participant face-to-face, or even the awareness that a face-to-face interview will occur at some stage of the research process, may alter a participant's responses. Significant differences between online responses and offline responses to similar questions would also impact on the authenticity of the research findings.

Orgad's (2005) method involved the development of research relationships and qualitative interviewing over a number of months prior to the request for a face-to-face interview. This method essentially provided her with two sets of data that could be assessed in relation to each other. Orgad (2005) observed several continuities and discontinuities between online and offline interviewing. One discontinuity involved the degree of participant articulation between methods. Whilst a number of participants 
were consistent in their online and offline responses, for others a significant difference between their online and offline responses occurred. Whereas some participants responded well to questioning online and were articulate and comprehensive in their answers, this did not translate into their offline responses to face-to-face interviewing. The inverse was also observed. If the results were not triangulated, those who are inarticulate, or offer inadequate responses, in either their online or offline responses would have risked their responses being inadequate if only one method had been employed. A second discontinuity involved the reluctance of participants to be involved in offline research who had previously participated enthusiastically online. Participants often felt that after participating in online research they had nothing more to give or say and required significant reassurance that their offline responses were equally applicable and valuable. Despite the discontinuities that occurred, Orgad (2005:63) concludes highly in favour of the combination of online and offline methods concluding that "the move from online to offline endorses our thinking about the indeterminacy of the Internet and the complexity of the relationship between online and offline experiences". Orgad (2005) also raises an interesting point in relation to the ways that researchers come to understand research participants when conducting online research. When conducting online interviews via email the researcher's ways of knowing and understanding the participant is biased towards the textual. Conversely, ways of understanding and knowing participants offline "are biased toward the visual, and embedded in embodied ways of expression" (Orgad, 2005:62, authors italics). The combination of online and offline methods affords the researcher with a richer understanding of the research participants. 
Sanders (2005) also stresses the importance of combining online and offline methods whilst negotiating the methodological challenges this presents. Sanders' (2005) recognised that a study addressing the mediation of risk by sex workers also needed to include an assessment of the use of advanced communication technologies. Sanders (2005:68) identified a "virtual community ... where sellers and buyers of commercial sex communicate and negotiate business". Sanders (2005) also identified a large online community providing support and knowledge to women within the industry. Women who were separated by distance and the hidden nature of their work were able to meet freely online to communicate with each other, including the widespread dissemination of information about dangerous clients and telephone numbers to avoid responding to.

The Internet easily facilitates covert non-participative observation and researchers attempting to observe online communities, the access to which is freely available, are restrained only by (self-determined) ethical criteria. This is especially favourable to researchers when revealing oneself as a researcher may hamper any future chance of gaining access to online communities. Additionally, Sanders (2005:71) recognises that the "negative repercussions of revealing one's professional identity and contact details can be unknown in a largely male-dominated, aggressive and anonymous world of cyberspace". Sanders (2005), in employing both online and offline interviewing, also stressed the importance of the interviewer-participant relationship. Despite the access 
and information that 'lurking ${ }^{37,}$ may provide the researcher, Sanders (2005) rejected this method in favour of the benefits afforded by triangulating online and offline findings. The combination of online and offline methods is linked to the second methodological consideration to be addressed which involves the importance of the embodied presence of the researcher.

\section{METHODOLOGICAL CONSIDERATION TWO: THE IMPORTANCE OF EMBODIED PRESENCE IN THE APPLICATION OF VIRTUAL METHODS.}

Chapter three explored the problems associated with subscribing to the online disembodiment thesis. The first methodological consideration explored the problems associated with subscribing to a belief in the demarcation between the online and offline environment, a key characteristic of the online disembodiment thesis. The second, and most salient, feature of the online disembodiment thesis relates the lack of physicality and physical presence online. Consequently, the second methodological consideration is concerned with the importance of research embodiment in the application of virtual methods and the concurrent concept of anonymity.

To begin with it is important to explore what is meant by embodied presence in relation to online research. The inclusion of an offline component in online research advocated by Orgad (2005) and Sanders (2005) present perhaps the most obvious means to

\footnotetext{
${ }^{37}$ The term lurking refers to those who enter online communities including chat rooms, message boards and online forums to observe communication but do not participate in conversation.
} 
achieve an embodied presence when conducting online research. This may involve a combination of online and offline interviewing, offline participant recruitment or meeting with participants offline prior to the commencing online research. Additionally one may research online phenomena through the application of offline methods. However, it is interesting to explore whether the embodiment of the researcher and participant can occur without any face-to-face meeting. For example, is embodiment constituted solely through physical presence or can the researcher and participant become embodied in other ways? Online video chat, the use of avatars, audio communication and embodied online textual communication (Bird, 2003) may all present opportunities for the researcher and participant to become embodied beyond the restrictions of text. Anderson and Kanuka (2003), for example, provide several examples of audio and video Internet based systems that provide the opportunity for a visual/auditory component in online focus groups. If embodiment remains an essential component of the research process, the means in which embodiment is negotiated will contribute to the methodological innovation occurring in the field of Internet research. Additionally, the exponential development of technology may facilitate embodied research to occur with geographically and temporally dispersed participants.

The Internet as a research environment affords the researcher a number of benefits including, for example, the lack of spatial and temporal restriction. However, prior to implementing such methods further consideration needs to be given to the disembodied nature of the online environment and the implications for online research. Firstly, 
embodiment gives authenticity to data as it overrides a number of problems associated with anonymity. As Boshier (cited in Mann and Stewart, 2002:208) states:

Electronic networking opens possibilities for deception because many of the cues that normally circumscribe roles and which foster or inhibit participation are not present. Unlike [face-to-face] communication where participants are largely 'known' to each other, at least on a visual level, in the online environment there is no such recognition.

Whereas the previous chapter outlined how the body acts as a mediator and physical presence tempers a certain degree of conflict, Boshier's (cited in Mann and Stewart, 2002) comment indicates that embodiment also ensures increased truth on the part of participants. Embodied presence may temper the validity of the data and the way it is received by academic peers due to the increased potential for deception in disembodied communication.

Additionally, embodied presence supports the development of a positive research relationship as evidenced by the combination of online and offline methods employed by a number of theorists (see, for example Orgad, 2005). Orgad (2005), who employed the combination of online and offline methods, argues that building rapport is particularly difficult online. Trust is an essential component of the online research relationship and Orgad (2005) notes the difficulty in achieving trust within an environment that is primarily anonymous, disembodied and textual in nature. Others go so far as to argue that gaining trust is impossible in an online setting (see Harrington 
and Bielby cited in Orgad, 2005) and the anonymous nature of the environment combined with the lack of physical presence explain this conclusion.

Researcher embodiment is especially relevant when researching topics of a sensitive nature. In relation to cyberstalking, and a number of other forms of interpersonal offending occurring online, similarities between the conduct of research and offending is problematic. Offending is carried out by an anonymous, disembodied offender whereby harm is inflicted primarily through discourse. Concurrently, research is conducted by an anonymous or disembodied researcher whereby questioning takes place primarily through discourse. The similarity is problematic. A researcher would rarely conduct criminological research with victims in a setting that so closely resembles the site of the crime and the means through which the crime was carried out.

\section{CRITICAL REFLECTIONS ON THE ORIGINAL RESEARCH PROJECT}

\section{Locating Participants}

Several methods were employed to locate participants for this research. Firstly, posters and smaller flyers were distributed around three of Victoria University's campuses and a number of student hostels. Secondly, notices were placed in the university student magazine Salient, the Post Graduate Students' Association (PGSA) newsletter, the PostgradLife online forum (via MyVictoria) and the Victoria University Facebook $($ ) Network. These methods required potential participants to make contact with the 
researcher if they were interested in participating or required further information. The most successful of these methods was the PGSA newsletter. This first stage of participant recruitment resulted in six participants expressing interest over a period of six weeks.

The second method of recruitment was the distribution of approximately 120 anonymous Participant Recruitment Questionnaires in university lectures (see Appendix C). The questionnaire provided participants with the opportunity to self identify as experiencing behaviours associated with cyberstalking adapted from the 24 characteristics of cyberstalking as outlined by Spitzberg and Hoobler (2002:83-84). Female participants who answered yes to two or more questions were asked to provide their contact details if they were interested in participating in the online forum. Participants remained anonymous unless opting to participate further. Approximately 20 students provided contact details however on follow-up, and the provision of further information, an insufficient number of students chose to participate in the focus groups research. The extended period of recruitment meant that students who had originally expressed interest in participating were no longer able to do so or were discouraged due to the prolonged recruitment period.

Preliminary findings from the Participant Recruitment Questionnaires proved inconclusive due to a small, and unrepresentative sample, although a section providing participants with the opportunity to provide a brief description of their experiences indicated that even in a relatively small sample a number of 
participants were experiencing behaviours congruent with most definitions of cyberstalking or cyberharassment (see Appendix D).

A number of factors may have contributed to the failure to recruit a sufficient number of focus group participants. Practical constraints on participant recruitment may have included:

- Unfamiliarity with the crime of cyberstalking and/or cyberharassment.

- Time commitments.

- Unfamiliarity with the research method or a lack of computer skills required.

\section{Are Virtual Focus Groups a Useful Method for Researching Online Victimisation?}

The decision was initially made to employ a virtual focus group method to study women's experiences of cyberstalking. Practical research constraints, and subsequently time constraints, meant the method could not be implemented as originally planned. Further research into the links between cyberstalking and the theories of the body and the subsequent ways in which these links informed methodology indicated that this method may not be suitable for researching the online victimisation of women. As indicated above, virtual focus groups possess a number of unique benefits for the social researcher intending to understand both online and offline phenomena. However, at this stage in the thesis the original research method requires further examination in light of 
the methodological conclusions drawn by combining an understanding of cyberstalking in relation to the theories of the body, primarily that of disembodiment.

Two key methodological considerations were developed earlier in this chapter. The necessary links between online and offline research methods were highlighted as was the importance of researcher embodiment. The extent to which online focus groups reflect these considerations is tenuous. The previous assessment of online focus groups did not identify the parallel implementation of an offline method. Additionally, those advocating the use of online focus groups tend to do so by presenting the method as one that is conducted solely online and the benefits of the method primarily result from this.

Focus groups offer an opportunity for group level data analysis. Additionally, the anonymity of group members resulting from the Internet research environment is seen as positively facilitating the openness of participants often hampered in offline focus groups by physical presence. Virtual focus groups, therefore, result in multiple instances whereby disembodiment and anonymity pervade the online research environment. This is not to say that in many instances this anonymity, and the numerous other benefits afforded by online focus groups, would not be beneficial. Evidence suggests that online focus groups are a useful method for gathering qualitative data. Therefore, it is not the method itself that is problematic but rather the application of the method to the topic being examined in this instance, and alignment with the epistemological position of the researcher. 
The second methodological consideration involved a discussion of the suitability of virtual methods to the assessment of sensitive topics and advocated the importance of researcher embodiment. Whilst online focus groups have been successfully applied to the assessment of a range of topics they have not, thus far, been applied to the assessment of sensitive topics. One may initially query the success of examining sensitive topics, in this case cyberstalking, within a group setting. Group level data analysis is a common feature of feminist research although the degree to which participants would feel comfortable discussing their experiences of victimisation in a group setting requires further examination. Perhaps, however, the collaborative nature of the group may provide a useful and supportive environment for women to collectively share their experiences of victimisation. As previously discussed, those who are psychologically invested in their online personas are more susceptible experiencing the effects of online harassment. For these participants the online focus group may be the method most suited to their needs due their familiarity with the medium and sense of security the medium offers.

There is overwhelming evidence to support the implementation of online focus groups to research online and offline phenomena. Stewart and Shamdasani (cited in Anderson and Kanuka, 2003) highlight the useful implementation of focus groups to explore topics on which very little is known. The application of focus groups to an assessment of cybercrime could, therefore, prove useful. However, as previously mentioned, the implementation of online focus groups may not be suitable for all topics despite the 
degree of information known about them. Perhaps the harshest criticism of online focus groups comes from theorists rejecting their validity or their future contribution in terms of methodological innovation. Van Nuys and Jacobson (cited in Anderson and Kanuka, 2003) argue that there is no such thing as online focus groups and these groups are merely moderated online discussions. The loss of paralinguistic cues has also resulted in criticism being directed at online focus groups (Anderson and Kanuka, 2003). The absence of facial expression, body posture and physical gestures, for example, are problematic due to the additional information they provide the researcher (Anderson and Kanuka, 2003). Additionally, Rezabek (cited in Anderson and Kanuka, 2003:106) identifies additional drawbacks which include, "lack of timeliness from beginning to end of the process, sporadic participation and loss of participation at times by certain members of the group, and variable interactions among the participants". My own problems with recruitment may well have translated to these problems later on.

The methodological considerations developed in this chapter have subsequently informed an assessment of the applicability of virtual focus groups to an assessment of cyberstalking victimisation. Inevitably, as a researcher, the decision needs to be made whether this method is responsive to these methodological considerations and the research topic. I reject the assertions of Van Nuys and Jacobson (cited in Anderson and Kanuka, 2003), for example, who argue that online focus groups are simply mediated online discussions and online focus groups do not exist. In certain circumstances virtual focus groups may be the most applicable and suitable method, and in specific case studies their success has been shown (see, for example, Kenny, 2000). 
Whilst the Internet continues to provide the opportunity for methodological innovation, the importance of Internet-based research as an alternative to offline research has yet to be firmly established, especially within the discipline of criminology. The current criminological response to cybercrimes has been established in this thesis and, as Smith (2004:7) states, criminologists are currently in an "exploratory research era" in relation to cybercrimes. Smith (2004) further argues that pre-existing research methods currently employed by criminologists are sufficient at this stage. Gaining trust is the key issue for criminologists attempting to qualitatively research cybercrime (Smith, 2004) and the methodological considerations outlined above posit that trust is concurrent with researcher embodiment, the removal of anonymity and the accountability this provides.

A virtual focus group was chosen as a suitable method to examine cyberstalking and interest in participating was expressed by a number of people. However, the development of a theoretical perspective that established the immutability of bodies online does not align with the development of a disembodied methodology. An exploration of research projects that have implemented a combination of online and offline methods to examine online phenomena indicated that independent online research preceding the addition of an offline component was suitable. Doing so ensured the online research was not altered by the restrictions on disclosure physical presence 
may present ${ }^{38}$. Evidence suggests that the principles of feminist research and the requirements of researching sensitive topics do not align in this instance with the implementation of research conducted solely online. For this reason, whilst online focus groups are a valuable methodological tool, the method is deemed unsuitable for researching online victimisation if the methodological considerations developed in this thesis are to be acknowledged. The original method adopted has been rejected in light of the methodological considerations arising from an assessment of cyberstalking in relation to the theories of the body. The importance of the link between the online and offline environment and the importance of overcoming the disembodiment and anonymity of the researcher do not align with the implementation of virtual focus groups.

\footnotetext{
${ }^{38}$ The original method employed for this thesis included a face-to-face meeting prior to the commencement of the research. Doing so provided the opportunity for the clarification of the method and the opportunity to obtain written consent. The 'offline' meeting in the original method did not, however, include a research component. Additionally, due to the nature of the research project and the participant characteristics a prior face-to-face meeting was required from an ethical perspective.
} 


\section{CONCLUSION}

As noted in the introduction, the progression of this thesis has, by no means, been formulaic. However, it was the problems I encountered when implementing the original method that subtly exposed evident methodological and theoretical gaps. Developing these methodological and theoretical foundations subsequently became the central concern of this thesis.

A review of cyberstalking literature indicated an evident gender disparity in cyberstalking statistics. This review also indicated a lack of comprehensive theoretical analysis of the subject of cyberstalking in relation to this disparity. Beyond the work of Adam (2005) and Ellison (2001) there has, thus far, not been a comprehensive gendered assessment of cyberstalking. Furthermore, a lack of critical academic scholarship, especially that which examines this gender disparity, prioritises the need for a gendered assessment of this offence. The development of a theoretical framework suitable for a gendered assessment of cyberstalking was a supported by the application of the theories of the body. Additionally, the rejection of the online disembodiment thesis and the prevailing notion of bodily transcendence via the Internet, further supported the development of a gendered theoretical framework.

The development of a theoretical framework suitable for a gendered assessment of cyberstalking subsequently informed the development of two key methodological 
considerations. These methodological considerations will not only inform further research but also informed a critical assessment of the original research project. In light of the methodological considerations developed in this thesis the original research method was rejected.

The rejection of online focus groups as a method for examining the online victimisation of women, primarily cyberstalking, necessitates the identification of a suitable alternative method. While Smith (2004) highlights the relevance of pre-existing methods this may still prove problematic. As previously indicated, the Internet presents multiple challenges for researchers. Take, for example, the opportunities virtual methods provide for the inclusion of spatially and temporally dispersed participants. The combination of online and offline methods is also problematic when researching dispersed populations. So what are the alternatives for feminist researchers planning to address the online victimisation of women with an awareness of the immutability of the body in online social interaction? Bearing in mind Smith's (2004:7) claim that criminologists are currently in an "exploratory research era" in relation to cybercrime, it is not my intention to attempt to solve the myriad methodological gaps that exist. Rather it is my intention that the preceding methodological discussion in relation to cyberstalking and the theories of the body provide perhaps an alternative theoretical perspective from which to construct methodologies to address the online victimisation. 
The opportunity exists to address the online victimisation of women from an inherently feminist and criminological perspective that incorporates an understanding of the role the body continues to play in online social interaction. To deny the role of the body, and its use as an important conceptual resource, is to greatly undermine the potential of the development of an embodied theoretical and methodological framework applicable to a gendered assessment of cyberstalking. 


\section{REFERENCES}

Adam, A (2002) Cyberstalking and Internet Pornography: Gender and the Gaze, Ethics and Information Technology. 4(2):133-142.

Adam, A (2005) Gender, Ethics, and Information Technology. New York: Palgrave Macmillan.

Ajana, B (2005) Disembodiment and Cyberspace: A Phenomenological Approach. Retrieved 19/03/2009 from http://www.sociology.org/content/2005/tier1/ajana.html

Alexy, E., Baker, T., Burgess, A \& Smoyak, S (2005) Perceptions of Cyberstalking Among College Students. Brief Treatment and Crisis Intervention, 5(3): 279-289.

Amnesty International (2006) Undermining Freedom of Expression in China: The Role of Yahoo!, Microsoft and Google. Retrieved 19/03/2009 from http://www.amnesty.org/en/library/info/POL30/026/2006/en

Anderson, T \& Kanuka, H (2003) E-Research: Methods, Strategies, and Issues. Boston: Allyn \& Bacon.

Ashcroft, J (2001) Stalking and Domestic Violence. Washington DC: United States Department of Justice.

Babbie, E (1999) The Basics of Social Research. Belmont: Wadsworth Publishing Company.

Balsamo, A (1995) 'Forms of Technological Embodiment: Reading the Body in Contemporary Culture'. In Featherstone, M \& Burrows, R. Cyberspace/cyberbodies/cyberpunk : cultures of technological embodiment (p. 215 237). London: Sage. 
Barak, A (2005). Sexual Harassment on the Internet. Social Science Computer Review, 23(1):77-92.

Barbour, R (2008) Introducing Qualitative Research: A Student's Guide to the Craft of Doing Qualitative Research. London: SAGE.

Bauman, Z (1989) Modernity and the Holocaust. Ithaca: Cornell University Press.

Bird, J (2003) "I Wish to Speak to the Despisers of the Body": The Internet, Physicality and Psychoanalysis. Journal for the Psychoanalysis of Culture and Society. 8 (1):121 126.

Bloor, M., Frankland, J., Stewart, K., \& Thomas, M (2001) Focus Groups in Social Research (Introducing Qualitative Methods Series). Thousand Oaks: Sage Publications Ltd.

Bocij, P (2004) Cyberstalking: Harassment in the Internet Age and How to Protect Your Family. Westport: Praeger Publishers.

Bocij, P. \& McFarlane, L (2003). Cyberstalking: The Technology Of Hate. Police Journal. 76(3):204-221.

Boler, M (2007) Hypes, Hopes and Actualities: New Digital Cartesianism and Bodies in Cyberspace. New Media and Society. 9 (1):139 - 168.

Boni, W., \& Kovacich, G (2000). Netspionage: The Global Threats to Information. St. Louis: Butterworth-Heinemann.

Brook, B (1999) Feminist Perspective on the Body (Feminist Perspectives Series). White Plains: Longman Publishing Group. 
Brownstein, A (2000) In the Campus Shadows, Women are Stalkers as Well as the Stalked. The Chronicle of Higher Education, 47(15):40-42.

Campbell, J (2004) Getting It on Online: Cyberspace, Gay Male Sexuality, and Embodied Identity. New York: Routledge.

Campbell, R \& Wasco, S (2001) Feminist Approaches to Social Science: Epistemological and Methodological Tenets. American Journal of Community Psychology. 28 (6):773 791.

Capeller, W (2001) Not Such a Neat Net: Some Comments on Virtual Criminality. Social Legal Studies. 10 (2):229 - 242.

Castells, M (2000) The Rise of the Network Society. Chicago: Blackwell Publishing Limited.

Chatterjee, B (2001) 'Last of the Rainmacs? Thinking about pornography in Cyberspace'. In Wall, D (ed) Crime and the Internet. (p. 74-99). Oxon:Routledge.

Chesher, C (1997) 'The Ontology of Digital Domains'. In. Holmes, D (ed). Virtual Politics: Identity and Community in Cyberspace (p. 79 - 92). Thousand Oaks:Sage.

Cohen, L and Felson, M (1979) Social Change and Crime Rate Trends: A Routine Activity Approach. American Sociological Review. 44:588-605.

Cook, J \& Fonow, M (1986) Knowledge and Women's Interests: Issues of Epistemology and Methodology in Feminist Sociological Research. Sociological Inquiry 56 (1):2-29.

Cooper (2007) Alter Ego: Avatars and their Creators Retrieved 28/01/2009 from http://www.alteregobook.com/gall.html. 
Dibbell, J (1994) A rape in cyberspace or how an evil clown, a Haitian trickster spirit, two wizards, and a cast of dozens turned a database into a society. Annual Survey of American Law. 3:471-489.

D’Ovidio, R \& Doyle, J (2003) A study on cyberstalking: Understanding investigative hurdles. FBI Law Enforcement Bulletin, 72(3):10-17.

Dowland, P., Furnell, S., Illingworth, H and Reynolds, P (1999) Computer Crime and Abuse: A Survey of Public Attitudes and Awareness. Computers and Security. 18 (8):718 - 726

Ellison, L (2001) 'Cyberstalking: Tackling Harassment on the Internet'. In Wall, D (ed). Crime and the Internet. (p. 141-151). Oxon:Routledge.

Elm, M \& Sunden, J. (eds) (2007) Cyberfeminism in Northern Lights: Digital Media and Gender in a Nordic Context. Newcastle: Cambridge Scholars Publishing.

Emerson, R., Ferris, K. \& Brooks Gardner, C (1998) On Being Stalked. Social Problems. 45(3):289-314.

Finch, E. (2002). Stalking: A Violent Crime or a Crime of Violence? Howard Journal of Criminal Justice, 41(5):422-433.

Finkelhor, D., Mitchell, K and Wolak, J (2000) Online Victimization: A Report on the Nation's Youth. Washington: National Centre for Missing \& Exploited Children.

Finn, J (2004) A Survey of Online Harassment at a University Campus. Journal of Interpersonal Violence. 2004(4):468-483.

Fisher, B., Cullen, F \& Turner, M (2000) The Sexual Victimization 
of College Women. Retrieved on 23/03/2009 from http://www.popcenter.org/problems/rape/PDFs/182369.pdf.

Flaming Definition. (n.d). Retrieved 28/01/2009 from http://techterms.com/definition/flaming.

Fleming, M., Greentree, S., Cocotti-Muller, D., Elias, K \& Morrison, S (2006) Safety in Cyberspace: Adolescents' Safety and Exposure Online. Youth and Society. 38 (2):135 154.

Gajjala, R. (November 1999). Cyberethnography: Reading Each “Other” Online. Paper presented at the annual meeting of the National Communication Association, Chicago, Illinois.

Gatens, M (1996) Imaginary Bodies: Ethics, Power and Corporeality. New York: Routledge.

Giddens, A (1990) The Consequences of Modernity. Stanford : Stanford University Press.

Grabosky, P (2001) Virtual Criminality: Old wine in New Bottles? Social and Legal Studies 10(2):243-249.

Greer, A (2007). 'Misogyny Bares its Teeth on Internet'. Sydney Morning Herald, 21 August. Retrieved 18/04/09 from: http://www.smh.com.au/news/opinion/misogynybares-its-teeth-on-internet/2007/08/20/1187462171087.html?page=fullpage.

Grosz, E (1994) Volatile Bodies: Toward a Corporeal Feminism (Theories of Representation and Difference). Bloomington: Indiana University Press. 
Guillen, M and Suarez, S (2005) Explaining the Global Digital Divide: Economic, Political and Sociological Drivers of Cross-National Internet Use. Social Forces. 84 (2):681708.

Halbert, D. (2004). Shulamith Firestone: Radical Feminism and Visions of the Information Society. Information, Communication and Society. 7 (1):115-135.

Haraway, D (1986) 'Primateology is Politics by Other Means' in Bleier, R. (ed). Feminist Approaches to Science. (p. 76-118) Oxford:Pergamon Press.

Haraway, D (1990) Primate Visions: Gender, Race, and Nature in the World of Modern Science. New York: Routledge.

Haraway, D (1991) 'A Cyborg Manifesto'. In Haraway, D. Simians, Cyborgs, and Women: The Reinvention of Nature. New York: Routledge.

Harvey, D (2003) Cyberstalking and Internet Harassment: What the Law Can Do. NetSafe II: Society, Safety and the Internet Conference Proceedings [Online]. Retrieved on 18/04/2009 from http://www.netsafe.org.nz/downloads/conference/netsafepapers_davidharvey_cyberstal king.pdf

Hawthorne, S. \& Klein, R. (1999) Cyberfeminism: Connectivity, Critique + Creativity Melbourne: Spinifex.

Herring, S (2002) Cyber Violence: Recognizing and Resisting Abuse in Online Environments. Asian Women. 14 (Summer):187-212.

Hirschi, T (1969) Causes of Delinquency. Berkeley: University of California Press. 
Hitchcock, J (2002) Net Crimes \& Misdemeanors: Outmaneuvering the Spammers, Swindlers, and Stalkers Who Are Targeting You Online. Medford: Information Today.

Holland, S (1996) 'Descartes Goes to Hollywood: Mind, Body and Gender in Contemporary Cinema'. In Featherstone, M \& Burrows, R. Cyberspace/cyberbodies/cyberpunk: cultures of technological embodiment (p. 157-174). London:Sage.

Howson, D (2005) Embodying Gender. Thousand Oaks: Sage Publications Ltd.

Hughes, F., Thom, K \& Dixon, R (2007) Nature and Prevalence of Stalking Among New Zealand Mental Health Clinicians. Journal of Psychosocial Nursing and Mental Health Services. 45 (4):33- 39.

Humphreys, L (2001) 'NP Author won't give in to stalker'. The Daily News. $20^{\text {th }}$ June.

Internet Safety: Cyber911 Emergency - Cyberstalking and Harassment. (n.d.). Retrieved 19/3/2009 from http://www.wiredsafety.org/cyberstalking_harassment/definition.html

The Internet Safety Group (2001) Girls on the net: The survey of adolescent girls' use of the Internet in New Zealand. Retrieved on 19/03/2009 from https://edorigami.wikispaces.com/file/view/girls+on+the+net.pdf

Jewkes, Y (2002) Dot.Cons: Crime, Deviance and Identity on the Internet. Collumpton: Willian.

Jewkes, Y (2004) Media and Crime (Key Approaches to Criminology). Thousand Oaks: Sage Publications Ltd.

Jones, S (ed) (1999) Doing Internet Research: Critical Issues and Methods for Examining the Net. Thousand Oaks: Sage Publications. 
Joseph, J (2002) 'Cyberstalking: An International Perspective'. In Jewkes, Y. Dot.Cons: Crime, Deviance and Identity on the Internet (p. 105 - 125). Collumpton: Willian.

Kendall, L. (1999). 'Recontextualizing "cyberspace": methodological considerations for online research'. In S. Jones. Doing Internet Research: Critical Issues and Methods for Examining the Net. (p. 29-56). Thousand Oaks: Sage Publications.

Kenny, A (2004) Interaction in Cyberspace: An online focus group. Journal of Advanced Nursing. 49 (4):414 - 422.

Kershaw, C., Nicholas, S \& Walker, A (2008) Crime in England and Wales in 2007/8: Findings from the British Crime Survey and Police Recorded Crime. Retrieved 23/03/2009 from http://www.homeoffice.gov.uk/rds/pdfs08/hosb0708.pdf.

Kivits, J (2005) ‘Online Interviewing and the Research Relationship'. In Hine, C (ed). Virtual Methods: Issues in Social Research on the Internet (p.35-50). Oxford:Berg.

Kowalski, R., Limber, S \& Agatson, P (2008) Cyberbullying: Bullying in the Digital Age. Malden:Blackwell.

Kroker, A., \& Kroker, M (1996) Hacking the Future: Stories for the Flesh-Eating 90s. New York: Palgrave Macmillan.

Lee, R (1998) Romantic and Electronic Stalking in a College Context. The William and Mary Journal of Women and Law. 373:381-82.

Levi, M (2001) “"Between Risk and the Reality Falls the Shadow”: Evidence and Urban Legends in Computer Fraud'. In Wall, D (ed). Crime and the Internet. (p. 44-58). Oxon:Routledge. 
Li, Q (2006) Computer-mediated communication: A meta-analysis of male and female attitudes and behaviors. International Journal on E-Learning, 5(4), 525-570.

Li, Q (2007) Bullying in the New Playground: Research Into Cyberbullying and Cyber Victimisation. Australasian Journal of Educational Technology. 23(4):435-454.

Lombroso, C (2006) Criminal Man. London: Duke University Press.

Lowney, K and Best, J (1995) 'Stalking Strangers and Lovers: Changing Media typifications of a crime problem'. In Best, J (ed). Images of issues: typifying contemporary social problems (p.35 - 57) New York: Aldine De Gruyter.

Lupton, D (1995) 'The Embodied Computer/User'. In Featherstone, M and Burrows, R. Cyberspace/cyberbodies/cyberpunk: cultures of technological embodiment (p. 97 112). London:Sage.

Lupton, D (2000) 'The Embodied Computer/User'. In. Kennedy, D \& Bell, B. The Cybercultures Reader (p. 477 - 487). London: Routledge.

Matza, D., \& Sykes, G (1957) Techniques of Neutralization: A Theory of Delinquency. American Sociological Review. 22(6):664-670.

MacKinnon, R (1997) Virtual Rape. Journal of Computer Mediated Communication 2 (4).

Mann, C., \& Stewart, F (2002) Internet Communication and Qualitative Research: A Handbook for Researching Online. Thousand Oaks: Sage Publications Ltd.

Martin, C., \& Schell, B (2004) Cybercrime: A Reference Handbook (Contemporary World Issues). Santa Barbara: ABC-CLIO. 
Martin, K (2000) Mapping Cyberspace. New York: Routledge.

Maxwell, A (2001) Cyberstalking. Department of Psychology, Auckland University.

Mayhew, P. and Reilly, J (2007) The New Zealand Crime \& Safety Survey 2006: Key Findings. Wellington: Ministry of Justice.

Merleau-Ponty, M (2002) Phenomenology of Perception. London:Routledge.

Messerschmidt, J (1999) Making Bodies Matter: Adolescent Masculinities, the Body, and Varieties of Violence. Theoretical Criminology. 3 (2):197 - 220.

Moloney, M., Dietrich, A., Strickland, O \& Myerburg, S (2003) Using Internet Discussion Boards as Virtual Focus Groups. Advances in Nursing Science. Oct-Dec 2003 (13)274.

MUD (n.d) Retrieved 29/01/2009 from http://www.answers.com/topic/mud-1.

Mullen, P. E., Pathe, M., \& Purcell, R (2000) Stalkers and their Victims. New York: Cambridge University Press.

Nunes, M (1995) Baudrillard in Cyberspace: Internet, Virtuality, and Postmodernity. Style. $29: 314-327$.

O’Connell, R (2002) Young People's Use of Chat Rooms: Implications for Policy Strategies and Programs of Education. Preston: CRU/UCLAN.

Ogilvie, E (2000) Cyberstalking. Trends and Issues in Crime and Criminal Justice. No. 166. Canberra: Australian Institute of Criminology. 
Orgad, S (2005) 'From Online to Offline and Back: Moving from Online to Offline Relationships with Research Informants'. In Hine, C (ed). Virtual Methods: Issues in Social Research on the Internet (p.51-66). Oxford:Berg.

Pathé, M. \& Mullen, P (1997) The Impact of Stalkers on Their Victims. British Journal of Psychiatry. 170:12-17.

Plant, S (1997) Zeros and Ones. London: Fourth Estate.

Sanders, T (2005) 'Researching the Online Sex Work Community'. In. Hine, C (ed). Virtual Methods: Issues in Social Research on the Internet (p.67-79). Oxford:Berg.

Sarkio, H (2009) “Online or Off, We're Always Girls”: Gendered Behavior on an Online Bulletin Board and Message Board Targeted at Girls'. Paper presented at the annual meeting of the International Communication Association, Sheraton New York, New York City, NY Online .

Schell, B. \& Martin, C (2004) Cybercrime: A Reference Handbook. Santa Barbara: ABCCLIO.

Scott, A., Semmens, L. \& Willoughby, L (2001) 'Women and the Internet: The Natural History of a Research Project'. In Green, E. and Adam, A (eds) Virtual Gender: Technology, Consumption and Identity Matters (p. 3-27). New York: Routledge.

Sennett, R (1992) The Fall of Public Man. New York: Norton.

Sheldon, W (1970) The Varieties of Human Physique: An Introduction to Constitutional Psychology. New York: Hafner Pub. Co. 
Shilling, C (ed) (2007) Embodying Sociology: Retrospect, Progress and Prospects. Malden: Wiley-Blackwell.

Skinner, T (2003) 'Email harassment left woman feeling 'emotionally raped'. The Marlborough Express. $28^{\text {th }}$ November.

Slevin, J (2000) The Internet and Society. University Park: Polity.

Smart, C (1995) Law, Crime and Sexuality: Essays in Feminism. Thousand Oaks: Sage Publications Ltd.

Smith, C (2004) 'Research on Crime and Technology'. In Savona, E (ed). Crime and Technology : New Frontiers for Regulation, Law Enforcement and Research (p. 105110). Dordrecht:Springer.

Spender, D (1995) Nattering on the Net. North Melbourne: Spinifex Press.

Spinello, R (2002) Regulating Cyberspace: The Policies and Technologies of Control. Westport: Quorum Books.

Spitzberg, B (2002) The Tactical Topography of Stalking Victimization and Management. Trauma, Violence and Abuse. 3 (4):261 - 288.

Spitzberg, B. \& Hoobler, G (2002) Cyberstalking and the Technologies of Interpersonal Terrorism. New Media Society, 4(1):71-92.

Stanley, L. \& Wise, S (2002) Breaking Out Again: Feminist Ontology and Epistemology. London: Routledge. 
Stanley, S (2001) Disembodiment is a Cyberspace Myth: Discourse and the Self in Real Space. Cyberpsychology and Behavior. 4(1):77 - 93.

Statistics New Zealand (2007) Household Use of Information and Communication Technology: 2006. Retrieved 20/03/2009 from http://www.stats.govt.nz/products-andservices/hot-off-the-press/household-use-of-information-and-communicationtechnologies-survey-2006/household-use-ict-2006-hotp.html

Sterne, J (1999) 'Thinking the Internet: Cultural Studies Versus the Millennium'. In Jones, S. Doing Internet Research: Critical Issues and Methods for Examining the Net. (p. 257287). Thousand Oaks: Sage Publications.

Stone, R (2000) 'Will the Real Body Please Stand Up? Boundary Stories About Virtual Cultures'. In Kennedy, D., \& Bell, B. M. The Cybercultures Reader (p. 504 - 525). London: Routledge.

Talamo, A. \& Logorio, B (2001) Strategic Identities in Cyberspace. Cyberpsychology and Behavior. 4 (1):109 - 122.

Thomas, D and Loader, B (2000) Cybercrime: Law Enforcement, Security and Surveillance in the Information Age. London: Routledge.

Tjaden, P and Thoennes, N (1998) Stalking in America: Findings From the National Violence Against Women Survey. Washington: U.S. Department of Justice, National Institute of Justice.

Tse, A (1999) Conducting electronic focus group discussions among Chinese respondents. Journal of the Market Research Society. 41 (4):407. 
Turner, B (2007) 'Culture, Technologies and Bodies: The Technological Utopia of Living Forever'. In Shilling, C (ed) Embodying Sociology: Retrospect, Progress and Prospects (p. 19 - 36) Malden: Wiley-Blackwell.

Turney, L. \& Pocknee, C. (2004). 'Virtual focus groups: New Technologies, New Opportunities, New Learning Environments'. In Atkinson, R., McBeath, C., Jonas-Dwyer, D \& Phillips, R (Eds). Beyond the comfort zone: Proceedings of the 21st ASCILITE Conference (p 905-912). Perth, 5-8 December http://www.ascilite.org.au/conferences/perth04/procs/turney.html

Underwood, M (2000) 'Lost in Cyberspace?: Gender, Difference, and the Internet 'Utopia.' In Forbes, B \& Mahan, J (eds) Religion and Popular Culture in America (p. 276291). Berkeley: California University Press.

Victoria University of Wellington (2008) Student Conduct Statute. Retrieved 23/3/2009 from http://policy.vuw.ac.nz/

Walby, S \& Allen, J (2004) Domestic Violence, Sexual Assault and Stalking: Findings from the British Crime Survey. Home Office. Retrieved 23/03/2009 from http://www.homeoffice.gov.uk/rds/pdfs04/hors276.pdf.

Wall, D. (2005). 'The Internet as a Conduit for Criminal Activity'. In Pattavina, A. The Criminal Justice System and the Internet (p. 77-98) Thousand Oaks: Sage.

Wall, D (2007) Cybercrime: The Transformation of Crime in the Information Age University Park: Polity.

Website for Halting Online Abuse (2007) WHOA Comparison Statistics 2000-2007 Retrieved 4/18/09 from http://www.haltabuse.org/resources/stats/Cumulative20002007.pdf 
Westrup, D. \& Fremouw, W (1998) Stalking Behaviour: A Literature Review and Suggested Functional Analytic Assessment Technology. Aggressive and Violent Behavior $3(3): 255-274$.

Williams, M (2006) Virtually Criminal. New York: Routledge.

Wykes, M (2007a) Constructing Crime: Culture, Stalking, Celebrity and Cyber. Crime, Media and Culture. 3 (2):158-74.

Wykes, M. (2007b) 'Cyber-stalking and the media construction of crime'. In Jewkes, Y. Crime On-line (p. 128-144). Cullompton: Willan.

Yar, M (2006) Cybercrime and Society. Thousand Oaks: Sage Publications Ltd.

Zimbardo, P (1972) Pathology of Imprisonment. Society. 9 (6).

Zona, M., Sharma, K. \& Lane, J (1993) A Comparative Study of Erotomanic and Obsessional Subjects in a Forensic Sample. Journal of Forensic Sciences. 38(4):894903.

Harassment Act (1997)

Crimes Amendment Act (2003)

Domestic Violence (1995)

Telecommunications Act (2001)

Crimes Act (1961)

Employment Relations Act (2000) 


\section{APPENDICES}

\section{APPENDIX A}

Wall (2005) classifies cybercrime based on the interaction of opportunity and the type of crime.

Table 4.1 The Matrix of Cybercrimes: Level of Opportunity by Type of Crime (with selected examples)

\begin{tabular}{|c|c|c|c|c|}
\hline & $\begin{array}{l}\text { Integrity-related } \\
\text { (Harmful Trespass) }\end{array}$ & $\begin{array}{c}\text { Computer-related } \\
\text { (Acquisition } \\
\text { theft/deception) }\end{array}$ & $\begin{array}{c}\text { Content-related } 1 \\
\text { (Obscenity) }\end{array}$ & $\begin{array}{c}\text { Content-related } 2 \\
\text { (Violence) }\end{array}$ \\
\hline $\begin{array}{l}\text { More opportunities } \\
\text { for tradional } \\
\text { crime (eg., } \\
\text { through } \\
\text { communications) }\end{array}$ & $\begin{array}{l}\text { Phreaking } \\
\text { Chipping }\end{array}$ & $\begin{array}{l}\text { Frauds } \\
\text { Pyramid schemes }\end{array}$ & $\begin{array}{l}\text { Trading sexual } \\
\text { materials }\end{array}$ & $\begin{array}{l}\text { Stalking } \\
\text { Personal } \\
\text { Harassment }\end{array}$ \\
\hline $\begin{array}{l}\text { New opportunities } \\
\text { for traditional } \\
\text { crime (e.g., } \\
\text { organization } \\
\text { across } \\
\text { boundaries) }\end{array}$ & $\begin{array}{l}\text { Cracking/Hacking } \\
\text { Viruses } \\
\text { Hactivism }\end{array}$ & $\begin{array}{l}\text { Multiple } \\
\text { large-scale } \\
\text { frauds } \\
419 \text { scams } \\
\text { Trade secret theft } \\
\text { ID Theft }\end{array}$ & $\begin{array}{l}\text { Online Sex trade } \\
\text { Camgirl sites }\end{array}$ & $\begin{array}{l}\text { General hate } \\
\text { speech } \\
\text { Organized } \\
\text { paedophile rings } \\
\text { (child abuse) }\end{array}$ \\
\hline $\begin{array}{l}\text { New opportunities } \\
\text { for new types of } \\
\text { crime }\end{array}$ & $\begin{array}{l}\text { Spams (list } \\
\text { constuction and } \\
\text { content) } \\
\text { Denial of Service } \\
\text { Information Warfare } \\
\text { Parasitic Computing }\end{array}$ & $\begin{array}{l}\text { Intellectual } \\
\text { Property Piracy } \\
\text { Online Gambling } \\
\text { E-auction scams } \\
\text { Small-impact } \\
\text { bulk fraud }\end{array}$ & $\begin{array}{l}\text { Cyber-sex } \\
\text { Cyber-pimping }\end{array}$ & $\begin{array}{l}\text { Online Grooming } \\
\text { Organised Bomb } \\
\text { talk/Drug talk } \\
\text { Targeted hate } \\
\text { speech }\end{array}$ \\
\hline
\end{tabular}

Source: Wall, D. S. (2003). Mapping out cybercrimes in a cyberspatial surveillant assemblage. In F. Webster \& K. Ball (Eds.), The intensification of surveillance: Crime, terrorism, and warfare in the information age (pp. 112-136). London: Pluto, p. 115 (subsequently amended and updated). Reprinted with permission of Willan Publishing. 


\section{APPENDIX B}

Spitzberg and Hoobler (2002:83-84) separate cyberstalking into a comprehensive list of behaviours, escalating in seriousness. Separating the complex concept of cyberstalking into a range of individual behaviours makes assessing its occurrence easier to understand for both researcher and participant.

1. Sending token of affection: (e.g. poetry, songs, electronic greeting cards, praise, etc.)

2. Sending exaggerated messages of affection: (e.g. expressions of affections implying a more intimate relationship than you actually have, etc.)

3. Sending excessively disclosive messages: (e.g. inappropriately giving private information about his/her life, body, family, hobbies, sexual experiences, etc.)

4. Sending excessively 'needy' or demanding messages: (e.g. pressuring to see you, assertively requesting you go out on date, arguing with you to give him/her 'another chance', etc.)

5. Sending pornographic/obscene images or messages: (e.g. photographs or cartoons of nude people, or people or animals engaging in sexual acts, etc.)

6. Sending threatening written messages: (e.g. suggesting harming you, your property, family, friends, etc.) 
7. Sending sexually harassing messages: (e.g. describing hypothetical sexual acts between you, making sexually demeaning remarks, etc.)

8. Sending threatening pictures or images: (e.g. images of actual or implied mutilation, blood, dismemberment, property destruction, weapons, etc.)

9. Exposing private information about you to others: (e.g. sending mail out to others regarding your secrets, embarrassing information, unlisted numbers, etc.)

10. Pretending to be someone she or he wasn't: (e.g. falsely representing him- or herself as a different person or gender, claiming a false identity, status or position, pretending to be you, etc.)

11. 'Sabotaging' your private reputation: (e.g. spreading rumors about you, your relationships or activities to friends, family, partner, etc.)

12. 'Sabotaging' your work/school reputation: (e.g. spreading rumors about you, your relationships or activities in organizational networks, electronic bulletin boards, etc.)

13. Attempting to disable your computer (e.g. downloading a virus, sending too many messages for your system to handle, etc.) 
14. Obtaining private information without permission: (e.g. covertly entering your computer files, voicemail, or the files of co-workers, friends, or family members, etc.)

15. Using your computer to get information on others: (e.g. stealing information about your friends, family, coworkers, etc.)

16. 'Bugging' your home, car or office: (e.g. planting a hidden listening or recording device, etc.)

17. Altering your electronic identity or persona: (e.g. breaking into your system and changing your signature, personal information, or how you portray yourself electronically, etc.)

18. Taking over your electronic identity or persona: (e.g. representing him or herself to others as you in chatrooms, bulletin boards, pornography or singles sites, etc.)

19. Directing others to you in threatening ways: (e.g. pretending to be you on chat lines and requesting risky sex acts, kidnapping fantasies, etc.)

20. Meeting you first online and then following you: (e.g. following you while driving, around campus or work, to or from the gym or social activities, etc.) 
21. Meeting you first online and the intruding in your life: (e.g. showing up unexpectedly at work, front door, in parking lot, intruding in your conversations, etc.)

22. Meeting first online and then threatening you: (e.g. threatening to engage in sexual coercion, rape, physical restraint, or to harm him or herself, your possessions, pets, family, or friends)

23. Meeting first online and then harming you: (e.g. corresponding with you through an online dating service and then following, harassing, or otherwise stalking you)

24. First meeting you online and then stalking you: (e.g. corresponding through an online dating service or as acquaintances and then following, harassing, or otherwise stalking you) 


\section{APPENDIX C}

The 24 characteristics of cyberstalking outlined by Spitzberg and Hoobler (2002:83-

84) were adapted to form the basis of the Participant Recruitment Questionnaire.

\section{Participant Recruitment Questionnaire: Experiences of Cyber-harassment}

Researcher: Rachel Williams

School of Social and Cultural Studies - Victoria University of Wellington.

Email: rachel.williams@vuw.ac.nz

\section{Gender: Female Male (Please Circle) Age:}

How many hours per week do you use the Internet (Please Circle):

1-5 hours $\quad 5-10$ hours $\quad 10-20$ hours $\quad 20+$ hours

What do you use the Internet for most often? (Please select two)

Chat rooms

Instant messaging

Email

Study/Work

Social Networking sites (such as Bebo).

Shopping

Banking

Other - please state

When using the Internet has someone... 
1. Sent you unwanted or exaggerated tokens of affection via email, instant messaging or social networking sites such as poetry, songs, electronic greeting cards which imply a more intimate relationship than you actually have.

Yes No (Circle)

2. Sent you excessively disclosive messages including giving inappropriate private information about their life, body, family, hobbies, sexual experiences etc.

Yes No (Circle)

3. Sent you excessively needy, demanding or offensive messages including pressuring to see you, assertively requesting you go out on a date.

Yes No (Circle)

4. Sent you pornographic or obscene images or messages.

Yes No (Circle)

5. Sent you threatening written messages suggesting harm to you, your family/friends or property.

Yes No (Circle)

6. Sent you sexually harassing or threatening messages or pictures.

Yes No (Circle)

7. Exposed private information about you to others.

Yes No (Circle)

8. Pretended to be someone he/she is not.

Yes No (Circle)

9. Sabotaged your reputation by spreading false rumours about you.

Yes No (Circle)

10. Attempted to disable your computer by sending a virus or 'spamming'.

Yes No (Circle) 
11. Accessed your computer remotely to obtain private information.

Yes No (Circle)

12. Altered your electronic identity by accessing your computer or online profile and changing your personal information.

Yes No (Circle)

13. Impersonated and represented him/herself to others online as you by taking over your electronic identity.

Yes No (Circle)

14. Met you online and then followed you offline (i.e. in the 'real' world).

Yes No (Circle)

15. Met you online and then contacted you and intruded in your life offline.

Yes No (Circle)

16. Met you online and then threatened, stalked, followed, harassed or harmed you offline.

Yes No (Circle)

If you answered yes to any of the above questions please provide a brief description of your experience(s):

If you answered yes to two or more questions and would be interested in participating in a research project on the Internet please provide your contact details below (or email Rachel Williams for further information).

Name:

Email Address: 


\section{APPENDIX D}

The following is a selection of responses to the Participant Recruitment Questionnaire.

"My ... ex boyfriend wrote about me online and created a fake Bebo ${ }^{39}$ account". Female, 20

"I met someone on a MySpace page who sent me a request. After becoming friends with them they started being aggressive when I didn't reply to them straight away or ignored them. I also met a random person who pretended to be my own age, and when I was sent a sign up request from a site they had a profile on, they were much older". Female, 21

"I constantly get people say disgusting sexual things to me and show peoples private bits or of people having sex". Female, 21

"Met someone online gave them my number. He now contacts me excessively to a point where it feels like harassment". Male, 19

"People were added to my $\mathrm{MSN}^{40}$ or Facebook address ... but then the MSN person would continue to talk to me in an unwanted way". Female, 20

\footnotetext{
${ }^{39}$ Bebo, MySpace and Facebook are social networking sites.
} 
"[I] have had disturbing emails from someone that had added me on MSN".

Female, 22

"Someone hacked into my email account and sent strange messages". Female, 19

"This happens all the time. Guys find me on Facebook or MySpace and they try to message me for years or to meet up. Really creepy". Female, 20

${ }^{40} \mathrm{MSN}$ is a messaging programme. 